\title{
Evaluation of Alternatives for High-Level and Transuranic Radioactive-Waste Disposal Standards
}

\author{
R.D. Klett and M.M. Gruebel* \\ Sandia National Laboratories \\ Albuquerque, New Mexico 87185
}

\begin{abstract}
The remand of the U.S. Environmental Protection Agency's long-term performance standards for radioactive-waste disposal provides an opportunity to suggest modifications that woulc make the regulation more defensible and $r$ move inconsistencies yet retain the basic structure of the original rule. Proposed modifications are in three specific areas: release and dose limits, probabilistic containment requirements, and transuranic-waste disposal criteria. Examination of the modifications includes discussion of the alternatives, demonstration of methods of development and implementation, comparison of the characteristics, attributes, and deficiencies of possible options within each area, and analysis of the implications for performance assessments. An additional consideration is the impact on the entire regulation when developing or modifying the individual components of the radiological standards.
\end{abstract}

*Tech Reps, Inc., Albuquerque, NM 87110 MASTER

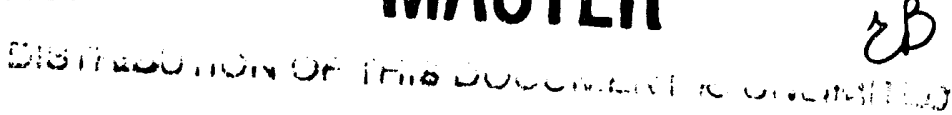




\section{ACKNOWLEDGMENTS}

The authors thank the following persons: Bob Becker (Department of Energy - WIPP Project Integration Office), Kenneth Lickliter (Benchmark Environmental Corp.) and Michael Wilson (Sandia National Laboratories - 6312) for their review of this report; Jim Garner (Applied Physics) for computer programming; Glenda Sweatt (Applied Physics) for library support; Tina Johnson and Debbie Marchand (Tech Reps) for graphics; and Virginia Gilliland ('Tech Reps) for editorial support. 


\section{CONTENTS}

ACRONYMS $\ldots \ldots \ldots \ldots \ldots \ldots \ldots \ldots \ldots \ldots \ldots \ldots \ldots \ldots \ldots \ldots \ldots \ldots \ldots \ldots \ldots \ldots$

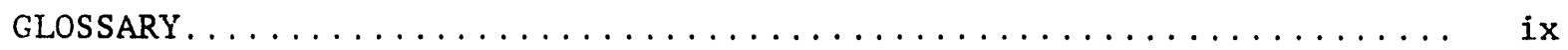

1 INTRODUCTION $\ldots \ldots \ldots \ldots \ldots \ldots \ldots \ldots \ldots \ldots \ldots \ldots \ldots \ldots \ldots \ldots \ldots$

2 TECHNICAL BASES FOR REGULATIONS $\ldots \ldots \ldots \ldots \ldots \ldots \ldots \ldots \ldots \ldots \ldots \ldots$

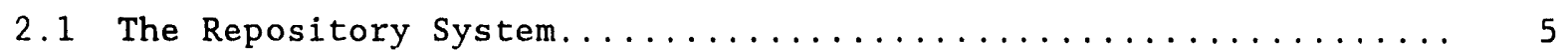

2.1.1 Essential Characteristics of a Nuclear-Waste

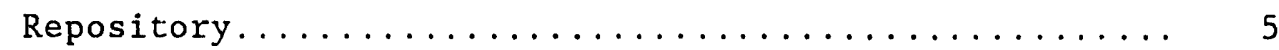

2.1.2 Repository Processes, Pathways, and Release Modes....... 6

2.2 Functions and Hierarchy of Regulations............... 9

3 THE PRESENT RELEASE LIMITS IN 40 CFR $191 \ldots \ldots \ldots \ldots \ldots \ldots \ldots \ldots$

3.1 Derivation of the Release Limits..................... 14

3.2 Problems with the Present Release Limits............... 18

4 Alternatives to THE PRESENT RELEASE Limits................. 21

4.1 Site-and-Pathway-Specific Release Limits................. 22

4.2 Multimode Generic Release Limits.................... 23

4.2 .1 Description............................. 23

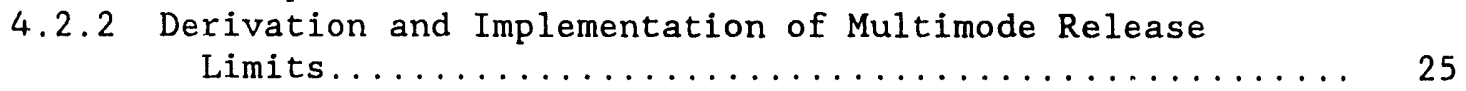

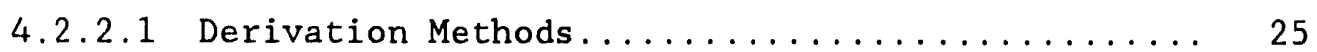

4.2.2.2 River-Release Mode................... 28

4.2.2.3 Well-Release Mode.................. 30

4.2.2.4 Ocean-Release Mode................... 33

4.2.2.5 Land-Release Mode................... 33

4.2.2.6 Atmospheric-Release Mode............... 33

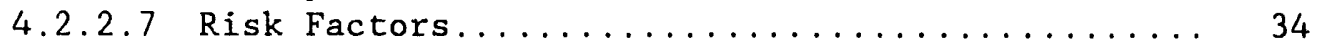

4.2.2.8 Development of Release Limits for $40 \mathrm{CFR}$

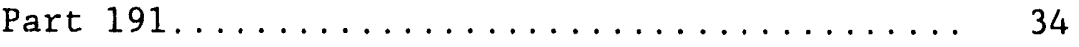

4.2.2.9 Summed Normalized Releases.............. 39

4.2 .3 Geologic Risk Attenuation................... 40

4.2 .4 Performance Assessments.................... 40

4.3 Dose Standards as the Primary Criterion and as an Option

with Release Limits......................... 42

4.3 .1 Dose Criteria.......................... 42

4.3.2 Release Limits with a Dose-Standard Alternative........ 43 


\subsubsection{Justilication for Alternative}

Dose Standards....................... 44

4.3.2.2 Description of the Dose-Limit Alternative..... 45

4.3.2.3 Dose Criteria and Reference Future States...... 45

4.3.2.4 Performance Assessment................ 51

4.3 .2 .5 Summary and Conclusions............... 52

5 COMPARISON OF ALTERNATIVES TO THE PRESENT RELEASE LIMITS ......... 53

5.1 Present Single Generic Release Limits................. 53

5.2 Site-and-Pathway-Specific Release Limits............... 53

5.3 Multimode Generic Release Limits..................... 54

5.4 Collective-Dose Limits as the Primary Criterion.............. 54

5.5 Collective-Dose Limits as an Option................... 55

6 PROBABILISTIC CONTAINMENT REQUIREMENTS FOR RADIOACTIVE-WASTE

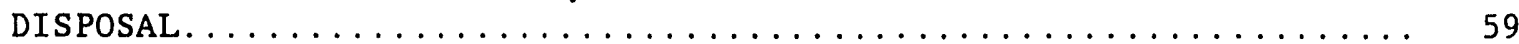

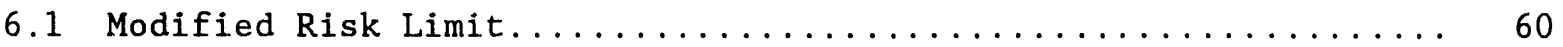

6.2 Probability/Consequence Limit on System CCDF............. 64

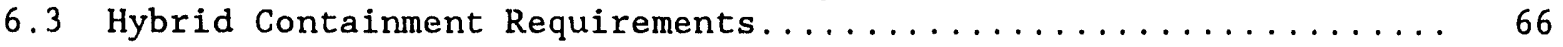

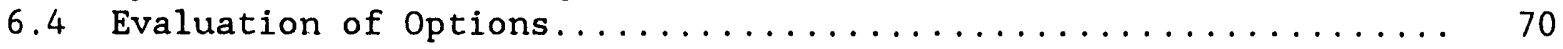

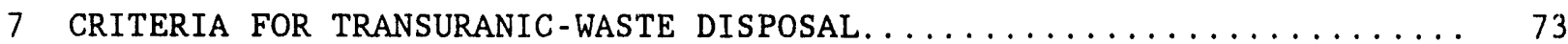

7.1 Fundamental Criteria........................ 73

7.1.1 HLW Fundamental and Derived Criteria in 40 CFR 191..... 74

7.1.2 Fundamental and Derived Standards for

TRU-Waste Disposal....................... 74

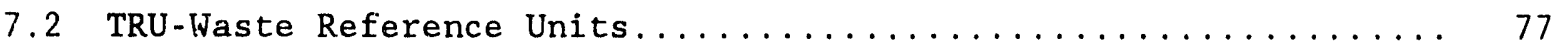

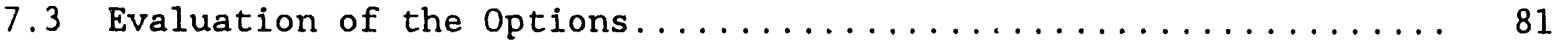

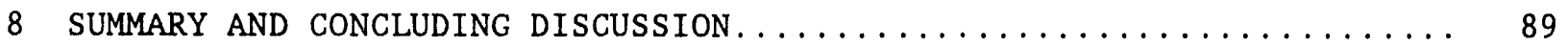

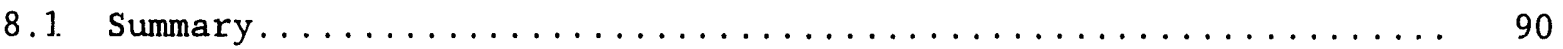

8.1.1 Technical Bases for Regulations.................. 91

8.1.2 Release and Dose Limits..................... 92

8.1.3 Probabilistic Containment Requirements.............. 94

8.1 .4 Criteria for TRU-Waste Disposal................. 96

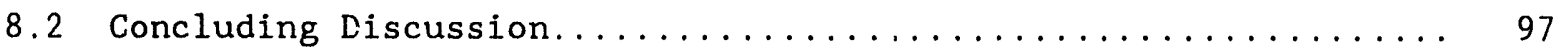

8.2.1 Standards for Radioactive-Waste Disposal........... 97

8.2.2 Standards Development...................... 99

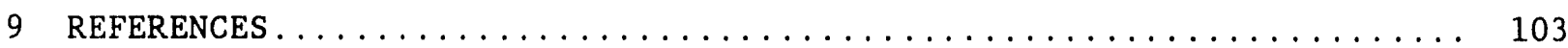




\section{Figures}

1 Schematic of a radioactive-waste disposal system showing possible release modes and risk-attenuation factors outside the repository.......................... 7

2 Typical time-limited, integrated-activity attenuation factors as a function of distance traveled in a aquifer............ 8

3 Alternative procedures for risk assessments............... 12

4 Probability distribution of the population risks per curie of Am-243 released to a generic river................ 17

5 Possible release modes from radioactive-waste repositories....... 19

6 Multimode release limits in the risk-assessment process........ 25

$7 \quad$ Generic river basin for the river-release mode............... 29

8 Deformation of a contaminated groundwater plume caused by

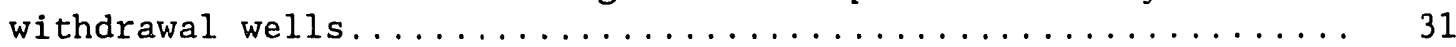

9 Generic groundwater diagram for the well-release mode........ 32

10 Effects of multimode release limits on the release CCDF........ 39

11 Attenuation-factor sensitivity (instantaneous release at the time of repository closure $\ldots \ldots \ldots \ldots \ldots \ldots \ldots \ldots \ldots \ldots \ldots$

12 Attenuation-factor sensitivity (retardation factor $=2$ ) $\ldots \ldots \ldots 1$

13 CCDF made up of normalized doses and/or normalized releases..... 46

14 Criterion curve corresponding to an annual individual-risk

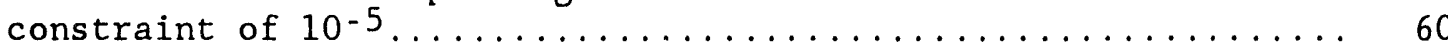

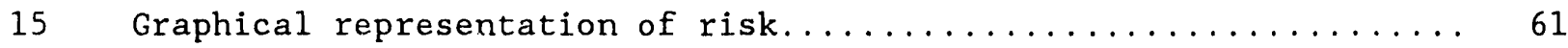

16 Family of CCDFs generated by Latin hypercube sampling of

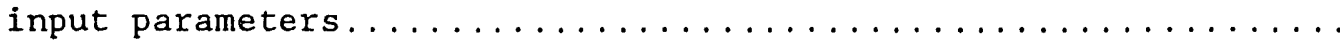

17 CDF of predicted normalized risk, dose, or release showing variability in events, processes, and parameter values........

18 Normalized containment requirements in $40 \mathrm{CFR} 191 \ldots \ldots \ldots \ldots 6$

19 Three-category containment requirements............... 67

20 Comparison of TRU-waste criteria with the reference HLW risk

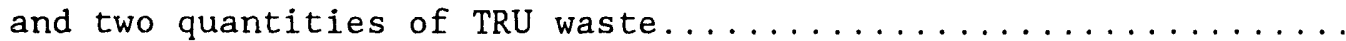




\section{Tables}

1 Criteria Traceability Using the YMP Thermal Design

Requirements as an Example...................... 10

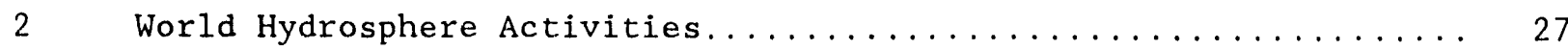

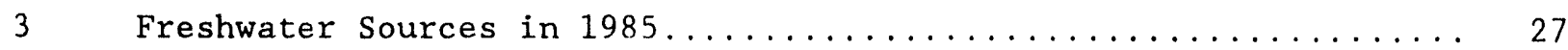

4a Fatal Cancers per Curie Released to the Biosphere for Multiple Release Modes............................ 35

4b Fatal Cancers per TBq Released to the Biosphere for Multiple

Release Modes............................. 36

5a Cumulative Release Limits for 10,000 Years (curies per 100,000 MTHM) for Multiple Release Modes............... 37

5b Cumulative Release Limits for 10,000 Years (TBq per 100,000 MTHM) for Multiple Release Modes................ 38

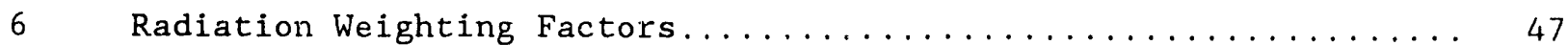

7 Tissue Weighting Factors...................... 48

8a Dose-Conversion Factors for Humans (curies and related units).... 49

8b Dose-Conversion Factors for Humans ( $\mathrm{TBq}$ and related units)...... 50

9 Comparison of Present Single Generic Release Limits and

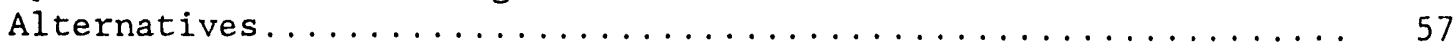

10 Characteristics of Containment-Requirement Options.......... 71

11 Features of HLW and TRU-Waste Criteria When Parallel Development of the Fundamental Criterion Is Used........... 78

12 Examples of TRU-Waste Units That Are "Equivalent" to 1,000 MTHM HLW Based on Risk Potential Metrics................ 81

13 Characteristics of TRU-Waste Criteria Options............ 83

14 Relative Stringency of Several Radioactive-Waste Disposal Criteria Alternatives.......................... 85 


\section{ACRONYMS}

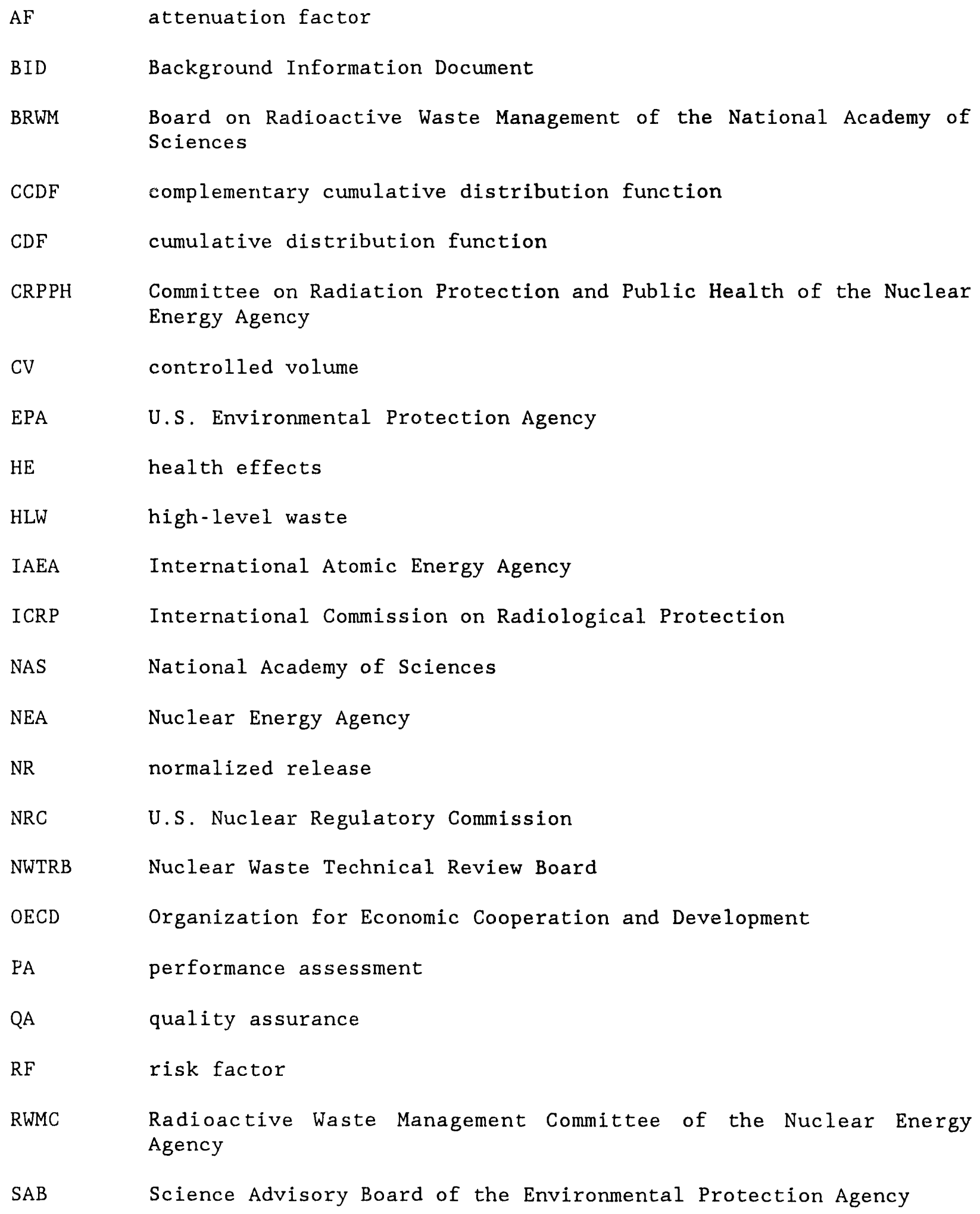


spent fuel

TRU

transuranic

UNESCO United Nations Educational, Scientific, and Cultural Organization

UNSCEAR United Nations Scientific Committee on the Effects of Atomic Radiation

USGS

United States Geological Survey

WIPP

Waste Isolation Pilot Plant for disposal of transuranic waste

YMP

Yucca Mountain Project for disposal of commercial spent fuel and high-level waste 


\section{GLOSSARY}

abnormal natural events - Low-probability natural events occurring in the vicinity of a repository that could result in release of radioactive material. Includes volcanism, earthquakes, climate changes, glaciation, meteor impacts, etc.

accessible - Capable of inflicting risk because of location, form, quantity, or concentration.

accessible environment - Defined in the proposed U.S. Environmental Protection Agency (EPA) high-level waste standard as, "The atmosphere, land surfaces, surface waters, oceans and all the lithosphere that is beyond the controlled area" [1].

advection - The transport of dissolved material by the motion of a fluid.

aquifer - A water-bearing layer of permeable rock that will yield water in usable quantities to wells.

attenuation - Reduction of a detrimental potential.

attenuation factor - The factor by which a component or entire disposal system reduces a dose or risk potential.

barrier - A material object that inhibits or restricts free movement of either the waste or the populace being protected.

biosphere - Generally includes the earth's surface, the oceans, and the atmosphere; those zones that contain or support life.

collective dose - The sum of doses to all the individuals in a specific group over a given period of time. Also called population dose. The unit is person-Sv.

component - Any part of the disposal system that can be treated separately because of function or location and can be analyzed as a unit.

conservative - Use of the assumptions, data, analyses, and interpretations that would lead to overestimations of risk and overly restrictive regulations.

controlled area (a volume by definition) - Defined in the proposed U.S. EPA high-level waste standard as, "(1) A surface location, to be defined by passive institutional controls, that encompasses no more than 100 square kilometers and extends horizontally no more than five kilometers in any direction from the outer boundary of the original location of the radioactive wastes in the disposal system; and (2) the subsurface underlying such a surface location" [1]. 
de minimis risk - Used by regulators to define an acceptable level of risk that is below regulatory concern. From de minimis non curat lex: the law does not take notice of very small or trifling matters.

derived standards - Requirements placed on the performance of components or processes in the disposal system, or on the flux or concentration of radionuclides at locations along pathways from the waste site to humans to facilitate regulation, control, and monitoring. They are computed from, and are traceable to, dose or risk standards. Derived standards are only applicable to the circumstances for which they were calculated.

dilution - Diminishing in strength or concentration by mixing the waste with large quantities of another substance.

dispersion - The expansion of a moving plume or band of contaminant carried by a moving fluid in a porous medium. Also, breaking up a concentrated source and distributing it to different locations.

disposal system - All engineered and natural components that act as pathways and alter the risk potential between the initial waste location and possible recipients of detrimental effects.

dose standards - Limits on allowable dose rates to individuals or populations, lifetime doses to individuals, or time-integrated doses to populations.

fission product - Ang radioactive or stable nuclide produced by fission, including both primary fission fragments and their radioactive-decay products.

fundamental standard - The standard that specifies the allowable detriment to humans, biota, and the environment from a process or substance. It is usually stated as a limit on risk or premature deaths and genetic effects. All requirements relating to radiological protection should be traceable to the fundamental standard.

groundwater - Water that exists or flows within underground geologic formations.

hazard - The source of risk or adverse effects.

health effects - Term used by the U.S. EPA to denote fatal cancers and firstgeneration genetic effects (leading to early death in individuals) predicted to occur in population groups exposed to ionizing radiation.

high-level waste - The highly radioactive materials resulting from the fission process in nuclear reactors. Can include the separated radioactive residues from chemical reprocessing of spent fuel or the unreprocessed spent fuel, when the latter is intended for disposal. 
human intrusion - Actions of humans in the future that result in contact with radioactive materials placed in a repository. Includes drilling of wells or sinking of shafts and withdrawal of contaminated water or geologic materials.

linear hypothesis - The assumption that health effects are linearly related to exposure of individuals to low- and mid-dose levels of ionizing radiation.

lithosphere - The outer zone of the solid earth including the crust and upper part of the mantle.

MTHM - The amount of HLW generated by the burnup of one metric ton of uranium.

pathway - A route taken by radionuclides in the lithosphere and biosphere between the initial waste location and the recipient of the detriment.

performance assessment - An analysis that predicts the behavior of a system or component under a given set of conditions. It includes estimates of the effects of uncertainties in events, processes, and data. As used in $40 \mathrm{CFR}$ 191, it is assessing compliance with the containment requirements in Subpart B (i.e., identifying significant events and processes and computing their effects, and estimating the cumulative release of radionuclides from the controlled volume and incorporating them into an overall probability distribution).

point of compliance - The location, for a given release mode, where radionuclides enter the biosphere. At this location, multimode cumulative releases over the time of regulation are calculated for comparison to the release limits.

population dose - See collective dose.

potential - A measure of the capacity of a risk-related characteristic to develop into actuality at any time or location in the disposal system. The characteristic could be activity, exposure, dose, effective dose, or health effects.

prescriptive standards - Requirements placed on a repository that are intended to reduce risk but are not traceable through models to the fundamental or dose standards. Retrievability is an example.

quality assurance - As applied to radiologic standards, it is all the systematic actions necessary to provide confidence that the requirements will provide adequate protection to the populace in a cost effective manner.

release mode - The way radionuclides are transported from the lithosphere to specific components of the biosphere resulting in exposure to humans. The release modes are: atmosphere (gaseous release), land (contaminated solids deposited on the land surtace), well (contaminated groundwater pumped to the surface), fresh surface waters (extracted contaminated water and aquatic food), and oceans (contaminated seafood). Each mode may consist of several pathways. 
repository - A facility, and the associated engineered structures and equipment, where radioactive wastes are placed for disposal.

resilience - The ability of a disposal system to function satisfactorily with a component or components operating at less than full efficiency. This can be accomplished by redundancy or by transfer of the function of the failed component to following components. This is a system characteristic with given components [2].

retardation - A process that increases the time required for waste to move between two locations, allowing more time for the waste to decay.

retardation factor - A measure of the delay of nuclide transport through geologic media due to sorption on pore surfaces.

risk - Probabilistic exposure to hazards and their severity or consequence; the expected detriment per unit time. In equation form it is the consequence of an event, times the probability the event will occur, summed over all events associated with the process or substance.

risk assessment - The modeling analyses of conceptual or operating disposal systems to predict the probal.iiistic detriment to humans or biota.

risk factor - Defined by the U.S. EPA as fatal cancers per curie of a radionuclide released to the environment for a specific release mode.

robustness - The ability to function satisfactorily under adverse conditions. See resilience and stability.

safe - Without harm or risk. As used in regulations, it is the likelihood of occurrence of a specific hazard that a social decision maker has set as an acceptable risk level.

sorption - The binding on a microscopic scale of one substance to another, such as by adsorption or ion exchange (e.g., the sorption of soluble radionuclides from the liquid phase onto the solid phase of a geologic formation or the particulates in a body of water).

spent fuel - Fuel assemblies removed from a nuclear-power reactor after their useful life, usually 2 to 3 years of operation at power.

stability - The ability of a component to function satisfactorily orer a wide range of environments or with an environmental change. This is a component characteristic for a given environmental variation and a given function in the system [2].

stable environment - An environment with negligible changes or fluctuations of important characteristics during the period of interest.

temporal dispersion - Distributing a relatively high-intensity, shortduration release of waste over a longer period of time, resulting in lower transfer rates; pulse spreading. 
transuranic waste - Radioactive-waste material containing elements with atomic numbers above 92 , in concentrations above and with half-lives greater than specified values.

water travel time - The average time fo, water that has contacted wastes in a repository to move from the repository location through the surrounding geologic formations to a specified location where the water could be used by humans. 


\section{INTRODUCTION}

The present version of the U.S. Environmental Protection Agency's (EPA) "Environmental Standards for the Management and Disposal of Spent Nuclear Fue1, High-Level and Transuranic Radioactive Wastes" (40 CFR 191) [1], promulgated in 1985, was vacated by the U.S. Court of Appeals for the First Circuit on July 17, 1987 [3]. The regulation's Subpart B-Environmental Standards for Disposal-was remanded to the EPA for further consideration. Only portions of Subpart B were cited specifically, but the remand provir": an opportunity to reevaluate the safety and confidence level provided by the standards as a whole.

The intent of this report is not to rewrite the radiological standards or to discuss all the approaches and options that have been proposed since the 1987 remand. The EPA has indicated that it will retain the rasic structure of the 1985 version of 40 CFR 191 when the standard is repromulgated. For that reason, modifications are suggested in three specific areas within the existing framework of 40 CFR 191 that would make the regulation more defensible and remove inconsistencies, even though more extensive changes could produce better regulatory standards. The EPA will have to make and defend decisions on what to change and how to make the changes.

Several options for modifying and extending the standards were discussed in a previous report [4]. Those options were intended to make the standards more appropriate for the sites now under consideration, relate them more directly to the actual safety of the repositories, and make them more defensible. The current report is an expansion of discussions of previously considered options and a presentation of additional options. The chapters in this report are discussions of alternatives, demonstrations of methods of development and implementation, comparisons of the characteristics, attributes, and deficiencies among the options, and discussions about possible implications for performance assessment (PA).

Modifications to 40 CFR 191 would be in accordance with the Supplementary Information for Section 191.17 of the rule, which states that

in developing the disposal standards, the [EPA] has had to make many assumptions about the characteristics of disposal systems that have not been built, about plans for disposal that are only now being formulated, and about the probable adequacy of technical information that will not be collected for many years. Thus, although the [EPA] believes that the disposal standards being promulgated... are appropriate based upon current knowledge, [the EPA] cannot rule out 
the possibility that future information may indicate needs to modify the standards [1].

Two radioactive waste disposal facilities-the Waste Isolation Pilot Plant (WIPP) in New Mexico for transuranic (TRU) waste and the Yucca Mountain Project (YMP) in Nevada for high-level waste (HLW) -have been proposed and are in various stages of planning and development. A considerable amount of data has been collected for the two sites, and preliminary performance assessments based on the EPA's 1985 standards have been performed for both the WIPP and the YMP. Modifications of the remanded standards have been proposed based on the preliminary results of the performance evaluations and on traditional methods of regulating chemical and radiological carcinogens. New approaches and options have been put forth in response to working drafts prepared as proposed revisions of the 1985 standards.

The options in this report are analyzed systematically using elements of quality assurance that

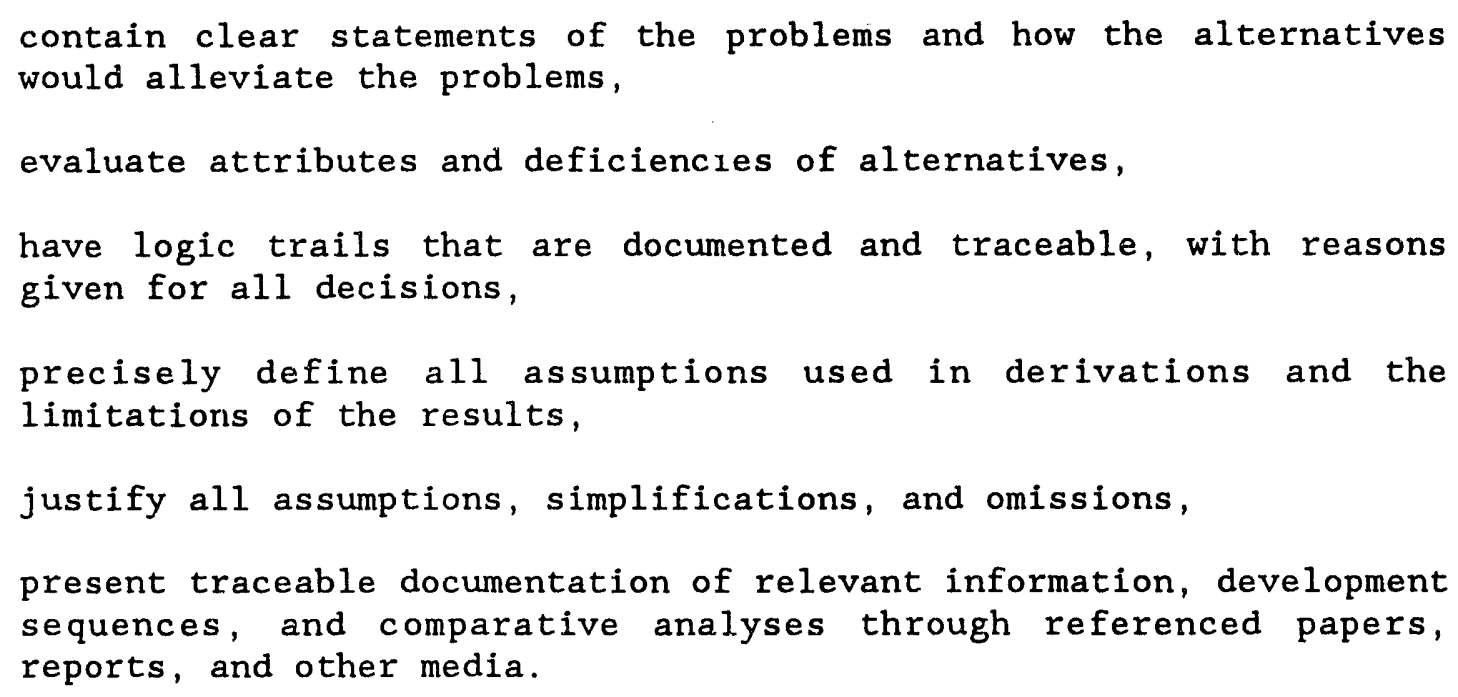

Chapter 2 is a general discussion of radioactive-waste repositories and the hierarchy of regulations that are intended to assure that these repositories meet safety standards. The generic derived release limits of 40 CFR 191 are described in Chapter 3. Chapter 4 is a discussion of approaches other than the current release limits in 40 CFR 191 that can be used to obtain more realistic risk assessments and to regulate TRU waste and HLW repositories. Chapter 5 is a comparison of the present single generic set of release limits with the four alternatives described in Chapter 4 . The current containment requirements and two options are considered in Chapter 6 . Chapter 7 is a discussion of an option that uses a TRU-waste fundamental criterion with the present release limits and a comparison of that option to the concept of using a family of TRU-waste reference units that are equated 
to HLW on an allowable risk for a TRU-waste reference repository. Portions of the evaluations in Chapters 4 through 7 of this report were presented at workshops of the Electric Power Research Institute (EPRI) in September 1991 and February 1932 but have been expanded and refined. The concluding chapter is a summary of the main points of the report and a discussion of important considerations when developing or modifying radiologicai standards. 


\section{TECHNICAL BASES FOR REGULATIONS}

This chapter contains a brief discussion of the requirements of a radioactive-waste repository and how a repository functions to accomplish these requirements. The hierarchy of regulations that assures repositories meet the safety requirements and the function of each level of criteria are then discuss $t$.

\subsection{The Repository System}

Regulators need to know how a class of repositories (e.g., deep geological radioactive waste) will function before they can regulate it effectively. Because of component interactions, it may be necessary to conduct preliminary or generic assessments of an entire disposal system. However, this does not imply that predicted repository capabilities should replace safety requirements as the fundamental criteria for waste disposal. Input parameters for generic system assessments and analyses for derived criteria include potential waste composition; waste form; containers; repository layouts and design; geology; geochemistry; hydrology; gas permeability; tectonics; natural resources; demography; and distances to water supplies, oceans, and agricultural centers.

\subsubsection{Essential Characteristics of a Nuclear-Waste Repository}

The top priority for any repository is the ability to meet acceptable $r$ isk limits for individuals, single generations, and/or collective populations. These risks may occur during handling; transportation; emplacement; closure; and post-closure undisturbed operation, human intrusion, and abnormal natural events. In addition to having acceptable predicted risks, a good repository should be reliable and there should be high confidence in risk predictions.

Many characteristics of a repository that make it reliable also enhance confidence in risk predictions. Resilience, which is the ability of a disposal system to function satisfactorily when parts of the system are disturbed or do not operate at full predicted efficiency, is one of these characteristics. Resilience can be obtained by using redundant engineered barriers or by site selection and system design that transfers the function of a failed component to the following components in the system. A simple example of function transfer is that in some formations a canister could fail shortly after closure with almost no change in risk because the risk 
attenuation normally accomplished by the canister, which retards short-lived radionuclides long enough for significant decay, would be transferred to the surrounding formation. Resilience is a characteristic of the disposal system for a given waste composition, site, and repository design. Another dualpurpose characteristic is the stability of system components. This is the ability of components to function satisfactorily over a wide range of expected environments or with an environmental change. Stability also is a measure of how predicted risks are affected by imprecision in all parameters used in performance assessments. This is a component characteristic for a given environmental variation and a given function in the system. High resilience and stability make the system less sensitive to changes and performance assessments less sensitive to the quality of input data. Examples are given in Reference 2. Robustness is a broader term used to define the ability to function satisfactorily under adverse conditions.

Confidence in risk prediction is enhanced by a stable environment surrounding the repository that will have relatively small changes or fluctuations in important parameters during the time of interest. Other advantageous site characteristics are a simple uniform geologic structure, seismic stability, and a lack of abundant mineral resources. The site should be relatively easy to characterize without jeopardizing its integrity. Finally, the cost of the repository must be commensurate with the benefit gained in risk reduction.

Other characteristics may or may not be beneficial, depending on overall system requirements. It is therefore essential tc understand how all components interact before finalizing the disposal system and before promulgating regulations that are more restrictive than risk or dose criteria. Section 2.2 develops this subject in more detail.

\subsubsection{Repository Processes, Pathways, and Release Modes}

The risk potential for mined geologic repositories is atteruated by retardation, dilution, and time and space dispersion of the radionuclides along the entire length of all pathways from the source to humans [2]. Since sites are selected to minimize risk, a large part of the attenuation takes place outside the repository boundaries. Radionuclide pathways can include transport to an aquifer by diffusion or infiltration, advection in the aquifer, withdrawal from wells or release to surface water, surface-water flow and circulation, atmospheric transport, and finally to humans via drinking water, the food chain, inhalation, immersion, and direct exposure. The magnitude of the attenuation factor (AF) of each component in the wastedisposal system depends on what is being attenuated (individual dose or 
collective dose), the waste inventory (HLW or TRU waste), pathways (distance, media, and transport mechanism), the time span of interest, and the performance of all the components of the disposal system that precede it on the pathway to humans. Each pathway will attenuate the risk potential by a different amount. The risk potential of each radionuclide will be attenuated by a different amount because of factors such as half-life, solubility, diffusivity, retardation, and concentration factors.

Figure 1 shows the release modes and the pathways, from the initial waste location to the release points, for a generic disposal system. Nuclide transport to an aquifer or to the surface in an undisturbed repository would be by diffusion or groundwater movement. Human intrusion and abnormal natural events could result in release to the surface and enhanced transport to an aquifer. Gaseous wastes could be released to the atmosphere from a repository located in porous media or as the result of human or natural. disturbances. The water withdrawn from the aquifer by wells can account for a large part of total water usage and is a significant release mode. For repositories located near surface water, withdrawal from rivers, lakes, and oceans and aquatic food consumption also could be significant.

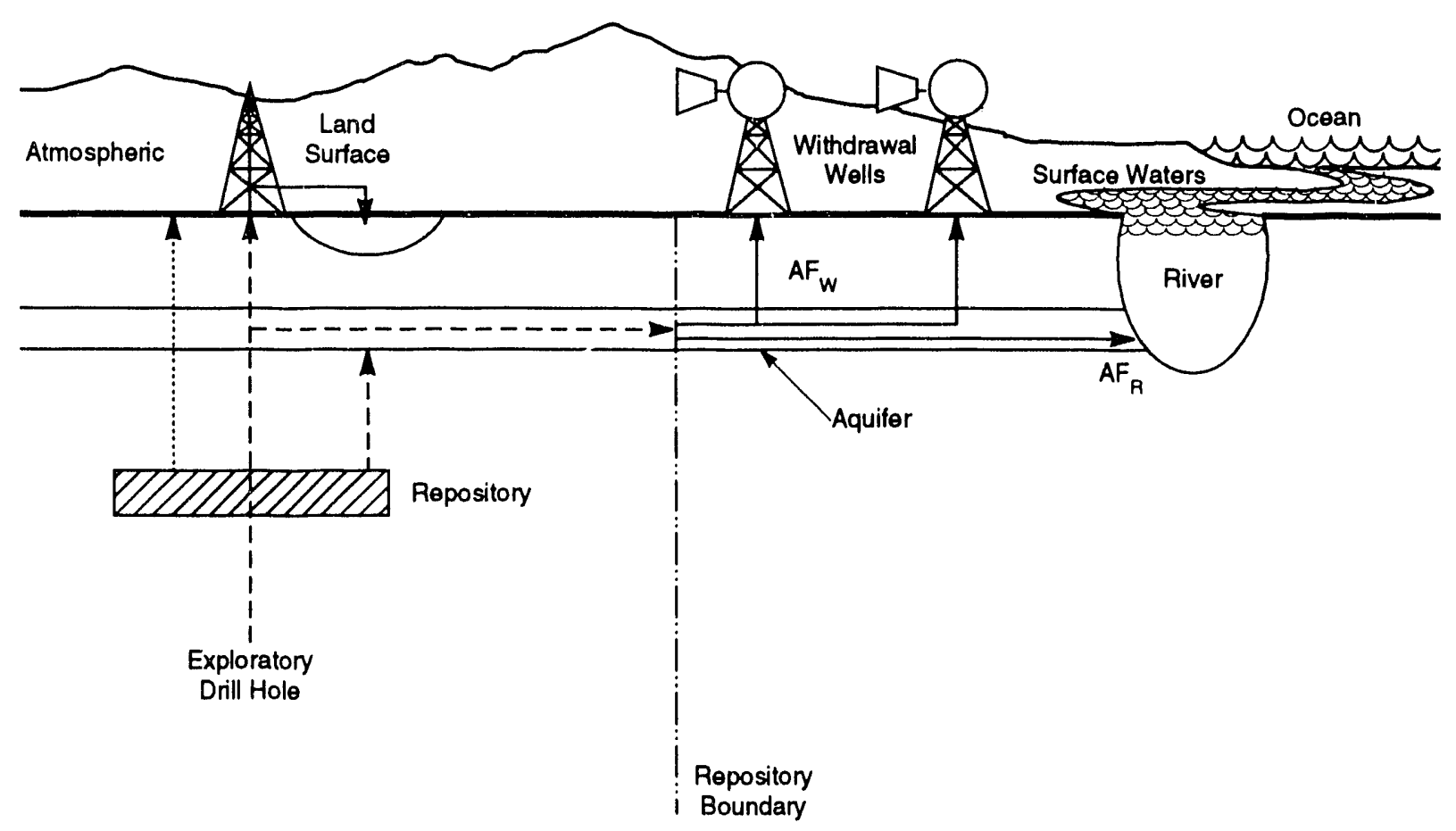

TRI-6341-141-1

Figure 1. Schematic of a radioactive-waste disposal system showing possible release modes and risk-attenuation factors outside the repository. 
Risk attenuation for advection in an aquifer pathway outside the controlled volume (CV) depends on flow rates, retardation, decay rates of the nuclides, the duration of regulation, and the performance of the components within the $C V$ [2]. Diffusion rates and dispersion could affect the $A F$ in some regions. Figure 2 shows typical attenuation factors as a function of the distance traveled in an aquifer from the CV toward the release point. Attenuation is greater for short-lived, highly retarded radionuclides at any given distance. AFs are an inverse function of flow rates. The initial exponential increase in slope is caused by decay and retardation. If the distance is long enough, nuclides will not be released before the end of the regulation period. At that distance the $\mathrm{AF}$ for an individual nuclide becomes infinite, which accounts for the final increase in the slope. Site characterization is not required beyond the location where all AFs become infinite. The retardation of radionuclide transport by sorbing media is particularly significant relative to the 10,000-year duration of regulation. Most of the wastes from a well-selected site would not reach the release points of either the well or river modes in that time. Some computed AFs for a proposed repository are given in Section 4.2.2.

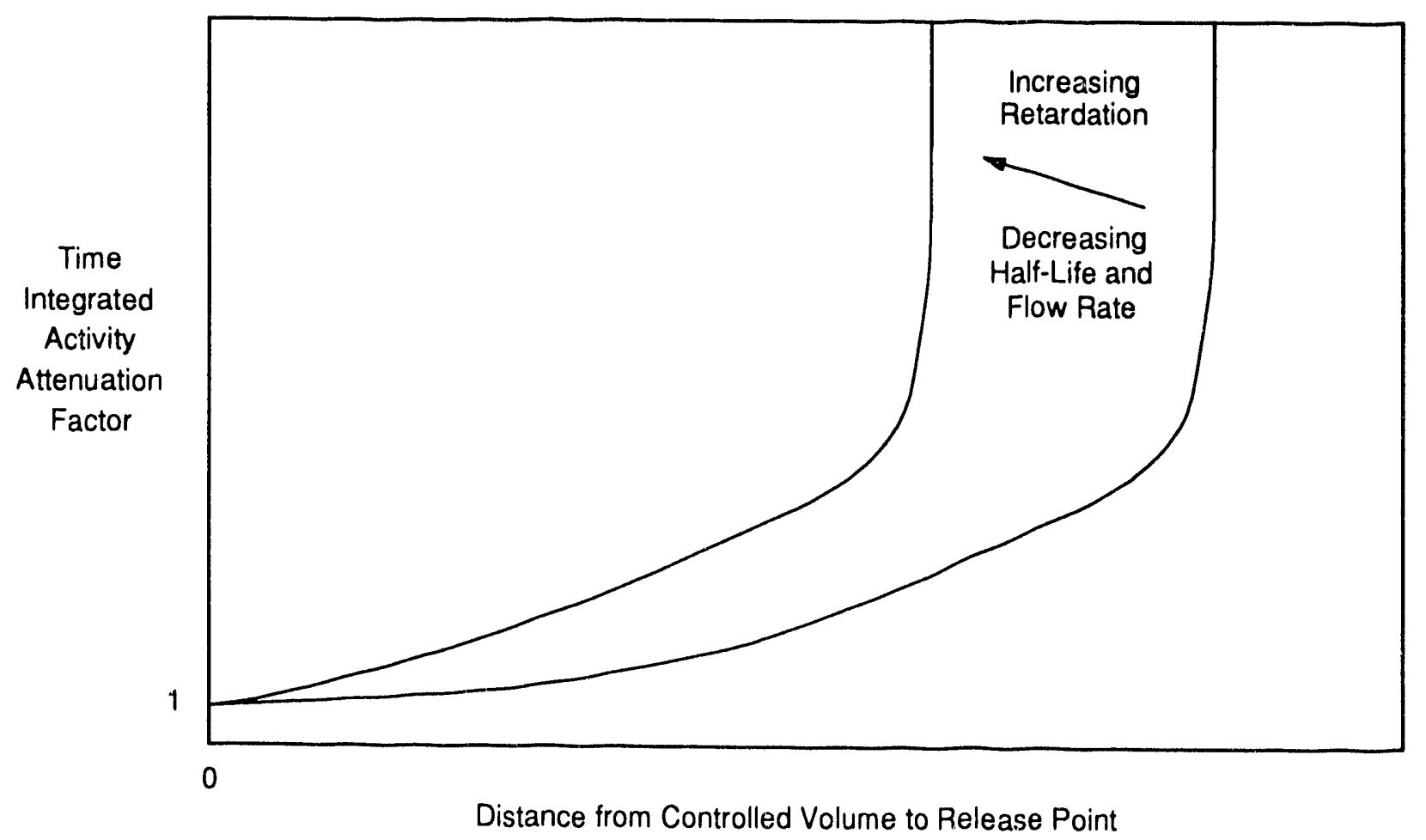

TRI-6341-142-0

Figure 2. Typical time-limited, integrated-activity attenuation factors as a function of distance traveled in an aquifer. 


\subsection{Functions and Hierarchy of Regulations}

There can be multiple levels of criteria that regulate the performance of waste repositories. These criteria should evaluate how well a repository meets the requirements given in section 2.1.1. To do this, the standards can:

1. Control what can be measured or can be predicted with sufficient certainty. Because of the long lives of some radionuclides and toxic wastes, and the slow migration from efficient repositories, few meaningful direct measurements can be made, so there is a heavy reliance on performance assessments based on current data and some predictions of future states.

2. Place derived and prescriptive requirements on site characteristics and designs that will foster the essential repository characteristics. Functional analyses could be useful in defining what should be enhanced and what should be avoided. Since risk attenuation is a total system process and all possible site and design combinations cannot be foreseen, care must be taken to prevent these requirements from being too restrictive.

Table 1 shows the hierarchy and relationship of seven criteria levels for one aspect of the YMP repository. Lower levels of criteria cannot be computed or defined until all the levels above them are fixed. The top level, which is the fundamental criterion, specifies the detriment or level of risk that is acceptable for a specific material or process. This is the only level that explicitly defines the safety requirements of the repository. To have any radiologic risk significance, all other levels must be traceable to level 1. Fundamental criteria can limit risk rates to maximally exposed individuals or single generations during a specified time interval or at the time of peak risks. They can also limit collective population risks over a specified time, or any combination of the above. One of the basic philosophies for the level of protection is that waste disposal should not impose any greater risk on future generations than is accepted today. On the other hand, the standards cannot be so stringent that repositories cannot be built at reasonable costs. Guidance for setting fundamental criteria is given by advisory bodies such as the International Commission on Radiological Protection (ICRP) $[5,6]$.

The second level (dose criteria) defines the dose limits that correspond to the level 1 risk limits. Derived criteria (level 3 ) are computed from dose criteria using nuclide-transport models. Prescriptive criteria (level 4) are requirements placed on a repository that are intended to reduce risk but are not derived mathematically from the fundamental criterion. They are 
Table 1. Criteria Traceability Using the YMP Thermal Design Requirements as an Example

\begin{tabular}{|c|c|c|}
\hline $\begin{array}{l}\text { Criteria } \\
\text { Level }\end{array}$ & $\begin{array}{l}\text { Criteria } \\
\text { Category }\end{array}$ & Criteria Example \\
\hline 1 & Fundamental & $\begin{array}{l}\text { Level of allowable risk to the populace } \\
\text { (U.S. EPA } 40 \text { CFR 191) }\end{array}$ \\
\hline 2 & Dose & $\begin{array}{l}\text { Level of allowable dose (ICRP } 60 \text { and } \\
\text { Working Draft } 4 \text { of } 40 \text { CFR 191) }\end{array}$ \\
\hline 3 & Derived & $\begin{array}{l}\text { Time-integrated radionuclide flux across } \\
\text { repository boundaries (U.S. EPA } 40 \text { CFR } \\
\text { 191) }\end{array}$ \\
\hline 4 & Prescriptive & $\begin{array}{l}\text { Retrieval, containment, and groundwater } \\
\text { travel time (U.S. NRC } 10 \text { CFR 60) }\end{array}$ \\
\hline 5 & $\begin{array}{l}\text { Functional } \\
\text { Requirements }\end{array}$ & $\begin{array}{l}\text { Dry canister, no spalling, no phase } \\
\text { change, limit on fuel rod failure, limit } \\
\text { on surface condition change, limit on } \\
\text { rock thermal fracturing, and maintain } \\
\text { human access to drifts }\end{array}$ \\
\hline 6 & $\begin{array}{l}\text { Design } \\
\text { Requirements }\end{array}$ & $\begin{array}{l}\text { Temperature limits on canisters, bore- } \\
\text { holes, drifts, and the formation }\end{array}$ \\
\hline 7 & $\begin{array}{l}\text { Secondary } \\
\text { Design } \\
\text { Requirements }\end{array}$ & $\begin{array}{l}\text { Areal power density, repository layout, } \\
\text { inventory, ventilation cooling, and } \\
\text { ventilation drying }\end{array}$ \\
\hline
\end{tabular}

usually based on the requirements in the 3 higher levels but are neither necessary nor sufficient to ensure compliance. Functional requirements (level 5) define how the repository must function to meet the higher-level criteria. It is the second step in formal system engineering, following the functional analysis. Functional analyses for repository designs and site selections are restricted and partially replaced by criteria levels 1 through 4. There can be multiple levels of design requirements (levels 6 and 7 in the example). These are the specifications used in the design of the repository. If criteria levels lower than dose limits are issued before the repositories, pathways, and processes are adequately defined, they may put unrealistic requirements on the system and have adverse effects on the design and safety of the repository. The lower the leval. of repository regulation, the less opportunity there is to optimize the disposal system and to evaluate 
the actual system resilience and component stability. The following chaptars of this report pertain to only the top three criteria levels.

Derived collective release limits are a significant part of the 40 CFR 191 regulatory strategy. The uses and limitations of derived standards are discussed in more detail to help clarify the evaluations of dose and releaselimit options in this report. Derived standards are requirements placed on the performance of components or processes in the disposal system, or on the flux or concentration of radionuclides at locations along pathways from the waste site to humans. The purpose of derived standards is to facilitate regulation, control, and monitoring. They must be computed from, and traceable to, the fundamental criteria that define the acceptable detriment. They never replace the fundamental or dose criteria and are a measure of risk only as they relate to the fundamental criteria [7]. Therefore, a single derived standard that is traceable to a single fundamental criterion will be site and application specific. Derived standards must only be used for the circumstances for which they were derived [7]. Therefore, generic derived standards that are applied to all sites, all pathways, or all release modes are inherently inaccurate. Multiple generic derived standards are more accurate than single generic derived standards because they allow the regulator to select the most appropriate standards and apply them at the most appropriate locations. Because of these inaccuracies there is a tendency to make generic derived standards extremely conservative. The level of conservatism is unknown and nonuniform, which makes the allowable risk different for each repository and the actual risk margin of safety unknown.

Derived standards can be set at any location in the disposal system, preferably at a component boundary to expedite analyses. They are computed by modeling the disposal system from the location of the derived standard to the locations of the populace at risk. The accuracy of this link depends on the realism of these models [8]. The PA models only cover the radionuclide transport from the initial waste location to the location of the derived standard. The derived standards along with the performance assessments constitute the risk assessment for the repository. This relationship is illustrated in Figure 3. Two approaches to risk assessment are shown. One procedure uses only the fundamental or dose criteria and computes the nuclide transport sequentially from the source to humans; the other uses derived release limits computed from the fundamental criteria, followed by PAs that compute nuclide transport from the source to the location of the release limits. The accuracy of the risk assessment depends on the accuracy and realism of all models, regardless of the procedure used. Splitting the risk assessment into two segments does not reduce the accuracy requirements of either segment, nor does it reduce the uncertainty. Since the derived 


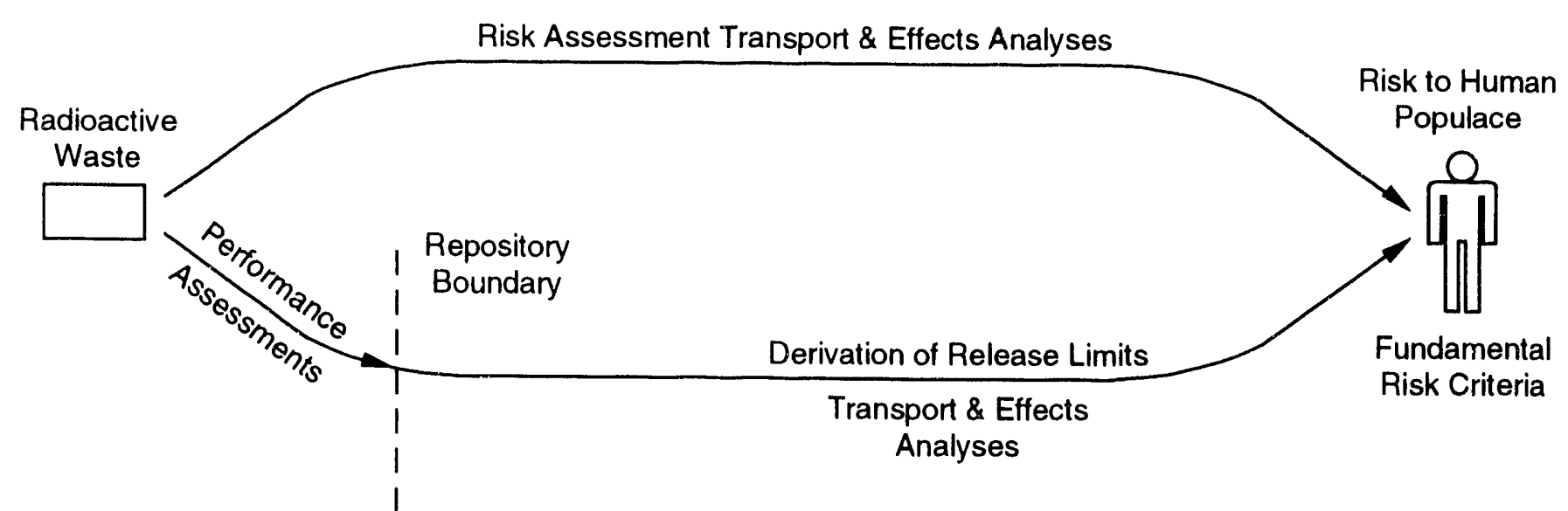

Derived Release

Limits 40 CFR 191

TR1.6341.145.0

Figure 3. Alternative procedures for risk assessments.

standard is an integral part of the risk assessment, it should be computed with the same level of functional quality assurance (QA) that the PA uses to evaluate the repositories. If the derived standards are to be defensible, formalized logic should be used, the steps in their development and all decisions should be traceable, verified models should accurately represent pathways and effects, data and assumptions should be realistic for the application, and assumptions, data, and results should be used consistently.

Component interactions in geologic repositories are complex and should be carefully considered when defining the type and point of compliance of derived standards. This problem does not occur with dose standards because the analyses are conducted sequentially from the waste source to humans. The complexity, uncertainty, and absence of proven guidelines for radioactivewaste disposal standards require the development of all criteria levels for all waste categories to be conducted in a systematic manner to assure consistency and appropriateness. 


\section{THE PRESENT RELEASE LIMITS IN 40 CFR 191}

This chapter covers the philosophy behind the present single-mode generic release limits, how they were derived, and some problems that should be rectified. The EPA standards for radioactive-waste disposal are unique in several ways [1], and this uniqueness must be taken into account when changes or extensions are considered. The information in this chapter serves as background for the discussion of alternatives in Chapter 4 and the evaluation of all options in Chapter 5.

A single derived standard that limits time-integrated radionuclide releases from repository boundaries applies to all HLW, SF, and TRU-waste repositories and all release modes. Variability in the lithosphere and biosphere surrounding the repositories, the site locations, and repository designs were not considered in the derivation. The dependence of the detriment on the release mode was also not considered. Because there is a large difference in dose attenuation by each disposal system and for each pathway, the single release limit forces the level of protection to be different for every site and every mode of release for each site. The derivation of the release limits omitted one of the most important components in the disposal system, omitted the three most likely release modes for the YMP and the WIPP, and was based on two release modes that are highly improbable for these repositories.

Differences of opinion exist on these and other features of 40 CFR 191. Review panels [12], advisory boards [13,14], and individual investigators have recommended numerous modifications to all versions of the EPA radioactive-waste standards $[1,15,16]$. Most of the reviewers recommended substantial changes in regulation philosophy, format, and stringency, but there was not complete agreement on what to change or how to change it. Minor changes have been made that involve models and data, but there have been no changes to the promulgated standards or to any of the many drafts that involve the philosophy, methodology, or format of the standards. Although major changes of the type recommended probably would produce the most appropriate standards, they may not be practical at this stage of standards development and could result in challenges, unacceptable delays, and loss of public confidence. The second obstacle to change is obtaining agreement on all aspects of the standards. There is no single solution that is best for all situations and meets everyone's values. Whichever approach is selected, the development of the standards should be consistent and logical.

The designs of radioactive-waste repositories, performance assessments to evaluate them, and licensing are all driven by radiological criteria as 
much or more than they are by scientific and engineering principles. Therefore, accuracy and appropriateness of the regulations are essential. Apparent stringency of a standard alone does not assure safety if the standards are inaccurate or inappropriate for the application. Inappropriate standards can greatly increase the cost of a repository while offering inadequate protection to the populace.

The first step in the critique of the release limits is a review of development procedures, functions, and characteristics of derived standards. The development and resulting release limits in 40 CFR 191 are then reviewed and analyzed. Differences between the requirements and the standards and their possible causes are discussed. Problems that may be caused by the present standards are also covered. In subsequent chapters, suggestions are made for modifying or extending the present standards, but no specific recommendations are made. Methods of analyses are suggested for the proposed extensions.

\subsection{Derivation of the Release Limits}

The background documents $[17,18,19,20]$ for 40 CFR 191 were reviewed to trace the development of the 10,000-year, time-integrated release limits that apply to any surface of the repository $\mathrm{CV}$. The generic models used by the EPA [13,14] considered four general modes of radionuclide releases to the environment: direct releases to a river, to an ocean, to a land surface, and from a volcanic or meteoritic interaction with a waste repository. The purpose of the EPA analyses was to compute the number of premature cancer deaths per curie (risk factors) of each radionuclide released to the biosphere via the various release modes. The geologic formations and resulting dose attenuation between the repository and the release locations were not included in any of the computations. It was assumed that all radionuclides leaving any surface of any repository boundary are instantaneously deposited in the river or ocean, or on the land surface. This is an extremely conservative simplification because a large part of the risk attenuation takes place outside the repository.

All consequences were assumed to be independent of release rates and times of release. The models were based on world-average values and contained many predictive assumptions. Except for the world population, which was assumed to be a constant 1010, the values of all parameters were the current world average. The following is a list of some parameters used in the analyses with values that are very likely to change over time or are not presently well defined:

World population,

Total flow rates of all rivers, 
The amount of river water drunk by humans,

Freshwater fish consumption,

Fraction of river water used for irrigation,

Land area irrigated,

Consumption of irrigated crops, milk, and meat,

Number of people fed per unit area of irrigated land,

Saltwater fish and shellfish consumption,

Resuspensio 2 factors,

Household shielding and occupancy factor,

Uptake factors,

Whole-body, effective-dose equivalents,

Health-effect conversion factors .

The release-mode biosphere model for rivers included ingestion of drinking water, freshwater fish, food crops, milk, and beef; inhalation of resuspended material; and external exposure to ground contamination and air submersions. No other pathways and no sorption or sedimentation in the rivers were included in the river model. The derivation only accounted for the approximately 608 of water use that comes from surface water. Contaminated well water was omitted. Considering the uncertainties in the data, the model simplifications, and the variability with site location, the biosphere model for the river-release mode could be either conservative or nonconservative.

The same source term was used for both the river and ocean models. That is, all radionuclides leaving the $\mathrm{CV}$ of the repository were assumed to enter both the river and the ocean instantaneously. There are several serious problems with the ocean model. The model represents all ocean waters with only two layered compartments (elements). It assumes that all releases instantaneously mix in the top compartment. The model contains no ocean circulation, and only vertical nuclide transport is allowed between the two compartments. The coastal shelves, where rivers enter the ocean and aquatic food is concentrated, are not represented in the model. A draft report for the Subseabed Disposal Project showed that radioactive waste released to a shelf region would result in 10,000-year population doses that are about 100 times higher than those predicted by a model without shelf compartments (Interim Radiological Safety Standards and Evaluation Procedure for Subseabed High-Level Waste Disposal, SAND88-1700, by R.D. Klett, Sandia National Laboratories, Albuquerque, NM; see also References 21 and 22). There are much better ocean models available than the one used in the EPA analysis $[22,23]$. Ingestion of fish and shellfish was the only pathway to humans that was considered in the EPA model. The draft report and references 21 and 22 showed that these are not the only significant pathways when radionuclides enter the shelf as they would from a river. Harvest limits of the ocean 
fisheries would affect maximum population-dose rates but were not included in the analyses.

The draft report for the Subseabed Disposal Project showed that dose tes are proportional to release rates only when the radionuclides have a short residence time, such as in rivers or on ocean shelves. In ocean waters beyond the shelves and in the atmosphere, dose rates are proportional to the accumulated inventory (the time-integrated release rate minus decay, scavenging, and removal) or concentration. The peak accumulation occurs long after the time of peak release rates. Therefore, doses from the deep ocean are very sensitive to when the radionuclides enter the ocean. The only reliable derived metric to represent doses from deep oceans was found to be the accumulated inventory, not the time-integrated release. The present EPA model assumes exponentially decreasing release rates to the oceans, whereas any releases to the ocean during the period of regulation would start late and gradually increase. Considering all the omissions, simplifications, and predictive assumptions, the ocean model is probably nonconservative.

The biosphere model for land surfaces represents waste brought to the surface by inadvertent human intrusion. These releases were assumed to be small and of short duration. Pathways to humans include food crop, milk, and beef ingestion; inhalation of resuspended material; and external exposure from ground and air contamination. This is a realistic model because instantaneous release is appropriate, fewer assumptions are required, and it is less dependent on predicted data values.

Carbon-14 was treated as a separate case, and a single risk factor was used for all release modes. It was assumed that all C-14 is released to the atmosphere as carbon dioxide. A good global-circulation model [24] was used to compute the atmospheric C-14 risk factors.

The risk factors for each release mode apply uniformly to all repositories and all release modes. If release limits based on each of these risk factors had been applied at the release locations, PA could have selected the appropriate release mode for each pathway and included the entire lithospheric pathway in the analyses. However, the derivation was carried one step further, which caused nonuniform levels of protection, several inconsistencies, and the omission of an important component of the disposal system.

In the derivation of the release limits, the EPA chose to base the values on only surface-water releases, which is the combination of the riverand ocean-release modes. Risk factors for the other modes that had been computed [18] were not used. The release limits were derived by dividing the number of acceptable premature deaths from 1000 MTHM of waste for 10,000 
years (10) by the risk factors (premature deaths per curie) for each radionuclide. The limits are applied to releases from all surfaces of the CV rather than to the locations for which they were computed. They are also used for all repository locations and all pathways.

The variabilities and uncertainties found in risk assessments also apply to derived standards. The single-valued release limits in Table 1 of 40 CFR 191 are actually distributions that span from five to over nine orders of magnitude, depending on the radionuclide $[17,19,25,26]$. The Envirosphere Company performed a combined variability and uncertainty analysis on the river-release model that was used to derive the release limits $[25,26]$. Probability distributions were assigned to 12 of the input parameters, and stochastic analyses were conducted for each radionuclide. Uncertainties in process assumptions and varying expert opinion on probability distributions were not included in this study. Figure 4 is a typical predicted probability distribution of population risk per curie released to the generic river. Also shown is the risk factor that corresponds to the EPA release limit. Most release-limit equivalents for the 13 radionuclides that were analyzed are above the medians of the risk-factor distributions. In the Envirosphere analysis, 908 confidence intervals for release limits span an average of about four orders of magnitude, showing that the use of derived standards does not reduce the total uncertainty in risk assessments. Reference 25 concluded that identifying specific repositories would considerably reduce

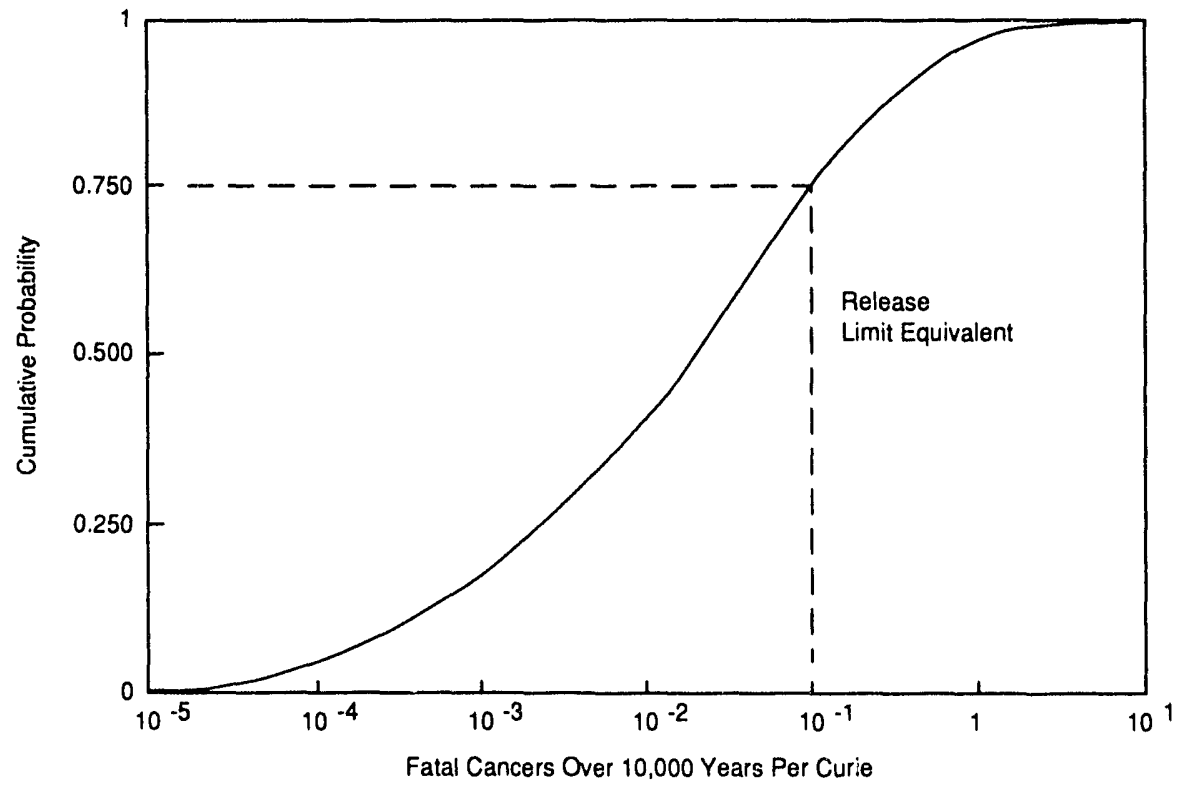

TRI.6341.150-0

Figure 4. Probability distribution of the population risks per curie of Am243 released to a generic river. 
many key uncertainties. This illustrates one of the disadvantages of single generic release limits. Another disadvantage of all generic release limits is that information about the variability and uncertainty in the biosphere pathways is lost because single averaged values are used in the release tables.

The derived release limits in Table 1 of Reference 1 specify the amount of each radionuclide that can be released from the $\mathrm{CV}$ during the regulation period if that is the only radionuclide in the inventory. For the actual waste inventories, a summed normalized release ( $R$ ) is used. The ratios of total release of each radionuclide $\left(Q_{i}\right)$ to the release 1 imit for that nuclide $\left(R L_{i}\right)$, summed over all radionuclides, must be less than one (Equation 1$)$ :

$$
\mathrm{Q}_{\mathrm{a}} / \mathrm{RL}_{\mathrm{a}}+\mathrm{Q}_{\mathrm{b}} / \mathrm{RL}_{\mathrm{b}}+\ldots .+\mathrm{Q}_{\mathrm{n}} / \mathrm{RL}_{\mathrm{n}}<1 .
$$

\subsection{Problems with the Present Release Limits}

There are several inconsistencies and discrepancies between the derivation and application of the 40 CFR 191 release limits, and the reasoning for some decisions is obscure. Most of the assumptions and limitations of the risk-factor computations were clearly stated in Reference 19, but the results were not used accordingly. The following are the major features of the present release limits and their derivation that do not meet the requirements for derived standards, or are internally inconsistent:

1. One of the most important parts of the disposal system was left out of the release-limit derivation. The assumption that all radionuclides except $\mathrm{C}-14$ that exit through any surface of the CV of any repository instantaneously enter both a generic river and the ocean is not realistic. This assumption ignores all forms of risk attenuation outside the repository boundary.

2. The release limits were not applied to the same circumstance for which they were derived. The generic model used in the derivation cannot represent specific disposal systems. The two systems currently being considered, the WIPP and the YMP, have very dissimilar lithologies, hydrologies, inventories, distances to release locations, pathways to humans, and system attenuation factors. The only nongaseous release modes considered in the release-limit derivation were rivers and oceans. It is unlikely that any waste from either repository would reach any surface water in 10,000 years. The only plausible nongaseous release modes are withdrawal wells, which were not included in the derivation, and release to the land surface, which was computed but not used. The atmospheric release mode was used for the gaseous $\mathrm{C}-14$ release-limit 
derivation. The inappropriateness of the release modes used in the generic release-limit derivation is illustrated in Figure 5 .

3. Reference 27 requires that the regulatory process must "consist of establishing generally applicable environmental standards for the protection of the general environment." The EPA interprets this to mean that requirements may not be site specific [28]. Environmental standards are level 1 criteria, which means that the fundamental criterion for HLW/SF of no more than 10 premature deaths from $1000 \mathrm{MTHM}$ of waste in 10,000 years cannot be site specific. Presently a single derived standard that only limits radionuclide releases from repository boundaries applies to all repositories. Since there is a large difference in the dose attenuation of each repository system and each mode of release, the single generic release limit forces the fundamental criterion (population safety) to be different for every site and for every mode of release at each site.

4. The degree of conservatism in the derivation is unknown. Some simplifications, predictions, and assumptions were conservative and some nonconservative. Even when the assumptions and omissions are definitely conservative, the level of conservatism is far from uniform for all repositories and all release modes. The standard is probably unrealistically conservative for all applications, but the confidence level of this conclusion is low.

It may be that the release limits in 40 CFR 191 were promulgated before sufficient information was available on repository designs, waste forms, site locations, and site properties. Fundamental safety criteria should remain

Probable Modes for the YMP

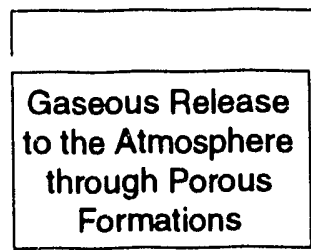

Probable Modes for the WIPP

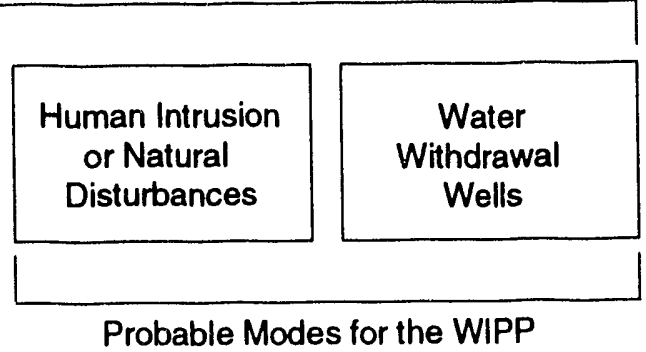

Modes that are the Basis for the Release Limit Table

(All Nuclides except C-14)

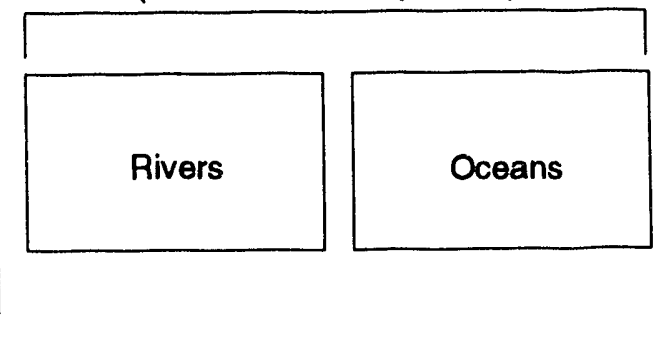

TRI-6342-1839-0

Figure 5. Possible release modes from radioactive-waste repositories. 
fixed, but derived standards should reflect the characteristics of the wastedisposal system. If derived standards are set before this can be accomplished, provisions should be made to update them if there are significant changes in repository configurations, data, or process definitions, or if new information shows that they are inappropriate for a specific application. 


\section{ALTERNATIVES TO THE PRESENT RELEASE LIMITS}

Fundamental and dose standards are the only criteria levels that accurately limit risk for all repositories and all pathways [4,29]. Derived standards are requirements placed on the performance of components or processes in the disposal system, or on the flux or concentration of radionuclides at locations along pathways from the waste site to humans. Because derived standards require modeling of specific pathways and processes, using specific data, the ICRP cautions that they must only be used for the circumstances for which they were derived [5]. Therefore, generic derived standards that apply to all repositories and all pathways, such as the present release limits in $40 \mathrm{CFR} 191$, are inherently inaccurate and the more generic they are, the more inaccurate they are. All assumptions and simplifications in generic derivations must be conservative to assure adequate protection for all applications. The compounding of conservatism resulting from generic derivations can lead to excessive repository costs or exclude some repositories that have acceptable risk levels. In all cases the degree of conservatism is unknown and is not uniform for all applications. In addition, generic derived standards applied close to the repository force the level of protection to change for each repository and each pathway.

The present release-limit table in 40 CFR 191 [1] is an example of a single generic derived standard. Only one release-limit table is used for all release modes, and it is based on simultaneous release to all the world's rivers and oceans. Cumulative releases are evaluated at the boundary of the repository instead of at actual locations of release (Figure 1). Because the limits are based on releases to surface waters and the only release modes expected for the WIPP and the YMP are atmospheric, land surface, and well withdrawal, this single generic derived standard is not being applied to the circumstances for which it was derived. This distinction is illustrated in Figure 5. By applying the standard at the repository boundary instead of at the actual release locations, one of the most important components of the disposal system, risk attenuation between the boundary and the release locations, is left out of the risk assessment. Examples of the magnitude of geologic risk attenuation outside the repository boundary are given later in this chapter. In addition, the risk-limit derivation was based on worldaverage parameters, which could cause inaccurate risk evaluations unless corrections for local conditions are made during PAs. These difficulties are to be expected with a single generic derived standard.

At least four approaches can be taken to obtain more realistic risk assessments and regulation of HLW and TRU-waste repositories than with the present release limits. Two approaches would retain the derived release- 
limit format. The other two would use the higher-level, more precise dose limits as either the primary criterion or an option to release limits.

\subsection{Site-and-Pathway-Specific Release Limits}

One alternate approach that uses release limits is an extension of the present derivations. More is known about release modes and pathways than when the present release limits were computed, and better data and models are available. Two very different candidate sites have been selected, and sitespecific definitions of the disposal systems between the repository and the release locations can now be made. Although site-specific parameters probably will change more with time than world-average parameters, sitespecific analyses do not have the initial bias that world-average analyses do. More complete and appropriate release limits applied at the surfaces of the CV could be computed for each site using the same basic methodology that the EPA used in the original derivation.

The first step for each site would be to define the possible pathways and release modes. The generic release modes illustrated in Figure 5 apply to both sites. For the YMP, $\mathrm{C}-14$ gas could escape through the unsaturated tuff. Other radionuclides could be brought to the land surface by human intrusion or abnormal natural events. Unsaturated flow could eventually transport radionuclides to the underlying aquifer, which would carry them off site. The most likely release mode for this pathway would be withdrawal we11s. For the WIPP, human intrusion could bring radionuclides to the land surface, and drilling into the repository could enhance trassport to the overlying aquifer. Diffusion and advection would eventually transport radionuclides to the aquifer, where they would be carried off site. The most likely release mode from the aquifer would be withdrawal wells. It is very unlikely that either repository would release any radionuclides to surface water in 10,000 years. Atmospheric, land surface, and well withdrawal are the only probable release modes for these two sites, but the river and ocean modes should be included unless they can be conclusively shown to be insignificant. Methods of updating the risk factors, computing the attenuation in the formations outside the $\mathrm{CV}$, and allocating releases for each mode are suggested in Reference 4.

Release tables would be computed using the EPA method described in Reference 17. The maximum number of fatalities allowed by the fundamental criterion would be divided by the fatal cancers per curie for each site and each significantly different pathway. Upward movement of gas, radionuclide movement to the land surface caused by human intrusion, and radionuclide transport through an aquifer and subsequent withdrawal by a well would be the 
only pathways for release from the controlled volume, resulting in a maximum of three release tables for each repository. The summed normalized release limit would include the release fractions for each nuclide for each release pathway (up to three release fractions for each nuclide):

$$
\begin{aligned}
& \mathrm{Q}_{\mathrm{G}, \mathrm{a}} / \mathrm{RL}_{\mathrm{G}, \mathrm{a}}+\mathrm{Q}_{\mathrm{G}, \mathrm{b}} / \mathrm{RL}_{\mathrm{G}, \mathrm{b}}+\ldots+\mathrm{Q}_{\mathrm{L}, \mathrm{a}} / \mathrm{RL}_{\mathrm{L}, \mathrm{a}}+\mathrm{Q}_{\mathrm{L}, \mathrm{b}} / \mathrm{RL}_{\mathrm{L}, \mathrm{b}}+ \\
& . .++\mathrm{Q}_{\mathrm{A}, \mathrm{a}} / \mathrm{RL}_{\mathrm{A}, \mathrm{a}}+\mathrm{Q}_{\mathrm{A}, \mathrm{b}} / \mathrm{RL}_{\mathrm{A}, \mathrm{b}}+\ldots .++\mathrm{Q}_{\mathrm{A}, \mathrm{n}} / \mathrm{RL}_{\mathrm{A}, \mathrm{n}}<1 .
\end{aligned}
$$

$Q$ is the computed 10,000-year release of a radionuclide from the controlled volume, and RL is the release limit for that nuclide. The subscripts G, L, and $A$ refer to the gas, land-surface, and aquifer pathways, respectively, and the subscripts $a, b, \ldots . ., n$ refer to the individual radionuclides listed in the tables.

This approach would use the appropriate release mode for each pathway and include all pathways and all components for the repositories covered in the derivation. It also would assure uniform safety requirements. The negative aspects of this approach are that the requirements would be site specific, would not cover future repositories, and would require additional site characterization and considerable time and effort to develop.

\subsection{Multimode Generic Release Limits}

\subsubsection{Description}

The other alternate approach that uses release limits would set release limits at the predicted locations of release (points of compliance) to the biosphere for each release mode. This is a significant change because the present single set of release limits is based on only surface-water releases and is applied at the surfaces of the controlled zone, which are the actual release locations of only the land and atmospheric release modes. The multimode approach is analogous to risk assessments that use risk or dose criteria. These assessments require all predicted pathways and release modes from the initial location of the waste to humans to be in the analysis. Dose and risk analyses do not stop at an imaginary boundary around the repository but include all geologic risk attenuation from the repository to the predicted points of release to the biosphere.

Multimode standards would apply uniformly to all repositories and all pathways. All major components in the disposal system would be included in risk assessments. EPA generic analyses from the release locations to humans would ensure uniform modeling of the biosphere for all applications (dashed 
lines in Figure 6). A five-column release table would be required to cover all possible release modes for generic repositories. PA would be able to select the appropriate release mode for each pathway and include all disposal system components in the assessment. This is similar to the present approach, and most of the derivations of risk factors have already been completed $[17,19]$. Release limits would still be computed by dividing the fundamental criterion by the risk factor for each radionuclide. Besides eliminating inconsistencies and omissions, this approach would not be site specific and would allow the fundamental standard to remain constant for all repositories and a11 pathways.

Multimode release limits would not alter land-withdrawal or marker requirements. The point of compliance is part of the analytical PA modeling simulation and is not a controlled parameter. Geologic transport of radionuclides in the "controlled zone" is not controlled any more than it is in the "accessible environment." Accessibility changes continuously from the original waste location to the location where the dose is received by humans. The disposal system does not stop at a manmade boundary but includes all components from the original waste location to the recipients of risk. Withdrawing additional land would not alter actual release locations, nor would it change the risk caused by any releases.

Using actual release locations as the points of compliance would not require more markers. The purpose of markers is to prevent inadvertent intrusion into the repository proper, which could result in some of the packaged waste being brought to the surface or enhanced transport of the waste to an aquifer. Markers are not intended to keep people from using contaminated groundwater or surface water, eating contaminated crops, meat, or fish, or breathing contaminated air caused by undisturbed releases to the biosphere. Even with the present single generic release limit, the location of the markers does not have to coincide with the location of compliance.

The following sections describe methods used in developing a five-column table of release limits, adjustments for repository locations, methods for combining releases from all modes into a single summed normalized release, geologic risk attenuation outside the repository, and suggestions for PAs. These multimode release limits would still be generic derived standards and consequently would contain some generalizations that may not apply to specific repositories, but the generalizations would be limited to the processes between the release locations and humans. 


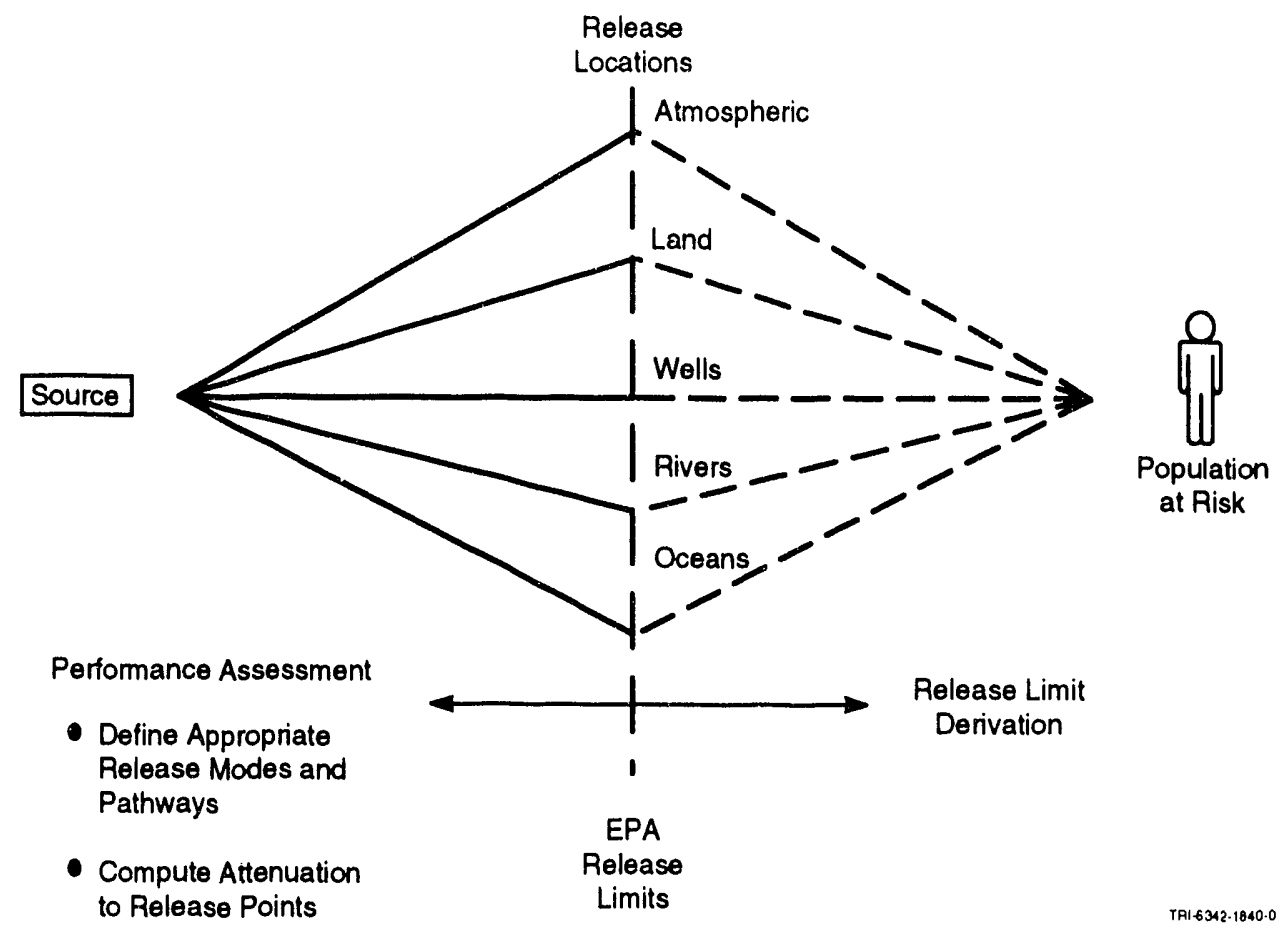

Figure 6. Multimode release limits in the risk-assessment process.

\subsubsection{Derivation and Implementation of Multimode Release Limits}

\subsubsection{DERIVATION METHODS}

The derivation of the present single generic table of release limits assumes that all the fresh water that is used comes from the world's rivers. Multimode release tables would separate fresh water into the actual sources, surface water and groundwater. All other uses remain the same as in the present derivation $[18,19]$.

The EPA used world-average parameters to compute risk factors included in the present standards [19]. This approach is compatible with fundamental criteria for collective risk and can be used with multimode derivations. The pathways to humans include ingestion of drinking water, freshwater fish, food crops, milk, and beef; inhalation of resuspended material; and external exposure to ground contamination and air submersion. In order to be consistent with previous EPA usage, "river" includes all sources of fresh surface water. 
Several generalizations and assumptions are common to both the EPA derivation of river-release limits [19] and the derivation of well-release limits presented in this report. They are:

1. The ratio (local consumption of water and food)/(local water flow rates) equals the ratio (world consumption)/(world water flow rates).

2. The ratio (local population at risk)/(local contaminated water flow rates) equals the ratio (world population)/(world water flow rates).

All risk-factor pathway equations for river-and well-release modes are of the form:

$$
D^{\prime}{ }_{i}=\frac{Q^{\prime}}{F} \cdot f(\text { individual use rates and conversion factors) }
$$

where

$$
\begin{aligned}
& D^{\prime}{ }_{i}=\text { dose rate to individuals (rem/person-yr) } \\
& Q^{\prime}=\text { release rate of radionuclide to the environment (Ci/yr) } \\
& F=\text { river or groundwater flow rate }\left(\mathrm{km}^{3} / \mathrm{yr}\right) .
\end{aligned}
$$

Multiplying by population ( $P$ ) and integrating over time produces the final form of the risk-factor equations:

$$
\frac{D_{P}}{Q}=\frac{\mathrm{P}}{\mathrm{F}} \cdot f(\text { individual use rates and conversion factors) }
$$

where

$$
\begin{aligned}
& D_{P}=\text { population dose (rem) } \\
& Q=\text { total release of radionuclide to the environment (Ci). }
\end{aligned}
$$

Except for the fish-consumption pathway, which applies to only the river mode, all biosphere pathway equations are the same for the river-and wellrelease modes. The only differences in the risk factors are caused by the radionuclide concentrations in the water $\left(Q^{\prime} / F\right)$. With the assumptions used in Reference 19, the concentration is a linear function of total world volumetric flow rates. The total volumetric flow rates for both modes are computed by dividing the volumes of each part of the hydrosphere by their exchange activities. This information is available in a United Nations Educational, Scientific, and Cultural Organization (UNEjCO) report for all the major hydrosphere divisions [31] and is summarized in Table 2. 
Table 2. World Hydrosphere Activities [Reference 31]

\begin{tabular}{lccc}
\hline $\begin{array}{l}\text { Part of } \\
\text { Hydrosphere }\end{array}$ & $\begin{array}{c}\text { Volume } \\
\left(\mathrm{km}^{3}\right)\end{array}$ & $\begin{array}{c}\text { Exchange } \\
\text { Activity (yrs) }\end{array}$ & $\begin{array}{c}\text { Volumetric } \\
\text { Flow (km } / \mathrm{yr})\end{array}$ \\
\hline Rivers & $1.2 \mathrm{E}+03$ & $3.2 \mathrm{E}-02$ & $3.8 \mathrm{E}+04$ \\
Lakes & $2.3 \mathrm{E}+05$ & $1.0 \mathrm{E}+01$ & $2.3 \mathrm{E}+04$ \\
Active Groundwater & $4.0 \mathrm{E}+06$ & $3.3 \mathrm{E}+02$ & $1.2 \mathrm{E}+04$ \\
Total Groundwater & $6.0 \mathrm{E}+07$ & $5.0 \mathrm{E}+03$ & $1.2 \mathrm{E}+04$ \\
World Oceans & $1.4 \mathrm{E}-09$ & $3.0 \mathrm{E}+03$ & $4.6 \mathrm{E}+05$ \\
\hline
\end{tabular}

Therefore, the risk factors for each biosphere pathway for the well mode will be the river-mode values times the river flow divided by the groundwater flow in Table 2.

The derivation of the release limits for both the river-and wellrelease modes assumed that each one is the only source of fresh water for a1 uses. The U.S. Geological Survey (USGS) publishes estimates of water sources and uses at 5-year intervals. Table 3 gives the 1985 percentages of water used for irrigation, livestock, and human drinking water that came from groundwater and surface water. Values are given for the Rio Grande Region (WIPP), the Great Basin (YMP), and the United States. This table could be used to allocate water use to the well- and river-release modes, so the total of the two sources will equal 1008 of the water used. Some average source fraction could be stated in the standards, or regulators or PA could select the percentages appropriate for each repository region

Table 3. Freshwater Sources in 1985 [Reference 31]

\begin{tabular}{lcc}
\hline & \multicolumn{2}{c}{ Percentage } \\
\cline { 2 - 3 } Region & Groundwater & Surface Water \\
\hline & 28 & 72 \\
Rio Grande Region & 19 & 81 \\
Great Basin & 36 & 64 \\
United States & & \\
\hline
\end{tabular}


Generic or world-average parameter values are used to compute multimode release limits, just as they were in the derivation of the present standards. Therefore they may not represent the actual radionuclide pathways or risk of specific repository locations. There are several site adjustment factors (SAFs) that could be applied to release limits for specific repositories to compensate for these generalizations that could either increase $o_{t}$ decrease the release limits. Generic SAFs could be defined in the standards that would apply to all sites, or the selection of site-specific adjustment factors could be left to the implementing agency for each repository. Generic SAFs have the advantage of consistent use for all repositories, and an equitable selection of SAFs that increase and decrease the release limits would be predefined. The disadvantages of generic adjustment factors are that they may overcorrect or undercorrect at any given site. The advantage of developi.g SAFs for each repository is that local conditions such as repository location relative to rivers, oceans, agriculture, and populations at the time of assessment can be defined more precisely. The disadrantag 3 is the potential for nonuniformity in the selection of SAFs and the potential for an unreasonable number of SAFs.

Either option should produce nore acclirate predictjons of actual risk than generic analyses with no site adjustments. The ragnitude of the net adjustinent would depend on site characteristics and may be insignificant for some repositories. Generic SAFs for two of the most obvious cases are suggested for the river-and well-release modes in their respective sections. The alternative to SAFs for repositories that carnot be a dequate? $\mathrm{v}$ assessed with generic release limits is the use of collective-dose limits, which do not require adjustments but require additional site characterization and PA.

\subsubsection{RIVER-RELEASE MODE}

Except for possible updating of the release limits for the river mode with more recent data and removing ocean releases, which would be a separate release mode, this derivation is complete. The world-average radionuclide concentration in river waters was an independent variable in the risk-factor equations for all pathways [19]. It was evaluated by dividing the reference release of each nuclide ( 1 curie) by the total volumetric flow rate of all rivers ( $3 \times 10^{4} \mathrm{~km}^{3} / \mathrm{yr}$ was used in the EPA derivation). For the assumption that there is a uniform concentration of radionuclides in all fresh surface water, this is a slightly conservative value. Except for freshwater fish consumption, which would be totally in the river mode, the risk factors for the river pathway would be weighted by the water-source fractions in Table 3 . 
The following is an example of one of the generic SAFs that could be applied to river-mode release limits. The derivation of the risk factors for the river-release mode, using world-average parameters, assumes that the entire drainage system of all rivers is contaminated with the released radionuclides regardless of the repository location [17]. Figure 7 shows that, in reality, only the downstream section of the tributary that is fed by groundwater passing the repository is contaminated. Assuming that use is proportional to availability, the same as in the release-limit derivations, the ratio of the actual available contaminated water to the total available water in the drainage system can be approximated by dividing the sum of the products of contaminated tributary lengths and flow rates by equivalent sums of all tributaries:
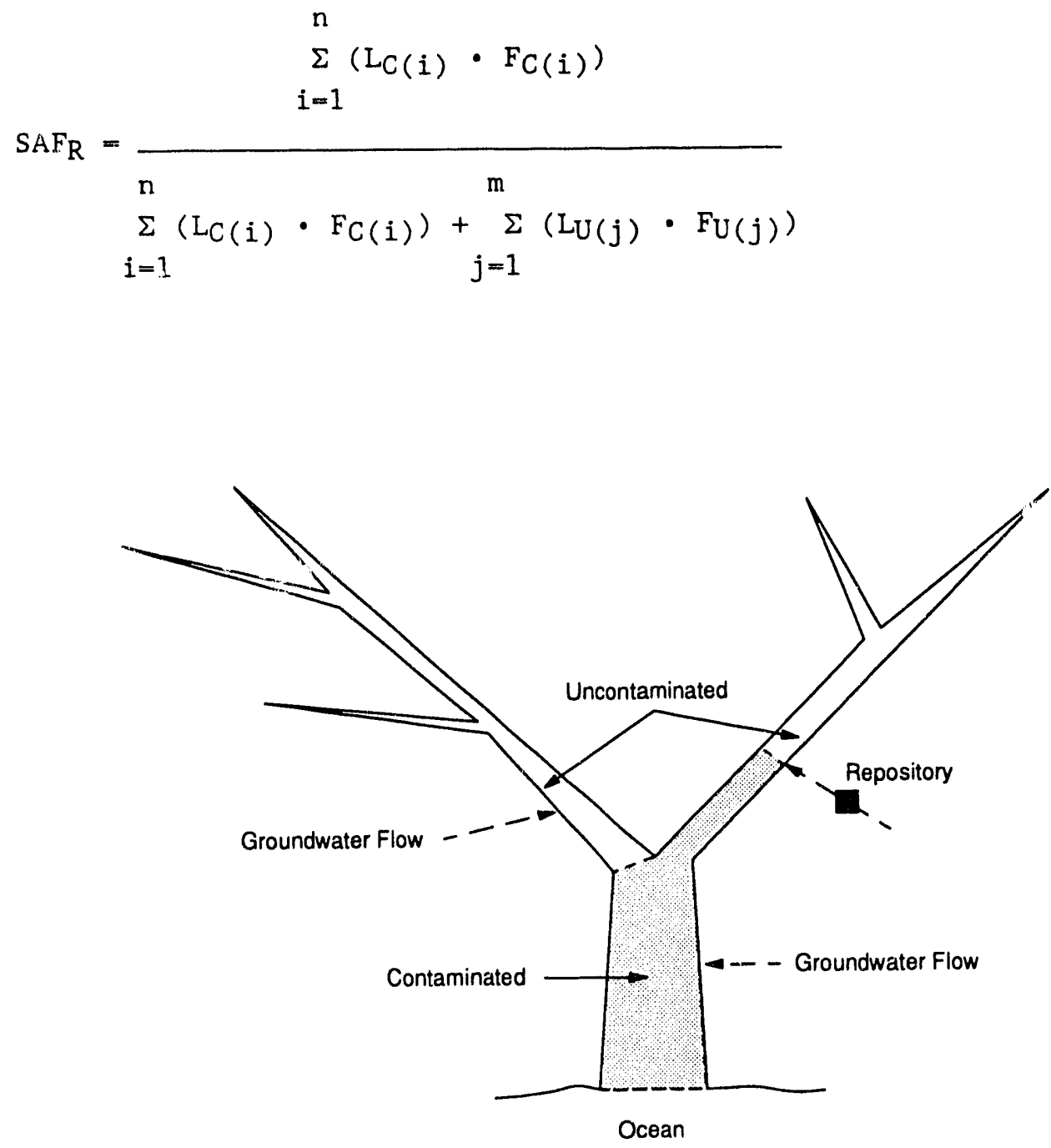

TRII-6342-2.0

Figure 7. Generic river basin for the river-release mode. 
$\mathrm{SAF}_{\mathrm{R}}$ is the site adjustment factor used to correct the risk factors for the river - release mode, $L$ is the length of the river segments, and $F$ is the volumetric flow rate of that segment. The subscripts $C$ and $U$ refer to contaminated and uncontaminated segments, respectively. If the correction is applied directly to the release limits rather than to the risk factors, the reciprocal of the $S_{A F_{R}}$ is used. This definition of water availability would be compatible with the present derivation.

AFs for nuclide transport in aquifers depend on flow rates, diffusion, dispersion, retardation, decay rates of the nuclides, the duration of regulation, and the performance of all preceding repository components [2]. Some examples of geologic risk attenuation between a repository and a river are given later in this section. The AFs for the river-release mode would be an extension of the present assessments inside the $\mathrm{CV}$.

\subsubsection{WELL-RELEASE MODE}

Pathways in the biosphere for the well-release mode would be the same as those for the river mode except for fish consumption. The radionuclide concentrations in groundwater used to compute risk factors for the well mode must be based on world averages, the same as the river mode, if the standards are to be consistent. The risk factors for well releases would be weighted by the water-source fraction in Table 3 .

The development of the well-release limits is parallel to that of the current river-release limits. Both are based on world populations and flow rates. Neither depend on the actual size of the aquifer or river basin or the water velocities because of the linear hypotheses and the use of collective population doses in the criteria. In base-case PAs, the rivers are assumed to be at their present location, and the groundwater plume is computed based on present hydrology. Withdrawal wells can distort the contaminated groundwater plume by drawing uncontaminated waters into the plume, as illustrated by Well 1 in Figure 8 , or by enlarging the plume (Well 2). Over the 10,000-year regulation period, these effects should tend to cancel. The river-and well-release limits share the same simplifications and assumptions, and have the same deficiencies and attributes.

The present derivation of the river risk factors used a volumetric flow rate of $3 \times 10^{4} \mathrm{~km}^{3} / \mathrm{yr}$. The flow rates for groundwater are a factor of 2.5 lower (Table 2), which means the radionuclide concentrations in groundwater are a factor of 2.5 higher. Because the risk factors in the EPA derivations [19] are linear functions of concentration, the risk factors for the two 


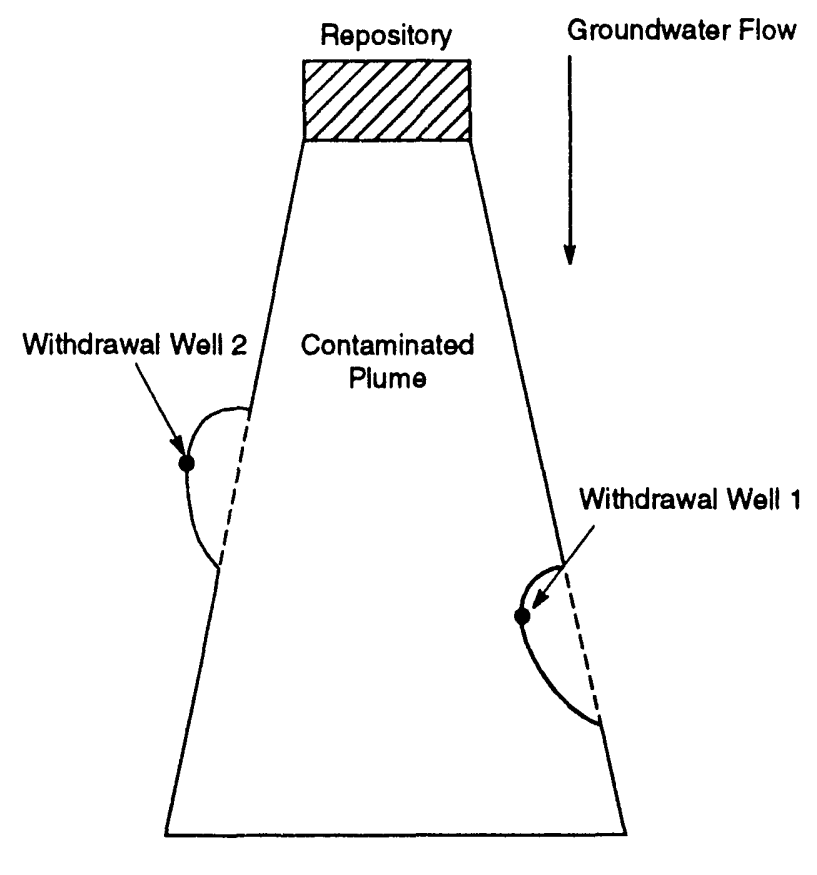

TRI-6342-1876-0

Figure 8. Deformation of a contaminated groundwater plume caused by withdrawal wells.

modes would scale with concentration. The ratio of release limits for the well-release mode to those for the river mode would range from 0.400 for $\mathrm{Zr}$ 93 to 0.803 for Cs -137 . This variation is caused by fish consumption in the river mode.

This derivation of the limits for the well-release mode using worldaverage parameters assumes all groundwater from the recharge area to the locations where it enters surface waters is contaminated. This is similar to the river derivation problem. Figure 9 shows that, in reality, wells upgradient of the repository do not produce contaminated water. In addition, during the 10,000-year regulation period, the contaminated plume may not reach the discharge location, and some uncontaminated water also would be withdrawn downgradient from the repository. With the assumption that groundwater withdrawal is proportional to its residence time in each region, the ratio of contaminated to total available water can be approximated by dating the water at the repository $\left(A_{1}\right)$, at the point that the radionuclides are expected to reach in 10,000 years $\left(A_{2}\right)$, and at the location where groundwater is discharged to a river $\left(\mathrm{A}_{3}\right)$, as shown in Figure 9. A generic site adjustment factor $\left(\mathrm{SAF}_{\mathrm{W}}\right)$ can then be approximated by dividing the difference in the ages of the water at the farthest point of projected 


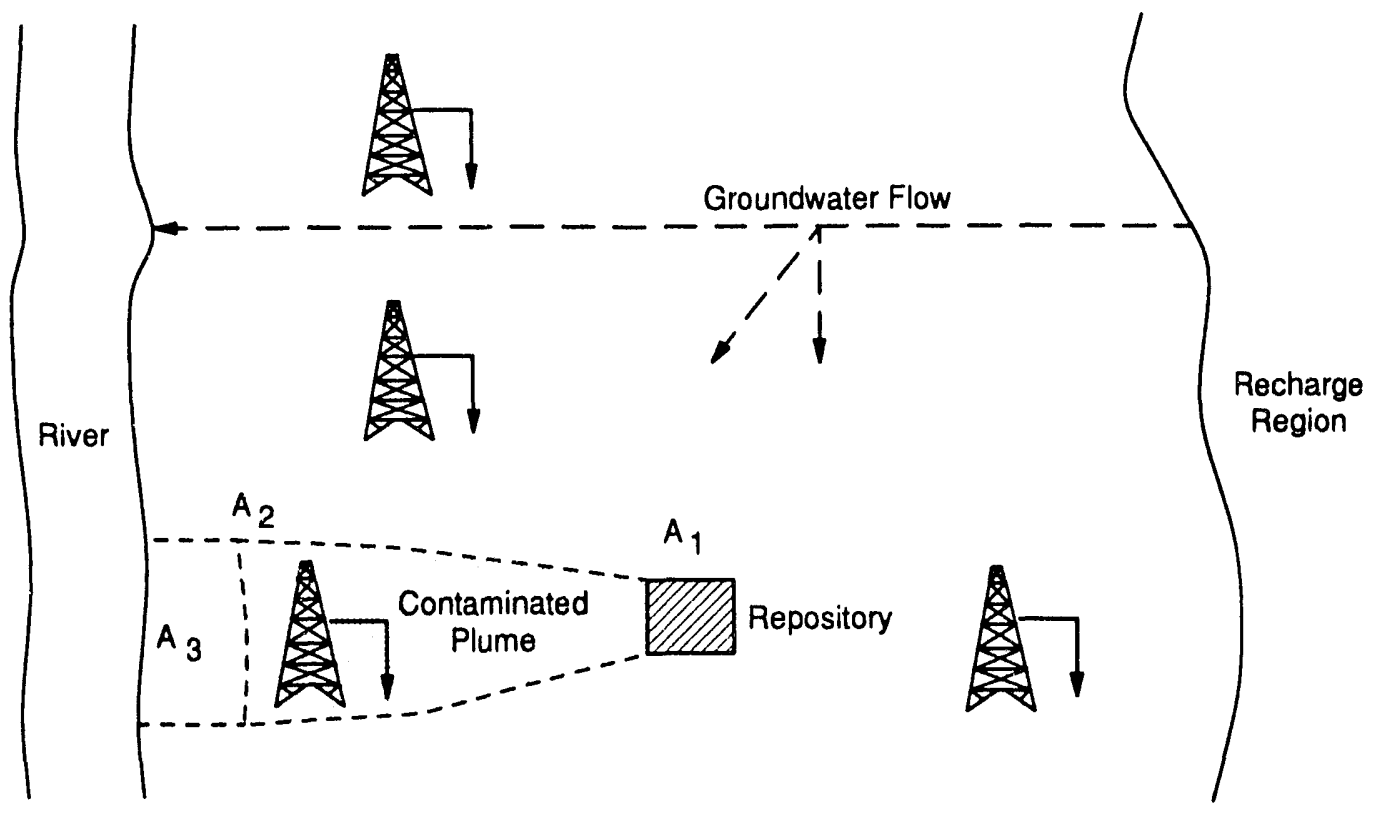

TR||-6342-3.0

Figure 9. Generic groundwater diagram for the well-release mode.

radionuclide migration in 10,000 years $\left(A_{2}\right)$ and at the repository ( $A_{1}$ ) by the age of the water at the point of discharge to the river $\left(A_{3}\right)$ :

$$
\mathrm{SAF}_{\mathrm{W}}=\frac{\mathrm{A}_{2}-\mathrm{A}_{1}}{\mathrm{~A}_{3}}
$$

However, if the contaminated plume is projected to reach a river within 10,000 years, the $\mathrm{SAF}_{\mathrm{W}}$ can be approximated by the following formula:

$$
\mathrm{SAF}_{\mathrm{W}}=\frac{\mathrm{A}_{3}-\mathrm{A}_{1}}{\mathrm{~A}_{3}}
$$

The risk factors could be corrected by these ratios. If the correction is applied directly to the release limits rather than to the risk factors, the reciprocal of the $\mathrm{SAF}_{\mathrm{W}}$ is used. 
Computations of attenuation factors would be similar to those for the river-release mode. Over a 10,000-year period, withdrawal wells could be located anywhere in the contaminated plume. Therefore, assuming uniform withdrawal in the plume for the entire time is reasonable. This is in contrast to the single fixed distance for the river-release mode.

\subsubsection{OCEAN-RELEASE MODE}

Ocean risk factors in References 17 and 19 were compared with those computed with the MARINRAD [32] computer program and deep ocean and shelf models for the Subseabed Disposal Project $[22,23]$. The comparison showed that the ocean risk factors used to derive the present release limits were up to a factor of 100 too low [4]. This difference was confirmed by a preliminary study of ocean risk factors that are defined in a letter from R.D. Klett (Sandia National Laboratories [SNL]) to D. Ensminger (The Analytical Sciences Corporation [TASC]), "Ocean Model for Release Limit Derivation," dated October 22, 1991. The preliminary study was conducted by TASC, and the results were given in a letter from $S$. Oston (TASC) to $R$. Williams (EPRI), "Ocean Pathway Modeling," dated December 10, 1991. A thorough study of the ocean mode should be conducted with a program such as MARINRAD and more detailed coupled shelf and deep-ocean models.

No correction factors for repository location are required for the ocean mode. With the conservative assumptions of no risk attenuation in the rivers and the return of all irrigation water to the rivers, the same geologic AFs could be used for the river- and ocean-release modes for each repository.

\subsubsection{LAND-RELEASE MODE}

Changing the method of computing risk factors for the land mode is not necessary, but the risk factors could be updated using the latest data. No corrections for repository location and no computations of risk attenuation are required for the land-release mode.

\subsubsection{ATMOSPHERIC-RELEASE MODE}

The method of computing C-14 risk factors for release to the atmosphere is consistent with the other derivations in Reference 19. Updating the analysis with a later version of the global-circulation model would only increase the release limit by a factor of 1.4. For completeness, a value for I-129 [33] has been added. No corrections for repository location and no additional computations of attenuation are required for atmospheric releases. 
One alternative to the present atmospheric collective release limit would be to base the release limit on the Clean Air Act [34] and the corresponding regulations promulgated by the EPA [35]. However, 40 CFR 61, Subpart 1 states that it does not apply to facilities regulated by $40 \mathrm{CFR}$ 191, Subpart B. Alternative approaches might be to develop an entirely different method for determining cumulative atmospheric releases, or to remove atmospheric releases from the table for multimode release limits and consider atmospheric releases separately. Removal of one of the releaselimit columns would make it necessary to modify the containment requirements for collective releases. The present containment requirements were set to regulate an entire disposal system, containing all radionuclides, including all pathways, release modes, events, and scenarios. These same requirements cannot be used if a potentially significant release mechanism or radionuclide is removed from the collective-release complementary cumulative distribution function (CCDF).

\subsubsection{RISK FACTORS}

This section presents tables of risk factors, the premature fatal cancers for each curie of the various radionuclides that may be released to the accessible environment for each release mode. These risk factors are used to develop the radionuclide-release limits in Table 1 of 40 CFR Part 191. Risk factors in cancers per curie are shown in Table 4a, and the risk factors in cancers per $\mathrm{TBq}$ are shown in Table 4b. Source weighting factors for the well- and river-release modes have not been applied to the values in Tables $4 \mathrm{a}$ and $4 \mathrm{~b}$. These values would only apply if 1008 of fresh water came from either wells or from surface water.

\subsubsection{DEVELOPMENT OF RELEASE LIMITS FOR 40 CFR PART 191}

The analyses described in this chapter could be used to develop radionuclide-release limits that correspond to the level of protection chosen for the containment requirements of 40 CFR Part 191 (Section 191.13). These computations would result in a maximum of five columns in a release-limit table. The 1985 BID [17] describes the procedure used to determine release limits from the risk factors and the fundamental criterion. The maximum number of fatalities allowed by the fundamental criterion (1000 fatal cancers per 100,000 MTHM) were divided by the fatal cancers per curie for each release mode and each radionuclide. The release limits in curies are shown in Table 5a, and the release limits in $\mathrm{TBq}$ are shown in Table 5b. Note that the reference repository size of 100,000 MTHM is used as the basis for the limit values. Source weighting factors have not been applied to the welland river-release limits. 
Table 4a. Fatal Cancers per Curie Released to the Biosphere for Multiple Release Modes

\begin{tabular}{|c|c|c|c|c|c|}
\hline \multirow[b]{2}{*}{ Nuclide } & \multicolumn{5}{|c|}{ Cancers per curie } \\
\hline & Rivera & We11b & Oceanc & Land ${ }^{a}$ & Atmosphere \\
\hline$C-14$ & NA & NA & NA & NA & $5.83 \mathrm{E}-02^{\mathrm{a}}$ \\
\hline $\mathrm{Ni}-59$ & $4.61 E-05$ & $1.12 \mathrm{E}-04$ & & $6.79 E-07$ & NA \\
\hline Sr -90 & $2.25 \mathrm{E}-02$ & $5.60 \mathrm{E}-02$ & $2.45 \mathrm{E}-05$ & $3.76 \mathrm{E}-05$ & NA \\
\hline $\mathrm{Zr}-93$ & $1.51 \mathrm{E}-04$ & $3.77 E-04$ & $3.94 \mathrm{E}-05$ & $2.26 \mathrm{E}-05$ & NA \\
\hline Tc-99 & $3.65 E-04$ & $8.93 E-04$ & $1.59 E-06$ & $5.65 E-08$ & NA \\
\hline$S n-126$ & $1.05 \mathrm{E}-01$ & $2.57 \mathrm{E}-01$ & $1.07 \mathrm{E}-01$ & $1.38 \mathrm{E}-03$ & NA \\
\hline$I-129$ & $8.07 E-02$ & $2.01 \mathrm{E}-01$ & $2.71 E-04$ & $3.96 \mathrm{E}-03$ & $2.49 E-01 d$ \\
\hline Cs -135 & $7.73 E-03$ & $1.74 \mathrm{E}-02$ & $6.39 \mathrm{E}-05$ & $5.75 \mathrm{E}-04$ & NA \\
\hline Cs -137 & $1.07 \mathrm{E}-02$ & 1. $33 E-02$ & $4.92 E-04$ & $2.19 E-05$ & NA \\
\hline $\mathrm{Sm}-151$ & $9.38 \mathrm{E}-06$ & $2.27 E-05$ & & $6.71 \mathrm{E}-08$ & NA \\
\hline $\mathrm{Pb}-210$ & $1.18 \mathrm{E}-01$ & $2.61 \mathrm{E}-01$ & & $1.52 \mathrm{E}-04$ & NA \\
\hline $\mathrm{Ra}-226$ & $1.63 \mathrm{E}-01$ & $3.87 \mathrm{E}-01$ & & $5.62 \mathrm{E}-03$ & NA \\
\hline $\mathrm{Ra}-228$ & $2.41 \mathrm{E}-02$ & $5.62 E-02$ & & $1.57 \mathrm{E}-05$ & NA \\
\hline$A c-227$ & $6.67 \mathrm{E}-02$ & $1.61 \mathrm{E}-01$ & $1.53 \mathrm{E}-01$ & $1.24 \mathrm{E}-04$ & NA \\
\hline Th -229 & $3.49 E-02$ & $8.51 \mathrm{E}-02$ & $1.72 \mathrm{E}-01$ & $1.90 \mathrm{E}-02$ & NA \\
\hline Th -230 & $5.38 E-01$ & 1. $33 E+00$ & & $3.86 \mathrm{E}-01$ & NA \\
\hline Th -232 & $3.40 \mathrm{E}-01$ & $8.47 E-01$ & & $3.76 \mathrm{E}-01$ & NA \\
\hline $\mathrm{Pa}-231$ & $1.48 \mathrm{E}-01$ & $3.66 \mathrm{E}-01$ & $5.94 E-02$ & $2.36 \mathrm{E}-02$ & NA \\
\hline U-233 & $2.15 \mathrm{E}-02$ & $5.33 E-02$ & $9.25 \mathrm{E}-04$ & $7.51 \mathrm{E}-04$ & NA \\
\hline$U-234$ & $1.96 \mathrm{E}-02$ & $4.86 \mathrm{E}-02$ & & $6.54 \mathrm{E}-04$ & NA \\
\hline$U-235$ & $2.17 E-02$ & $5.38 \mathrm{E}-02$ & $8.36 E-04$ & $8.42 \mathrm{E}-04$ & NA \\
\hline$U-236$ & $1.85 E-02$ & $4.59 \mathrm{E}-02$ & & $6.18 \mathrm{E}-04$ & NA \\
\hline$U-238$ & $2.06 \mathrm{E}-02$ & $5.11 \mathrm{E}-02$ & & $6.90 E-04$ & NA \\
\hline$N p-237$ & $7.95 \mathrm{E}-02$ & 1. $21 \mathrm{E}-01$ & $1.44 \mathrm{E}-02$ & $1.21 \mathrm{E}-04$ & NA \\
\hline $\mathrm{Pu}-238$ & $4.23 E-02$ & $1.05 \mathrm{E}-01$ & & $3.10 \mathrm{E}-04$ & NA \\
\hline$P u-239$ & $4.97 E-02$ & 1.23E-01 & $5.73 E-02$ & $6.23 \mathrm{E}-03$ & NA \\
\hline $\mathrm{Pu}-240$ & $4.84 E-02$ & 1. $20 \mathrm{E}-01$ & $5.73 E-02$ & $5.22 E-03$ & NA \\
\hline $\mathrm{Pu}-241$ & $2.17 E-03$ & $5.36 \mathrm{E}-03$ & & $2.50 E-06$ & NA \\
\hline $\mathrm{Pu}-242$ & $4.79 E-02$ & $1.18 \mathrm{E}-01$ & & $6.34 \mathrm{E}-03$ & NA \\
\hline Am - 241 & $5.42 E-02$ & 1. $22 \mathrm{E}-01$ & $2.03 \mathrm{E}-01$ & $1.05 \mathrm{E}-03$ & NA \\
\hline Am - 243 & $5.72 \mathrm{E}-02$ & $1.29 E-01$ & $1.99 \mathrm{E}-01$ & $2.45 \mathrm{E}-03$ & NA \\
\hline $\mathrm{Cm}-245$ & $1.10 \mathrm{E}-01$ & $2.44 E-01$ & $2.99 E-01$ & $8.08 \mathrm{E}-03$ & NA \\
\hline $\mathrm{Cm}-246$ & $4.99 E-02$ & $1.20 \mathrm{E}-01$ & & $3.54 \mathrm{E}-03$ & NA \\
\hline \multicolumn{6}{|c|}{ Sources: } \\
\hline \multicolumn{6}{|c|}{ a Reference 17} \\
\hline \multicolumn{6}{|c|}{ b This report } \\
\hline \multirow{2}{*}{\multicolumn{6}{|c|}{ c Preliminary incomplete analysis by TASC using MARINRAD }} \\
\hline & nce 33 us & & per Sv & & \\
\hline
\end{tabular}


Table 4b. Fatal Cancers per TBq Released to the Biosphere for Multiple Release Modes

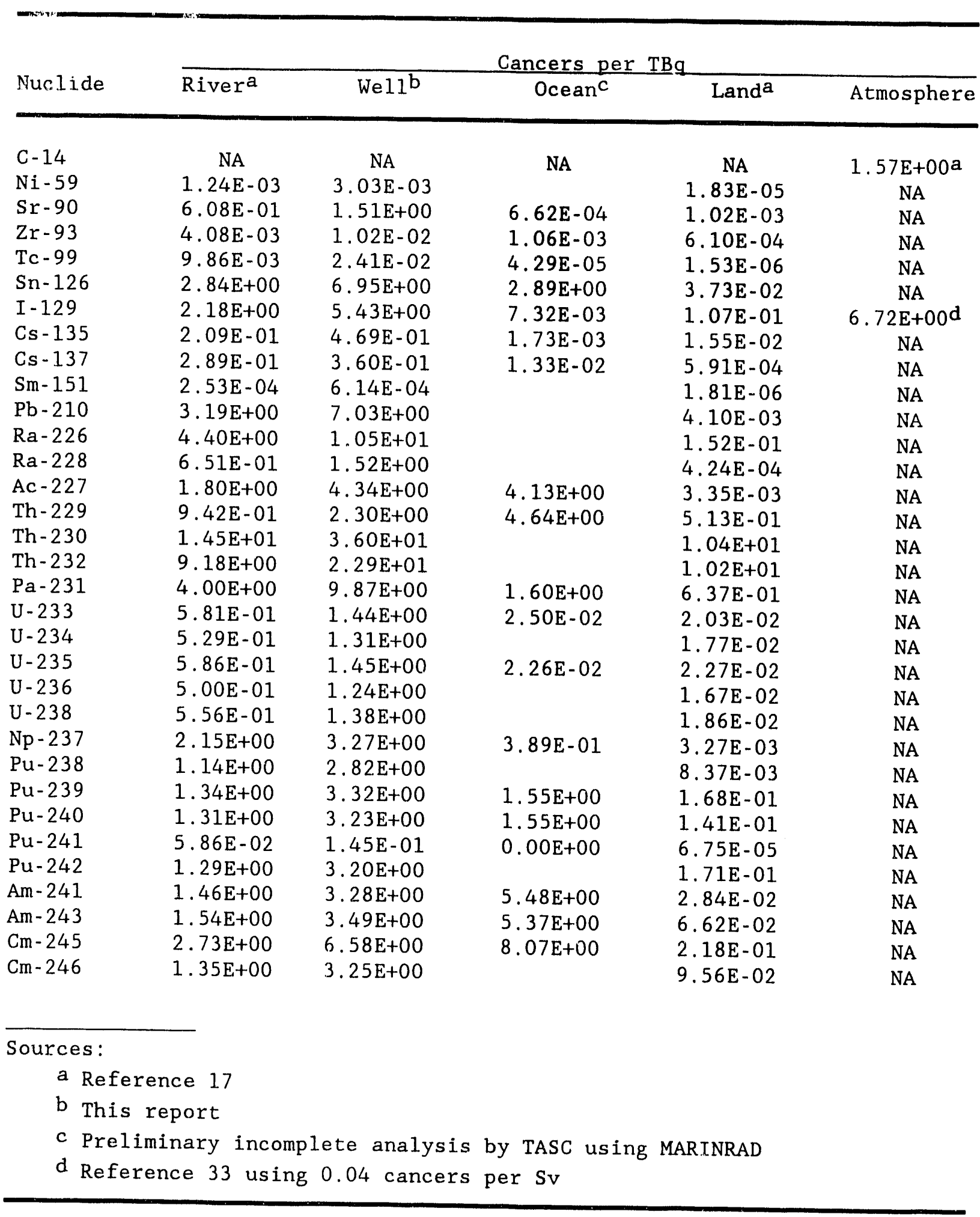


Table 5a. Cumulative Release Limits for 10,000 Years (curies per 100,000 MTHM) for Multiple Release Modes

\begin{tabular}{|c|c|c|c|c|c|}
\hline \multirow[b]{2}{*}{ Nuclide } & \multicolumn{5}{|c|}{ Release Limit (curies per 100,000 MTHM) } \\
\hline & Rivera & We $11^{b}$ & Oceanc & Land $^{a}$ & Atmosphere \\
\hline C- 14 & NA & NA & NA & NA & $2 \mathrm{E}+04 \mathrm{a}$ \\
\hline $\mathrm{Ni}-59$ & $2 E+07$ & $9 E+06$ & & $1 E+09$ & NA \\
\hline Sr -90 & $4 E+04$ & $2 E+04$ & $4 E+07$ & $3 E+07$ & NA \\
\hline Zr-93 & $7 \mathrm{E}+06$ & $3 \mathrm{E}+06$ & $3 \mathrm{E}+07$ & $4 \mathrm{E}+07$ & NA \\
\hline Tc-99 & $3 \mathrm{E}+06$ & $1 \mathrm{E}+06$ & $6 \mathrm{E}+08$ & $2 \mathrm{E}+10$ & $\mathrm{NA}$ \\
\hline Sn-126 & $1 \mathrm{E}+04$ & $4 \mathrm{E}+03$ & $9 E+03$ & $7 \mathrm{E}+05$ & NA \\
\hline I - 129 & $1 E+04$ & $5 E+03$ & $4 E+06$ & $3 E+05$ & $4 E+03 d$ \\
\hline $\mathrm{Cs}-135$ & $1 E+05$ & $6 E+04$ & $2 E+07$ & $2 E+06$ & NA \\
\hline Cs -137 & $9 \mathrm{E}+04$ & $8 \mathrm{E}+04$ & $2 \mathrm{E}+06$ & $5 E+07$ & NA \\
\hline $\mathrm{Sm}-151$ & $1 E+08$ & $4 E+07$ & & $1 E+10$ & NA \\
\hline $\mathrm{Pb}-210$ & $8 \mathrm{E}+03$ & $4 E+03$ & & $7 \mathrm{E}+06$ & NA \\
\hline $\mathrm{Ra}-226$ & $6 \mathrm{E}+03$ & $3 E+03$ & & $2 E+05$ & $\mathrm{NA}$ \\
\hline $\mathrm{Ra}-228$ & $4 E+04$ & $2 E+04$ & & $6 \mathrm{E}+07$ & NA \\
\hline Ac -227 & $1 E+04$ & $6 E+03$ & $7 \mathrm{E}+03$ & $8 \mathrm{E}+06$ & $\mathrm{NA}$ \\
\hline Th -229 & $3 E+C 4$ & $1 E+04$ & $6 E+03$ & $5 E+04$ & NA \\
\hline$T h-230$ & $2 E+03$ & $8 \mathrm{E}+02$ & & $3 E+03$ & NA \\
\hline Th- 232 & $3 E+03$ & $1 E+03$ & & $3 E+03$ & $\mathrm{NA}$ \\
\hline $\mathrm{Pa}-231$ & $7 \mathrm{E}+03$ & $3 E+03$ & $2 \mathrm{E}+04$ & $4 E+04$ & NA \\
\hline U-233 & $5 E+04$ & $2 \mathrm{E}+04$ & $1 \mathrm{E}+06$ & $1 E+06$ & NA \\
\hline$U-234$ & $5 E+04$ & $2 E+04$ & & $2 E+06$ & NA \\
\hline U-235 & $5 E+04$ & $2 E+04$ & $1 E+06$ & $1 E+06$ & NA \\
\hline$U-236$ & $5 \mathrm{E}+04$ & $2 \mathrm{E}+04$ & & $2 E+06$ & NA \\
\hline$U-238$ & $5 E+04$ & $2 E+04$ & & $1 E+06$ & $\mathrm{NA}$ \\
\hline$N p-237$ & $1 E+04$ & $8 E+03$ & $7 E+04$ & $8 \mathrm{E}+06$ & $\mathrm{NA}$ \\
\hline $\mathrm{Pu}-238$ & $2 E+04$ & $1 E+04$ & & $3 E+06$ & $\mathrm{NA}$ \\
\hline $\mathrm{Pu}-239$ & $2 E+04$ & $8 E+03$ & $2 E+04$ & $2 E+05$ & NA \\
\hline $\mathrm{Pu}-240$ & $2 E+04$ & $8 E+03$ & $2 E+04$ & $2 E+05$ & NA \\
\hline $\mathrm{Pu}-241$ & $5 E+05$ & $2 E+05$ & & $4 E+08$ & $\mathrm{NA}$ \\
\hline $\mathrm{Pu}-242$ & $2 E+04$ & $8 E+03$ & & $2 E+05$ & $\mathrm{NA}$ \\
\hline Am - 241 & $2 E+04$ & $8 E+03$ & $5 E+03$ & $1 E+06$ & $\mathrm{NA}$ \\
\hline$A m-243$ & $2 E+04$ & $8 \mathrm{E}+03$ & $5 E+03$ & $4 E+05$ & $\mathrm{NA}$ \\
\hline $\mathrm{Cm}-245$ & $1 E+04$ & $4 E+03$ & $3 E+03$ & $1 E+05$ & NA \\
\hline $\mathrm{Cm}-246$ & $2 E+04$ & $8 \mathrm{E}+03$ & & $3 E+05$ & NA \\
\hline \\
\hline \multicolumn{6}{|c|}{ a Reference 17} \\
\hline \multicolumn{6}{|c|}{ b This report } \\
\hline \multicolumn{6}{|c|}{ c Preliminary incomplete analysis by TASC using MARINRAD } \\
\hline$d \operatorname{Re}$ & nce 33 & $.04 \mathrm{can}$ & & & \\
\hline
\end{tabular}


Table 5b. Cumulative Release Limits for 10,000 Years (TBq per 100,000 MTHM) for Multiple Release Modes

\begin{tabular}{|c|c|c|c|c|c|}
\hline \multirow[b]{2}{*}{ Nuclide } & \multicolumn{5}{|c|}{ Release Limit ( $\mathrm{TBq}$ per 100,000 MTHM) } \\
\hline & Rivera & We1. $\mathrm{b}$ & Oceanc & Land $^{a}$ & Atmosphere \\
\hline C - 14 & NA & NA & NA & NA & $6 \mathrm{E}+02^{\mathrm{a}}$ \\
\hline $\mathrm{Ni}-59$ & $8 E+05^{a}$ & $3 E+05$ & & $5 \mathrm{E}+07$ & NA \\
\hline Sr -90 & $2 \mathrm{E}+03$ & $7 \mathrm{E}+02$ & $2 \mathrm{E}+06$ & $1 \mathrm{E}+06$ & NA \\
\hline Zr -93 & $2 \mathrm{E}+05$ & $1 \mathrm{E}+05$ & $9 E+05$ & $2 E+06$ & NA \\
\hline Tc- 99 & $1 \mathrm{E}+05$ & $4 \mathrm{E}+04$ & $2 \mathrm{E}+07$ & $7 E+08$ & NA \\
\hline Sn-126 & $4 \mathrm{E}+02$ & $1 \mathrm{E}+02$ & $3 E+02$ & $3 E+04$ & NA \\
\hline$I-129$ & $5 \mathrm{E}+02$ & $2 \mathrm{E}+02$ & $1 \mathrm{E}+05$ & $9 E+03$ & $1 \mathrm{E}+02^{\mathrm{d}}$ \\
\hline $\mathrm{Cs}-135$ & $5 E+03$ & $2 E+03$ & $6 E+05$ & $6 E+04$ & NA \\
\hline Cs -137 & $3 E+03$ & $3 E+03$ & $8 E+04$ & $2 E+06$ & NA \\
\hline Sm-151 & $4 E+06$ & $2 E+06$ & & $6 E+08$ & NA \\
\hline $\mathrm{Pb}-21.0$ & $3 E+02$ & $1 E+02$ & & $2 E+05$ & NA \\
\hline $\mathrm{Ra}-226$ & $2 \mathrm{E}+02$ & $1 \mathrm{E}+02$ & & $7 E+03$ & NA \\
\hline $\mathrm{Ra}-228$ & $2 E+03$ & $7 \mathrm{E}+02$ & & $2 E+06$ & NA \\
\hline$A c-227$ & $6 E+02$ & $2 \mathrm{E}+02$ & $2 \mathrm{E}+02$ & $3 E+05$ & NA \\
\hline Th -229 & $1 E+03$ & $4 E+02$ & $2 \mathrm{E}+02$ & $2 E+03$ & NA \\
\hline$T h-230$ & $7 E+01$ & $3 E+01$ & & $1 \mathrm{E}+02$ & NA \\
\hline Th -232 & $1 E+02$ & $4 E+01$ & & $1 E+02$ & NA \\
\hline $\mathrm{Pa}-231$ & $3 E+02$ & $1 \mathrm{E}+02$ & $6 \mathrm{E}+02$ & $2 E+03$ & NA \\
\hline$U-233$ & $2 \mathrm{E}+03$ & $7 E+02$ & $4 E+04$ & $5 E+04$ & NA \\
\hline U-234 & $2 \mathrm{E}+03$ & $8 E+02$ & & $6 E+04$ & NA \\
\hline U-235 & $2 \mathrm{E}+03$ & $7 E+02$ & $4 E+04$ & $4 E+04$ & NA \\
\hline U-236 & $2 E+03$ & $8 \mathrm{E}+02$ & & $6 E+04$ & NA \\
\hline$U-238$ & $2 E+03$ & $7 \mathrm{E}+02$ & & $5 E+04$ & NA \\
\hline $\mathrm{Np}-237$ & $5 \mathrm{E}+02$ & $3 \mathrm{E}+02$ & $3 E+03$ & $3 E+05$ & NA \\
\hline $\mathrm{Pu}-238$ & $9 \mathrm{E}+02$ & $4 E+02$ & & $1 \mathrm{E}+05$ & NA \\
\hline$P u-239$ & $7 \mathrm{E}+02$ & $3 E+02$ & $6 E+02$ & $6 \mathrm{E}+03$ & NA \\
\hline $\mathrm{Pu}-240$ & $8 \mathrm{E}+02$ & $3 E+02$ & $6 \mathrm{E}+02$ & $7 E+03$ & NA \\
\hline $\mathrm{Pu}-241$ & $2 E+04$ & $7 E+03$ & & $1 E+07$ & NA \\
\hline $\mathrm{Pu}-242$ & $8 \mathrm{E}+02$ & $3 E+02$ & & $6 E+03$ & $\mathrm{NA}$ \\
\hline Am-241 & $7 E+02$ & $3 E+02$ & $2 E+02$ & $4 E+04$ & $\mathrm{NA}$ \\
\hline $\mathrm{Am}-243$ & $6 E+02$ & $3 E+02$ & $2 E+02$ & $2 E+04$ & NA \\
\hline $\mathrm{Cm}-245$ & $4 E+02$ & $2 \mathrm{E}+02$ & $1 \mathrm{E}+02$ & $5 E+03$ & $\mathrm{NA}$ \\
\hline $\mathrm{Cm}-246$ & $7 \mathrm{E}+02$ & $3 E+02$ & & $1 E+04$ & $\mathrm{NA}$ \\
\hline \\
\hline \multicolumn{6}{|c|}{ a Reference 17} \\
\hline \multicolumn{6}{|c|}{ b This report } \\
\hline \multicolumn{6}{|c|}{ c Preliminary incomplete analysis by TASC using MARINRAD } \\
\hline $\mathrm{d} \operatorname{Re}$ & nce $33 \mathrm{u}$ & & & & \\
\hline
\end{tabular}




\subsubsection{SUMMED NORMALIZED RELEASES}

The values in the five-column table for multimode release limits are based on the total release coming from one radionuclide and one release mode. When all release modes and all radionuclides are considered, the summed normalized release limit for each scenario or event would include the release fractions for each nuclide for each release mode:

$$
\begin{aligned}
& \mathrm{Q}_{\mathrm{A}, \mathrm{a}} / \mathrm{RL}_{\mathrm{A}, \mathrm{a}}+\mathrm{Q}_{\mathrm{A}, \mathrm{b}} / \mathrm{RL}_{\mathrm{A}, \mathrm{b}}+\ldots .+\mathrm{Q}_{\mathrm{L}, \mathrm{a}} / \mathrm{RL}_{\mathrm{L}, \mathrm{a}}+\mathrm{Q}_{\mathrm{L}, \mathrm{b}} / \mathrm{RL}_{\mathrm{L}, \mathrm{b}}+\ldots .+
\end{aligned}
$$

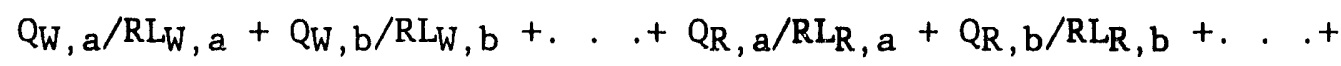

$$
\begin{aligned}
& \mathrm{Q}_{0, \mathrm{a}} / \mathrm{RL}_{\mathrm{O}, \mathrm{a}}+\mathrm{Q}_{0, \mathrm{~b}} / \mathrm{RL}_{\mathrm{O}, \mathrm{b}}+\ldots .+\mathrm{Q}_{0, \mathrm{n}} / \mathrm{RL}_{\mathrm{O}, \mathrm{n}}<1 .
\end{aligned}
$$

$Q$ is the computed 10,000-year release of a radionuclide for each release mode at the release location, and $\mathrm{RL}$ is the release limit for that nuclide and release mode. The subscripts $A, L, W, R$, and 0 refer to the atmospheric-, land-, well-, river-, and ocean-release modes, respectively, and the subscripts $a, b, \ldots . ., n$ refer to the individual radionuclides listed in the tables. This is analogous to the method presently used in 40 CFR 191. The effects of multimode release tables on the release CCDF would be to change the magnitude of the normalized release (R) for each scenario or event relative to the present single-release method, as illustrated in Figure 10.

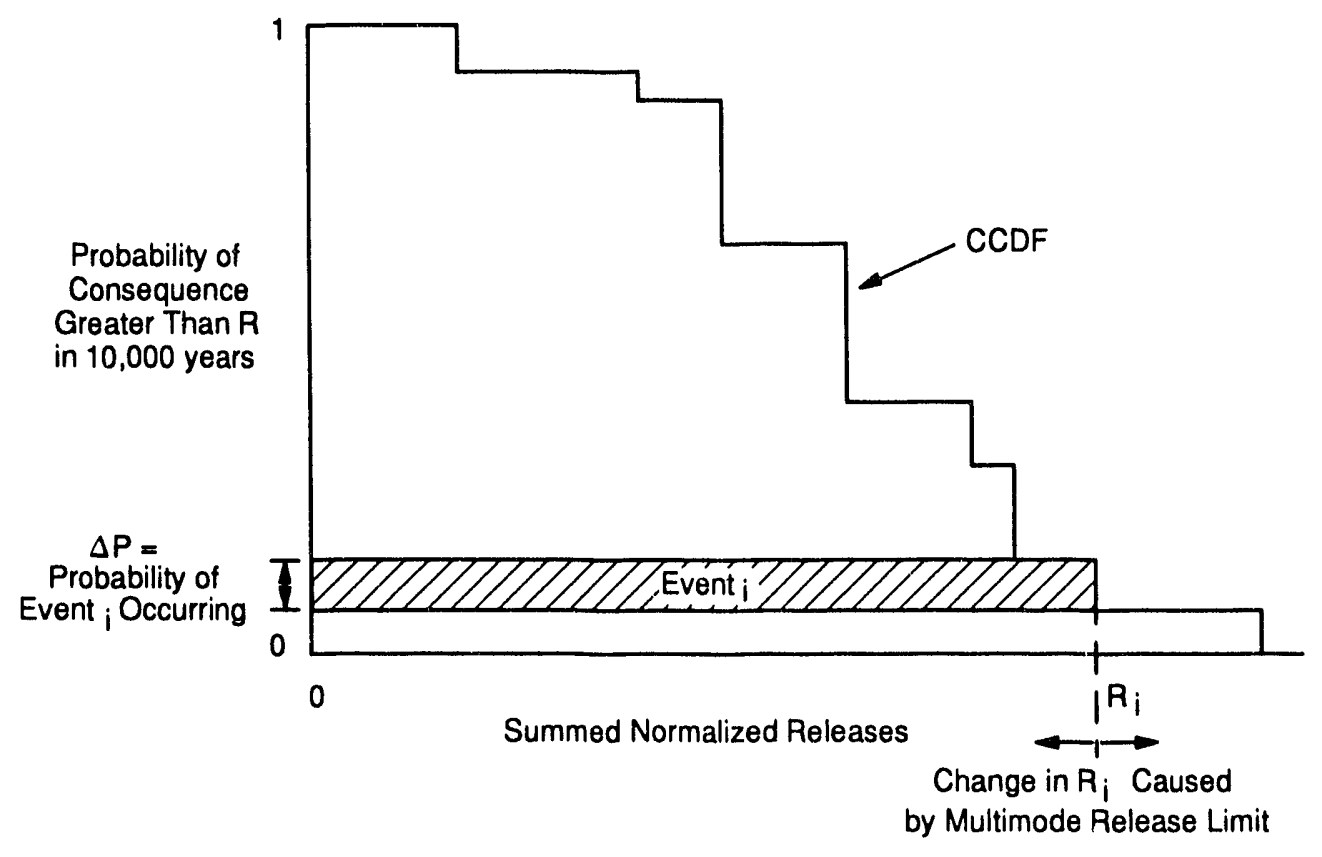

TRII-6342-5-1

Figure 10. Effects of multimode release limits on the release CCDF. 
The probabilities of the individual scenarios or events that make up the CCDF would be unchanged.

\subsubsection{Geologic Risk Attenuation}

A study of parametric geologic AFs was conducted to show the significance of the geologic component that is omitted in the present standards (CV to location of release to the enrironment) and show the sensitivity of AFs to the input parameters. The input parameters were: groundwater velocity, retardation factor, dispersivity, distance from the repository in the direction of groundwater flow, duration of regulation, radionuclide half-life, time of release from the repository, and rate of release. Figures 11 and 12 are examples of the results.

Figure 11 shows the retardation sensitivity when groundwater velocities are similar to those at the WIPP. Instantaneous release is assumed, which is unrealistically conservative even for human intrusion breaching an underlying brine pocket immediately after repository closure. The retardation factors for all the actinides in TRU waste are greater than 10 [36], so the longest travel distance for any nuclide would be about $12 \mathrm{~km}$, indicating that the geologic component of the disposal system that is outside the CV is too important to be omitted from PAs. Figure 12 shows the large effects of the time and rate of release from the repository on the distance traveled by a weakly retarded nuclide in 10,000 years. These important features of repository design cannot be evaluated when the geologic formation outside the $\mathrm{CV}$ is not included in the assessments. The conclusions of this study are: all components of the disposal systems should be included in risk assessments unless it can be shown that their effects are negligible, and the attenuation factors are strongly dependent on too many variables to be included in the standards rather than being part of PA.

\subsubsection{Performance Assessments}

Figure 6 illustrates the function of PAs using multimode release limits. Gaseous releases and some releases from human intrusion would be through the upper surface of the $\mathrm{CV}$, as shown in Figure 1. For these pathways, the PA segment of the risk assessment would be unchanged, but the releases would be evaluated against atmospheric- and land-release limits instead of the present single generic release limits. For nuclide transport through an aquifer, the groundwater that is not withdrawn by wells would eventually reach rivers, 


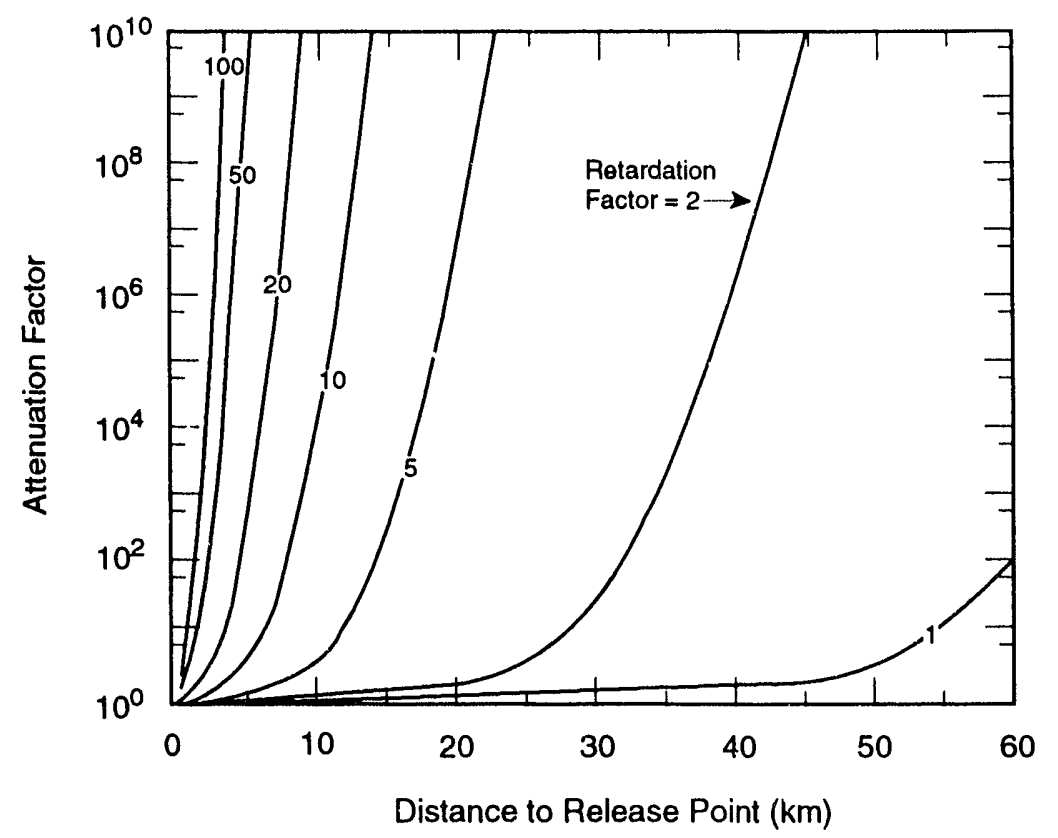

TRI.6342-1841.0

Figure 11. Attenuation-factor sensitivity (Velocity $=5 \mathrm{~m} / \mathrm{yr}$, Half-Life $=$ 10,000 yrs, Dispersivity $=200 \mathrm{~m}$, Instantaneous release at the time of repository closure).

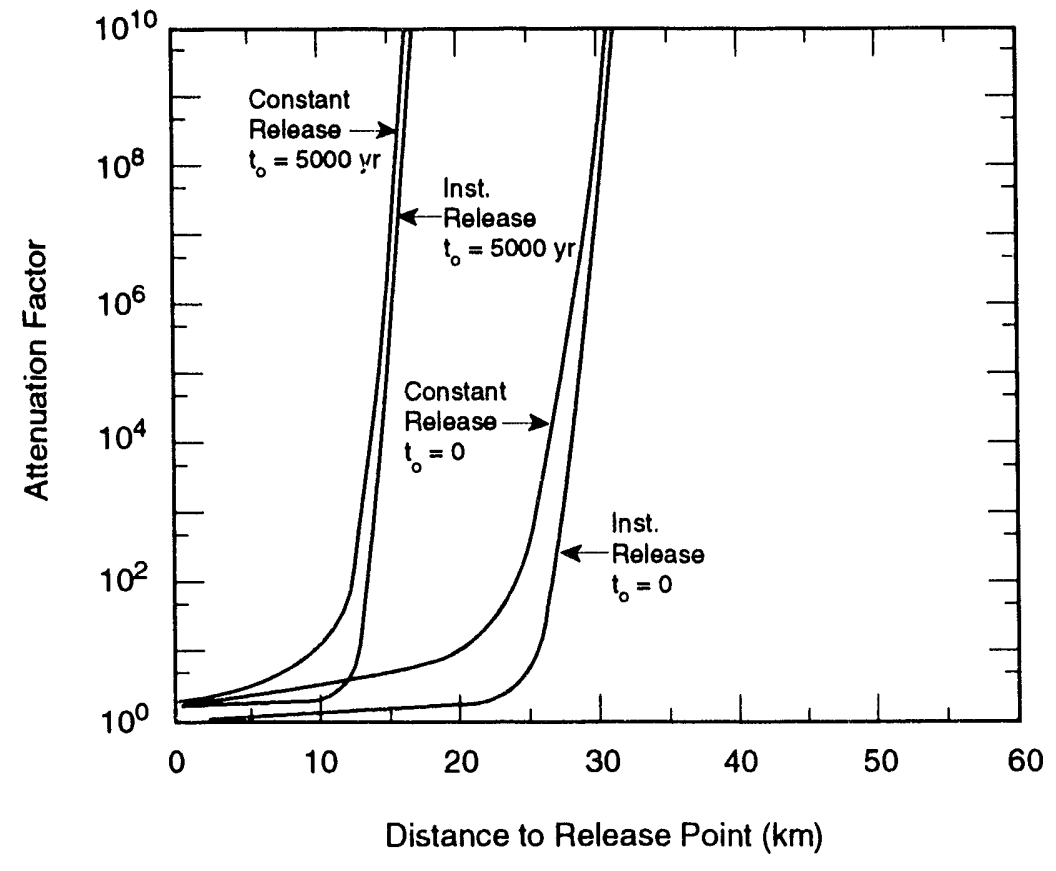

Figure 12. Attenuation-factor sensitivity (Velocity $=5 \mathrm{~m} / \mathrm{yr}$, Half-Life $=$ 10,000 yrs, Dispersivity $=200 \mathrm{~m}$, Retardation Factor $=2$ ) . 
lakes, and oceans. Computations of releases to wells, rivers, and oceans could require additional attenuation-factor analyses [2] by $P A$, and some site characterization past the $\mathrm{CV}$ might be required. Site characterization and analyses would only have to extend far enough to show compliance. The remainder of the disposal system could be considered an additional, but unquantified, margin of safety. If the release limits do not incorporate average fractions of freshwater usage obtained from groundwater and surface water, regional values would be defined and applied by PA. PA also would have to adjust the river- and well-release limits to account for the location of each repository relative to the recharge location and closest river or ocean and apply other SAFs if they are required or allowed by the regulations.

\subsection{Dose Standards as the Primary Criterion and as an Option with Relcase Limits}

The first part of this section discusses the uses of dose standards as an alternative to the present derived release limits. The second part describes the procedures for allowing the applicant or the regulating agency the option of using either dose or release limits, whichever is the most appropriate for the repository being regulated.

\subsubsection{Dose Criteria}

The alternative that has been widely recommended, but would require the greatest change in regulation philosophy, would eliminate the generic derived release limits and replace them with dose limits. These limits can be placed on individual or population doses. An individual-dose standard that limits peak rates to the maximally exposed group at any time has been recommended by the ICRP, the Nuclear Energy Agency (NEA), and the International Atomic Energy Agency (IAEA) $[5,37,38]$ and is being used with some modifications by other countries [9]. Population-dose limits could be on peak rates, or total dose for the period of regulation. Since the fundamental criterion in $40 \mathrm{CFR}$ 191 defines the maximum allowable cancer deaths per unit of waste during the time of regulation, collective dose per MTHM is the only type of dose lim: that would be compatible.

The argument that risk assessments using dose standards require more predictive assumptions and computations, contain more uncertainties, and are less accurate than those using derived standards is unfounded. If the use of approximations and predictions is valid for deriving release limits, they are also valid for dose analyses. The total risk assessment is the same in either case, as illustrated in Figure 3. 
Dose standards are more versatile than derived standards because they apply to all repositories and all pathways. Though derived standards such as generic release limits may poorly represent the actual attenuating process of some repositories, there is a reluctance to modify derived standards because of the complex and time-consuming steps that are required. Another advantage of dose standards is that they allow the risk assessment to be conducted sequentially from the waste source to humans. This is the only way that all attenuation functions of all components in the disposal system can be included in the assessment. The derivation of release-limit standards does not start at the source and therefore cannot include all the retardation and temporal dispersion effects of all preceding components [2].

Dose standards regulate the entire disposal system, whereas lower-level standards regulate components or groups of components. The requirement to have efficient components is not sufficient; components have to work together to produce an effective disposal system. If dose standards are used, standard future states of human populations could be specified in the regulations. This would assure more uniform assessment of all repositories, reduce the complexity of PAs, and maintain more control by the regulating agency. There are many advantages to using dose standards $[4,5,13,21]$, and the change to a higher-level standard would not require additional derivations by the EPA. However, it would require a change in regulatory philosophy, would increase the amount of site characterization, and would require additional $\mathrm{PA}$ analyses.

\subsubsection{Release Limits with a Dose-Standard Alternative}

A recommendation was made during the first EPRI workshop on the technical basis for EPA HLW and TRU-waste disposal criteria (September 24-26, 1991, in Arlington, Virginia) to allow the applicant or regulating agency the option of selecting either cumulative population-dose standards or cumulative normalized release limits to satisfy the containment requirements of $40 \mathrm{CFR}$ 191.12. The advantage of this option is that the conservative but approximate generic release limits could be used for many repositories, resulting in less site characterization and less complex PAs. For other repositories that are not adequately represented by generic release limits, the more precise dose standards could be used.

There are precedents for alternate methods of evaluation in EPA regulations. $40 \mathrm{CFR} 191.17$ permits the use of alternate provisions if the existing provisions of Subpart $B$ appear inappropriate [1]. The use of alternative methods of regulation also appears in 40 CFR 264.94(b), which allows the use of alternative concentrations for chemicals [39] and 40 CFR 
268.6, which allows the use of an alternative to the treatment of hazardous waste $[40]$.

Three changes to $40 \mathrm{CFR} 191$ would be required to make this modification work effectively. First, it is essential to explain why the use of alternate criteria is acceptable. Second, a clear statement is needed that defines the optional dose-standard method, provides guidance on when it should be used, and indicates how it would be implemented. Third, the standard should include the fundamental safety criterion that is the basis for the dose limits, the maximum allowed 10,000-year collective dose, a standard procedure and factors for computing the effective doses, and could include a standard biosphere, demography, and human characteristics that are compatible with the rest of $40 \mathrm{CFR} 191$ and its supporting documentation. Suggestions for these changes are given in the remainder of this section.

\subsubsection{JUSTIFICATION FOR ALTERNATIVE DOSE STANDARDS}

The hierarchy of criteria levels is explained in Section 2.2 of this report. The top-level fundamental criterion is the only level that explicitly defines the safety requirements of the repository. Some analyses are required to develop each criteria level below the fundamental requirement, and each analysis adds uncertainty to the criteria. Derived standards are only used to facilitate regulation and therefore can always be replaced by more precise, higher-level criteria without jeopardizing safety. Here, the more expedient but ultra-conservative derived release limits can be replaced by the higher-level, more exact dose limits. The release limits in Table 1 of 40 CFR 191 were derived from dose limits, and this derivation added considerable uncertainty because of the many predictive assumptions, generalizations, and simplifications. The derivation of the present generic single-mode release limits contains many conservative assumptions, and some important attenuating processes are omitted. The release limits are intended only to provide a simplified method of evaluation and are not a true measure of risk. Complying with the release requirements is sufficient, but not necessary, to demonstrate compliance with the fundamental criterion. Dose limits provide a more accurate measure of actual risk but require more extensive site characterizations and PAs. An unsafe repository could not comply with either dose or release limits, so there would be no advantage in using both standards.

A preliminary performance evaluation may be needed to select the most appropriate standard for a particular repository. Repository evaluations using release limits are less expensive and can be completed in less time because they require less site characterization and less complex PA. However, the conservative approximate release limits may not adequately 
represent the attenuating processes of some repositories, and the more precise dose standards may be required. Using dose limits that represent the fundamental criterion more accurately than the generic release limits does not weaken the standards.

\subsubsection{DESCRIPTION OF THE DOSE-LIMIT ALTERNATIVE}

Since dose limits are a higher-level criterion, all the information used to develop dose limits is also used in the development of release limits. There are also many similarities in the implementation of dose and release limits.

The dose limits would be based on the fundamental criterion of 1000 premature cancer deaths during the 10,000-year regulation period for the reference repositories (100,000 MTHM for HLW and a suggested 20 MCi for TRU waste, as explained in Chapter 7). The premature cancer deaths in the fundamental criterion are converted to allowable effective doses using a conversion factor supplied by the ICRP [6] to produce the dose limits. The EPA could specify procedures for computing the effective doses for a repository by one of the methods suggested in the next section, or the procedure selection could be left to the implementing agency.

Consequences could be normalized for any event or scenario using dose limits, similar to the way they are nornalized using release limits. The normalized dose consequence would be equal to the computed dose divided by the dose limit. PAs with dose-limit standards could produce the same type of normalized CCDF that is presently being produced using release limits. Therefore, the consequence CCDF based on dose and release limits could be regulated by the same containment requirements. The probabilities of events or scenarios in the CCDF would be the same with either limit. Only the values of individual normalized consequences ( $R$ for summed normalized release and $D$ for normalized dose) would be different, as illustrated in Figure 13. The CCDF could be constructed using all normalized releases, all normalized doses, or a combination of the two. The later option would be particularly advantageous for repositories that are expensive to characterize and analyze, and have only a few scenarios or events that cannot be represented properly by generic release limits.

\subsubsection{DOSE CRITERIA AND REFERENCE FUTURE STATES}

The consequences of radiation exposure that were used to develop the dose limits in Working Draft 4 of 40 CFR 191 [41] are the same as the latest ICRP recommendations [6]. The nominal probability coefficient for stochastic 


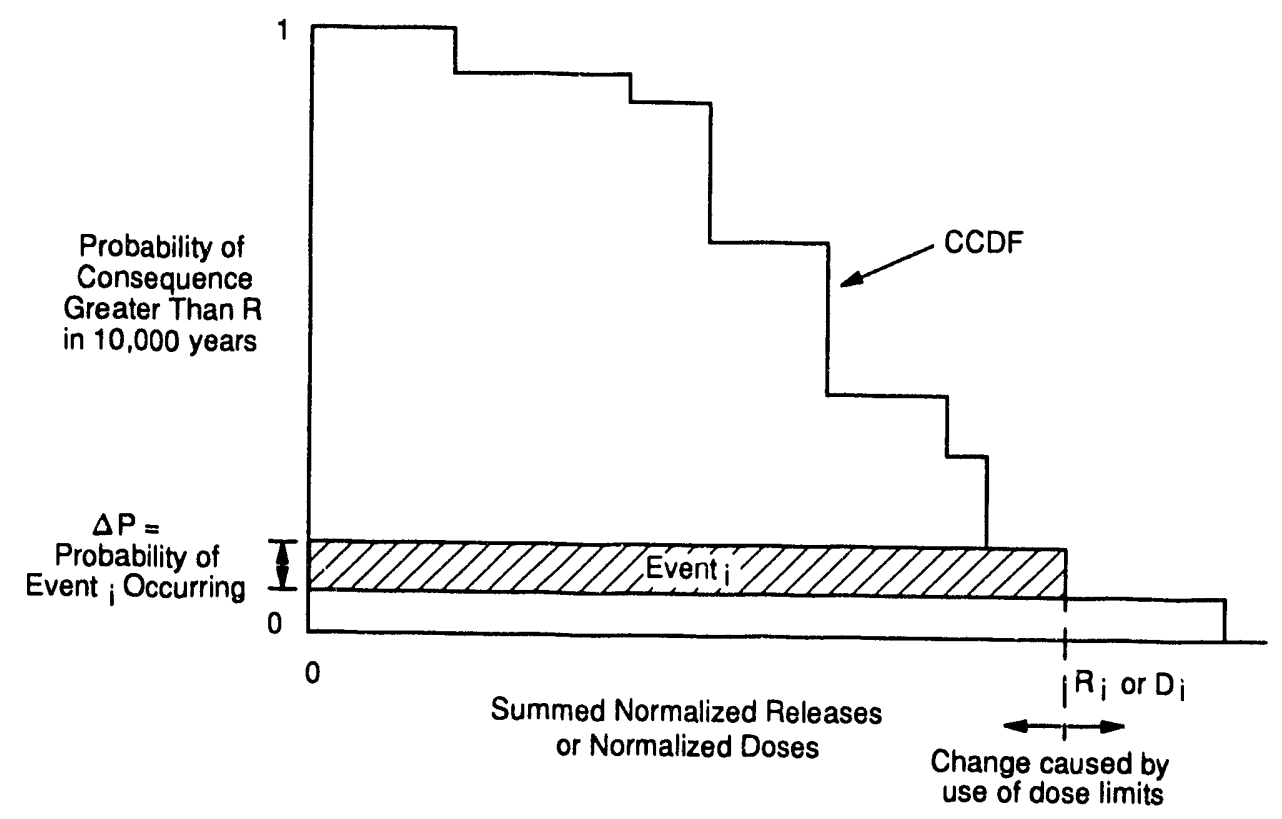

TRII-6342-5-0

Figure 13. CCDF made up of normalized doses and/or normalized releases.

effects used to set the effective dose limits is 0.04 premature cancer deaths per Sv. When this coefficient is applied to the fundamental criterion of 1000 premature deaths in 10,000 years for the HLW reference repository containing 100,000 MTHM, the effective dose limit is 25,000 person-sieverts per 100,000 MTHM ( 0.25 person-sieverts/MTHM). For the TRU-waste reference repository containing $20 \mathrm{MCi}$ that is defined in Chapter 7 of this report, the effective dose limit would be 25,000 person-sieverts per 20 MCi of radioactive waste $(0.00125$ person-sieverts/Ci).

The standards could provide optional basic procedures for computing collective effective doses. The procedures for computing the effective dose in Appendix B of Working Draft 4 of 40 CFR 191 [41] are identical to those in Annex A of ICRP 60 [6]. The effective dose (E) is the sum of weighted absorbed doses from all radiation types and energies, in all tissues and organs of the body. It is given by the expression:

$$
\mathrm{E}=\sum_{\mathrm{R}}^{\Sigma} \mathrm{w}_{\mathrm{R}} \underset{\mathrm{T}}{\Sigma} \mathrm{w}_{\mathrm{T}} \cdot \mathrm{D}_{\mathrm{T}, \mathrm{R}}
$$


where $D_{T, R}$ is the mean absorbed dose to organ $T$ delivered by radiation $R$. The radiation is that incident on the body or emitted by a source within the body. Values for the radiation weighting factors $\left(w_{R}\right)$ are given in Table 6 , and values of the tissue weighting factors $\left(w_{T}\right)$ are given in Table 7 . This basic procedure is the most versatile, but it could permit some variability in its use and would require detailed predictions of pathways and uptake of radionuclides.

Table 6. Radiation Weighting Factors, $w_{R}{ }^{1}$ [References 6,41]

Radiation type and energy range 2

$w_{R}$ value

Photons, all energies

1

Electrons and muons, all energies

1

Neutrons, energy $<10 \mathrm{keV}$

5

$10 \mathrm{keV}$ to $100 \mathrm{keV}$

10

$>100 \mathrm{keV}$ to $2 \mathrm{MeV}$

20

$>2 \mathrm{MeV}$ to $20 \mathrm{MeV}$

$>20 \mathrm{MeV}$

10

5

Protons, other than recoil protons, $>2 \mathrm{MeV}$

5

Alpha particles, fission fragments, heavy nuclei

20

1 All values relate to the radiation incident on the body or, for internal sources, emitted from the source.

2 The choice of values for other radiation types and energies not in the table is discussed in paragraph A14 of ICRP Publication 60 [6].

The NEA used a modification of the ICRP procedures in the dose analyses for the Subseabed Disposal Program [22]. The average effective dose per unit intake of activity for the ingestion and inhalation pathways was computed for each radionuclide. Similar dose-conversion factors were computed for external exposure. Most of the radioactive doses per unit intake for all the major radionuclides were taken from ICRP Publication 30 [42]. The exceptions are the doses per unit intake values for isotopes of plutonium and neptunium; these were calculated using values of the gut transfer fraction appropriate to the forms of these radionuclides found in environmental materials [43]. Tables $8 \mathrm{a}$ and $8 \mathrm{~b}$ list the dose-conversion factors for both systems of units. These tables simplify the dose calculations and assure uniform application. 
Table 7. Tissue Weighting Factors, $\mathrm{w}_{\mathrm{T}}{ }^{1}$ [References 6,41 ]

Organ or tissue

wT value

Gonads

Red bone marrow

0.20

Colon

0.12

Lung

0.12

Stomach

0.12

Bladder

0.12

Breast

0.05

Liver

0.05

Esophagus

0.05

Thyroid

Skin

Bone surfaces

Remainder

0.05

0.05

0.01

0.01

$0.05^{2}, 3$

1 The values have been developed from a reference population of equal numbers of both sexes and a wide range of ages. In the definition of effective dose, they apply to individuals and populations and to both sexes.

2 For purposes of calculation, the remainder is comprised of the following additional tissues and organs: adrenals, brain, upper large intestine, small intestine, kiiney, muscle, pancreas, spleen, thymus, and uterus. The list includes organs which are likely to be selectively irradiated. Some organs in the list are known to be susceptible to cancer induction. If other tissues and organs subsequently become identified as having a significant risk of induced cancer, they will be included either with a specific $w_{T}$ or in this additional list constituting the remainder. The latter may also include other tissues or organs selectively irradiated.

3 In those exceptional cases in which a single one of the remainder tissues or organs receives an equivalent dose in excess of the highest dose in any of the twelve organs for which a weighting factor is specified, a weighting factor of 0.025 should be applied to that tissue or organ and a weighting factor of 0.025 to the average dose in the rest of the remainder as defined above. 
Table 8a. Dose Conversion Factors for Humans (Curies and Related Units) [References 22,42,43]

\begin{tabular}{|c|c|c|c|c|}
\hline Nuclide & $\begin{array}{l}\text { Ingestion } \\
(\text { Rem/Ci) }\end{array}$ & $\begin{array}{l}\text { Inhalation } \\
(\mathrm{Rem} / \mathrm{Ci})\end{array}$ & $\begin{array}{c}\text { Immersion } \\
\left(\text { Rem } / \mathrm{Hr} \cdot \mathrm{Ci} \cdot \mathrm{m}^{3}\right)\end{array}$ & $\begin{array}{l}\text { Exposure to Soil } \\
\left(\mathrm{Rem} / \mathrm{Hr} \cdot \mathrm{Ci} \cdot \mathrm{m}^{3}\right)\end{array}$ \\
\hline$C-14$ & $2.07 E+03$ & $2.07 E+03$ & $0.00 \mathrm{E}+00$ & $0.00 \mathrm{E}+00$ \\
\hline $\mathrm{Ni}-59$ & $2.00 \mathrm{E}+02$ & 1. $33 E+03$ & $2.30 E-03$ & $0.00 \mathrm{E}+00$ \\
\hline $\operatorname{Sr}-90$ & $1.44 \mathrm{E}+05$ & $1.26 \mathrm{E}+06$ & $5.40 \mathrm{E}-04$ & $0.00 \mathrm{E}+00$ \\
\hline Zr-93 & 1. $55 \mathrm{E}+03$ & $3.18 \mathrm{E}+05$ & $0.00 \mathrm{E}+00$ & $0.00 \mathrm{E}+00$ \\
\hline Tc- 99 & 1. $26 \mathrm{E}+03$ & $7.40 \mathrm{E}+03$ & 1. $30 \mathrm{E}-04$ & $0.00 \mathrm{E}+00$ \\
\hline Sn- 126 & $1.89 \mathrm{E}+04$ & $7.40 \mathrm{E}+04$ & $1.80 \mathrm{E}-02$ & $9.00 \mathrm{E}+00$ \\
\hline I - 129 & $2.74 \mathrm{E}+05$ & $1.74 \mathrm{E}+05$ & $1.70 \mathrm{E}-02$ & $4.50 \mathrm{E}-01$ \\
\hline $\mathrm{Cs}-135$ & $7.03 E+03$ & $4.44 E+04$ & $6.60 \mathrm{E}-05$ & $0.00 \mathrm{E}+00$ \\
\hline $\mathrm{Cs}-137$ & $5.18 \mathrm{E}+04$ & $3.22 E+04$ & $1.00 \mathrm{E}+00$ & $4.20 \mathrm{E}+00$ \\
\hline $\mathrm{Sm}-151$ & $3.37 \mathrm{E}+02$ & $2.81 E+04$ & $2.60 \mathrm{E}-04$ & $4.80 \mathrm{E}-02$ \\
\hline $\mathrm{Pb}-210$ & $5.18 E+06$ & 1. $30 \mathrm{E}+07$ & $3.00 \mathrm{E}-03$ & 1. $30 \mathrm{E}-02$ \\
\hline $\mathrm{Ra}-226$ & $1.15 \mathrm{E}+06$ & $7.77 \mathrm{E}+06$ & $1.80 \mathrm{E}+00$ & $6.40 \mathrm{E}+00$ \\
\hline $\mathrm{Ra}-228$ & 1. $22 \mathrm{E}+06$ & $4.44 E+06$ & $6.75 \mathrm{E}+00$ & $2.60 \mathrm{E}+01$ \\
\hline$A c-227$ & $1.41 \mathrm{E}+07$ & $6.66 \mathrm{E}+09$ & $1.69 \mathrm{E}+00$ & $8.21 \mathrm{E}+00$ \\
\hline Th -229 & $3.70 E+06$ & $2.11 E+07$ & $5.80 \mathrm{E}-01$ & 2. $20 \mathrm{E}+00$ \\
\hline$T h-230$ & $5.55 \mathrm{E}+05$ & $3.18 \mathrm{E}+08$ & 1. $80 \mathrm{E}+00$ & $6.50 \mathrm{E}+00$ \\
\hline Th -232 & $2.74 E+06$ & $1.63 E+09$ & $4.00 \mathrm{E}+00$ & $1.56 \mathrm{E}+01$ \\
\hline $\mathrm{Pa}-231$ & $1.07 \mathrm{E}+07$ & 1. $26 \mathrm{E}+09$ & $5.00 \mathrm{E}-01$ & $2.20 \mathrm{E}+00$ \\
\hline $\mathrm{U}-233$ & $2.66 \mathrm{E}+05$ & 1. $33 \mathrm{E}+08$ & $5.90 \mathrm{E}-01$ & 2. $30 \mathrm{E}+00$ \\
\hline$U-234$ & $2.63 E+05$ & 1. $33 \mathrm{E}+08$ & $1.18 \mathrm{E}-03$ & 7. $32 \mathrm{E}-03$ \\
\hline U-235 & $2.52 E+05$ & 1. $22 E+08$ & $2.96 \mathrm{E}-01$ & 1. $31 \mathrm{E}+00$ \\
\hline $\mathrm{U}-236$ & $2.48 \mathrm{E}+05$ & 1. $26 \mathrm{E}+08$ & $2.97 E-06$ & $2.06 \mathrm{E}-04$ \\
\hline$U-238$ & $2.33 E+05$ & 1. $18 \mathrm{E}+08$ & $7.36 \mathrm{E}-02$ & $3.52 \mathrm{E}-01$ \\
\hline$N p-237$ & $4.07 E+06$ & $4.81 E+08$ & $3.60 \mathrm{E}-01$ & $1.40 \mathrm{E}+00$ \\
\hline $\mathrm{Pu}-238$ & $1.85 E+06$ & $4.44 E+08$ & $1.50 \mathrm{E}-04$ & 1. $30 \mathrm{E}-03$ \\
\hline $\mathrm{Pu}-239$ & $2.22 E+06$ & $5.18 E+08$ & 1. $20 \mathrm{E}-04$ & $7.90 \mathrm{E}-04$ \\
\hline $\mathrm{Pu}-240$ & $2.22 E+06$ & $5.18 E+08$ & $1.40 \mathrm{E}-04$ & $1.30 E-03$ \\
\hline $\mathrm{Pu}-241$ & $4.44 E+04$ & $1.04 E+07$ & $6.10 \mathrm{E}-05$ & $4.60 E-03$ \\
\hline $\mathrm{Pu}-242$ & $2.04 E+06$ & $4.81 E+08$ & $1.10 \mathrm{E}-04$ & $1.10 \mathrm{E}-03$ \\
\hline$A m-241$ & $2.22 E+06$ & $5.18 \mathrm{E}+08$ & $3.90 \mathrm{E}-02$ & $1.80 \mathrm{E}-01$ \\
\hline$A m-243$ & $2.18 E+06$ & $5.18 E+08$ & $3.10 \mathrm{E}-01$ & 1. $30 \mathrm{E}+00$ \\
\hline $\mathrm{Cm}-242$ & $6.66 E+04$ & $1.74 \mathrm{E}+07$ & $3.40 \mathrm{E}-04$ & $5.50 \mathrm{E}-03$ \\
\hline $\mathrm{Cm}-244$ & $1.11 E+06$ & $2.74 \mathrm{E}+08$ & $2.60 \mathrm{E}-04$ & $2.90 \mathrm{E}-03$ \\
\hline
\end{tabular}


Table 8b. Dose Conversion Factors for Humans ( $\mathrm{TBq}$ and Related Units) [References 22,42,43]

\begin{tabular}{|c|c|c|c|c|}
\hline Nuclide & $\begin{array}{l}\text { Ingestion } \\
\text { ( } \mathrm{Sv} / \mathrm{TBq})\end{array}$ & $\begin{array}{l}\text { Inhalation } \\
(\mathrm{Sv} / \mathrm{TBq})\end{array}$ & $\begin{array}{c}\text { Immersion } \\
\left(\mathrm{Sv} / \mathrm{Hr} \cdot \mathrm{TBq} \cdot \mathrm{m}^{3}\right)\end{array}$ & $\begin{array}{l}\text { Exposure to Soil } \\
\left(\mathrm{Sv} / \mathrm{Hr} \cdot \mathrm{TBq} \cdot \mathrm{m}^{3}\right)\end{array}$ \\
\hline$C-14$ & $5.60 \mathrm{E}+02$ & $5.60 \mathrm{E}+02$ & $0.00 \mathrm{E}+00$ & $0.00 \mathrm{E}+00$ \\
\hline $\mathrm{Ni}-59$ & $5.40 \mathrm{E}+01$ & $3.60 \mathrm{E}+02$ & $6.21 E-04$ & $0.00 \mathrm{E}+00$ \\
\hline $\operatorname{Sr}-90$ & $3.90 \mathrm{E}+04$ & $3.40 \mathrm{E}+05$ & $1.46 \mathrm{E}-04$ & $0.00 \mathrm{E}+00$ \\
\hline Zr-93 & $4.20 \mathrm{E}+02$ & $8.60 E+04$ & $0.00 \mathrm{E}+00$ & $0.00 E+00$ \\
\hline Tc- 99 & $3.40 E+C 2$ & $2.00 \mathrm{E}+03$ & $3.51 \mathrm{E}-05$ & $0.00 \mathrm{E}+00$ \\
\hline$S n-126$ & $5.10 E+C 3$ & $2.00 E+04$ & $4.86 \mathrm{E}-03$ & $2.43 E+00$ \\
\hline I - 129 & $7.40 E+04$ & $4.70 E+04$ & $4.59 E-03$ & 1. $22 \mathrm{E}-01$ \\
\hline Cs -135 & $1.90 \mathrm{E}+03$ & 1. $20 \mathrm{E}+04$ & $1.78 \mathrm{E}-05$ & $0.00 \mathrm{E}+00$ \\
\hline Cs -137 & $1.40 \mathrm{E}+04$ & $8.70 E+03$ & $2.70 \mathrm{E}-01$ & $1.13 E+00$ \\
\hline$S m-151$ & $9.10 E+01$ & $7.60 \mathrm{E}+03$ & $7.02 E-05$ & 1. $30 \mathrm{E}-02$ \\
\hline $\mathrm{Pb}-2.10$ & $1.40 E+06$ & $3.50 \mathrm{E}+06$ & $8.10 E-04$ & $3.51 E-03$ \\
\hline $\mathrm{Ra}-226$ & $3.10 \mathrm{E}+05$ & $2.10 \mathrm{E}+06$ & $4.86 \mathrm{E}-01$ & $1.73 E+00$ \\
\hline $\mathrm{Ra}-228$ & 3.20E+05 & 1. $20 \mathrm{E}+06$ & $1.82 E+00$ & $7.02 E+00$ \\
\hline$A c-227$ & $3.80 \mathrm{E}+06$ & 1. $80 \mathrm{E}+09$ & $4.56 \mathrm{E}-01$ & $2.22 E+00$ \\
\hline Th- 229 & $1.00 \mathrm{E}+06$ & $5.70 \mathrm{E}+06$ & $1.57 E-01$ & $5.94 \mathrm{E}-01$ \\
\hline$T h-230$ & $1.50 \mathrm{E}+05$ & $8.60 E+07$ & $4.86 \mathrm{E}-01$ & $1.76 \mathrm{E}+00$ \\
\hline Th- 232 & $7.40 \mathrm{E}+05$ & $4.40 \mathrm{E}+08$ & $1.08 \mathrm{E}+00$ & $4.21 E+00$ \\
\hline $\mathrm{Pa}-231$ & $2.90 E+06$ & $3.40 E+08$ & 1. $35 \mathrm{E}-01$ & $5.94 \mathrm{E}-01$ \\
\hline$U-233$ & $7.20 \mathrm{E}+04$ & $3.60 \mathrm{E}+07$ & $1.59 \mathrm{E}-01$ & $6.21 E-01$ \\
\hline$U-234$ & $7.10 \mathrm{E}+04$ & $3.60 \mathrm{E}+07$ & $3.19 E-04$ & $1.98 \mathrm{E}-03$ \\
\hline $\mathrm{U}-235$ & $6.80 \mathrm{E}+04$ & 3. $30 \mathrm{E}+07$ & $7.99 \mathrm{E}-02$ & $3.54 \mathrm{E}-01$ \\
\hline$U-236$ & $6.70 \mathrm{E}+04$ & $3.40 \mathrm{E}+07$ & $8.02 E-07$ & $5.56 \mathrm{E}-05$ \\
\hline $\mathrm{U}-238$ & $6.30 E+04$ & $3.20 \mathrm{E}+07$ & $1.99 \mathrm{E}-02$ & $9.50 \mathrm{E}-02$ \\
\hline$N p-237$ & $1.10 \mathrm{E}+06$ & 1. $30 \mathrm{E}+08$ & $9.72 \mathrm{E}-02$ & $3.78 \mathrm{E}-01$ \\
\hline $\mathrm{Pu}-238$ & $5.00 \mathrm{E}+05$ & 1. $20 \mathrm{E}+08$ & $4.05 E-05$ & $3.51 E-04$ \\
\hline $\mathrm{Pu}-239$ & $6.00 \mathrm{E}+05$ & $1.40 \mathrm{E}+08$ & $3.24 \mathrm{E}-05$ & $2.13 E-04$ \\
\hline$P u-240$ & $6.00 E+05$ & $1.40 \mathrm{E}+08$ & $3.78 \mathrm{E}-05$ & $3.51 E-04$ \\
\hline $\mathrm{Pu}-241$ & $1.20 \mathrm{E}+04$ & $2.80 \mathrm{E}+06$ & $1.65 E-05$ & $1.24 E-03$ \\
\hline $\mathrm{Pu}-242$ & $5.50 \mathrm{E}+05$ & 1. $30 \mathrm{E}+08$ & $2.97 \mathrm{E}-05$ & $2.97 \mathrm{E}-04$ \\
\hline Am- 241 & $6.00 \mathrm{E}+05$ & $1.40 \mathrm{E}+08$ & $1.05 E-02$ & $4.86 \mathrm{E}-02$ \\
\hline Am - 243 & $5.90 E+05$ & $1.40 E+08$ & $8.37 \mathrm{E}-02$ & $3.51 \mathrm{E}-01$ \\
\hline Cm- 242 & $1.80 E+04$ & $4.70 E+06$ & $9.18 \mathrm{E}-05$ & $1.49 \mathrm{E}-03$ \\
\hline $\mathrm{Cm}-244$ & $3.00 \mathrm{E}+05$ & $7.40 \mathrm{E}+07$ & $7.02 \mathrm{E}-05$ & $7.83 E-04$ \\
\hline
\end{tabular}


An intermediate approach was taken by the U.S. Department of Energy (DOE). The DOE has published dose-conversion factors for internal and external exposure for each radionuclide and each exposed organ $[44,45]$. Reference 44 states that DOE/EH-0071 "is intended to be used as the primary reference by the U.S. Department of Energy (DOE) and its contractors for calculating radiation dose equivalents for members of the public, resulting from ingestion or inhalation of radioactive materials." It also states that "the use of these committed dose equivalent tables should ensure that doses to members of the public from internal exposures are calculated in a consistent manner at all DOE facilities." The series of ICRP publications starting with Publication 26 [46] provides the technical base used in calculating the dose-equivalent factors listed in References 44 and 45 .

When defining a reference biosphere, demography, and human characteristics, care must be taken not to obscure important site characteristics and to assure compatibility with the standards and their derivations. Except for world population, present processes and parameter values were assumed in the derivation and justification of the standards. Therefore, it would be appropriate to assume that the reference future states are essentially as they are today. Changes could be assessed with sensitivity studies and stochastic analyses covering varying climatic, geologic, and hydraulic conditions. The present demographic pattern could be retained by multiplying local populations by the ratio of the 1010 world population used in the release-limit derivation to the present world population. Human characteristics such as physiology, nutrition, water use, technical and intellectual ability, medical resources, social structure, and values could be defined as they are today. Although the five basic release modes probably would still exist, they would not all apply uniformly to all repository sites. Geologic and hydraulic risk attenuation are site specific, and it would not be appropriate to include them as part of the standards. The more that is included in the definition of future states in the standards, the closer the dose-limit alternative comes to the multimode release-limit approach.

\subsubsection{PERFORMANCE ASSESSMENT}

Dose-based risk assessments, for repositories that do not have their attenuation processes adequately represented by either single-mode or multimode release limits, could result in extensive site characterization and analyses. If release limits are inappropriate for only a few events that are responsible for the significant releases, it would be possible to analyze only these events using dose criteria. The predicted doses for each event could be normalized relative to the dose limits set by the EPA in the same manner as predicted releases. The dose fraction could then replace the 
summed release fraction for that event in the CCDF. The probability would remain the same, so the only effect would be to change the consequence level for that event on the CCDF. Depending on the events, this could still be a large site characterization and analysis program, but it would be preferable to conducting dose-based assessments for all events.

\subsubsection{SUMMARY AND CONCLUSIONS}

The selective substitution of dose limits for events or scenarios that cannot be represented adequately with generic derived release limits is a viable option. Substitution of higher-level standards is always justified. This option could require additional site characterization and more analyses for PA. It would be possible to do dose analyses on only selected scenarios and normalize them to EPA-supplied dose limits. They would replace the corresponding normalized releases in the CCDF. All the information needed for dose limits is available, so no development program is necessary. This option would require a thorough explanation and justification in the standards.

The dose-standard alternative could be used with either the present single generic release limits or the multimode release limits. The single generic release limits would be inappropriate for most repositories even if used with the dose-standard alternative. It is also extremely conservative for most repositories, possibly making it necessary to use dose standards with added site characterization and analyses, when it would not be necessary with more appropriate release limits. The approach using multimode release limits would produce more accurate predictions of risk for all repositories. Since the conservatism would be uniform for all repositories and the risk attenuation of all disposal-system components could be included in the PA, fewer repositories would have to use the more expensive and time-consuming dose option. 


\section{COMPARISON OF ALTERNATIVES TO THE PRESENT RELEASE LIMITS}

Four alternatives to the single generic table of release limits in 40 CFR 191 have been suggested. These are: replace the single generic table of release limits with site-and-pathway-specific tables of release limits applied at the CV surfaces; replace the single set of release linits applied at the CV surfaces with a five-column table of release limits for each release mode applied at the release locations (multimode); eliminate the release limits and replace them with the higher-level, collective-dose limits; and allow the use of collective-dose limits as an option to release limits. These alternatives are discussed in detail in Chapter 4. The following sections provide a comparison of the present release limits, discussed in detail in Chapter 3 , and the four alternatives.

\subsection{Present Single Generic Release Limits}

These standards have already been derived and would require no additional development by the EPA. Applying a single set of limits at the CV surfaces requires the fewest analyses by $P A$ of any of the alternatives. However, single generic derived standards applied close to the repository force the fundamental safety requirement to change for each repository and each pathway. Also, one of the most important components in the disposal system, risk attenuation between the $\mathrm{CV}$ and the location of release to the environment, is left out of the assessment, giving a distorted indication of risk. In addition, these limits were based on the two release modes that are the least probable for the WIPP and the YMP, so they would not be applied to the circumstances for which they were derived. Finally, the degree of conservatism is unknown and nonuniform.

\subsection{Site-and-Pathway-Specific Release Limits}

This alternative would eliminate the most serious drawbacks of the present release limits. All applications would have uniform safety requirements, all components would be included in the risk assessment, and the appropriate release modes would be used. The location of the limits would not change, so no change in PA would be required. However, a large and time-consuming development program would be needed by the EPA to define specific pathways and release modes for each repository under consideration, update the risk factors, compute the attenuation in the formations outside the $\mathrm{CV}$, and allocate releases for each mode. Unlike the present release limits discussed in the previous section and the multimode release limits 
discussed in the next section, this alternative is not generic; the standards would be site specific and would have to be expanded to accommodate new repositories.

\subsection{Multimode Generic Release Limits}

This alternative also would eliminate the most serious drawbacks of the present release limits but would use a different approach. Because the EPA would compute all transport and biological effects from the release locations to humans for all five release modes, the biosphere and health effects would be uniform for all applications. These derivations would be conducted with generic models and data, so the release limits would still contain some inaccuracies. However, more appropriate release modes and release locations would be used for all pathways for each repository because they could be selected by the PA groups. PA would include all pre-release disposal-system components in the assessments, from the repository to the release locations. Multimode release limits would not be site specific and would apply to future repositories. This approach is compatible with the present $40 \mathrm{CFR} 191$ format. A moderate effort would be required to update and extend the derivations. The derivations for the land-, atmospheric-, and river-release inodes are complete but could be updated, the limits for the ocean-release mode definitely should be recalculated, and the derivation for the wellrelease mode would be a minor modification of the limits for the riverrelease mode. The role of $\mathrm{PA}$ would be expanded to include release-mode selection, possible corrections to account for repository locations, and possible analyses of attenuation factors outside the CV. Site characterization and analyses would only have to extend far enough to show compliance.

Some aspects of assessments using the multimode release method would be more restrictive than with the single generic release method and some would be less restrictive, but all aspects would be more appropriate and more accurate. Multimode release limits assess a disposal system as a unit rather than using one set of allowable releases without regard to pathways, as the single generic release limits do. Implementation of the two methods would be similar. The main differences are in appropriateness, uniformity, and accuracy.

\subsection{Collective-Dose Limits as the Primary Criterion}

This alternative would eliminate the derived release limits and use only the more precise and versatile collective-dose limits that apply uniformly to all repositories and all pathways. Dose limits allow risk assessments to be 
conducted sequentially from the waste source to humans, which is the only way that all the attenuation functions of all components in the disposal system can be included in the assessment. This alternative is similar to the individual-dose-rate standards recommended by the ICRP, NEA, and IAEA, and being used by other countries. Because the fundamental criterion in 40 CFR 191 defines the maximum allowable cancer deaths per unit waste during the time of regulation, collective dose per MTHM is the only type of dose limit that would be compatible with the present regulation. Only a moderate effort would be required by the EPA to implement this change, but it would require a major change in regulatory philosophy. Even if the EPA specified standard future states and an effects model, this alternative would require the most analyses by $\mathrm{PA}$ and the most additional site characterization.

\subsection{Collective-Dose Limits as an Option}

Selective substitution of collective-dose limits for release limits is a viable option and may be more appropriate for some repositories. The hierarchy of criteria levels is explained in section 2.2. The top-level fundamental criterion is the only level that explicitly defines the safety requirements of the repository. Some analyses are required to develop each criteria level below the fundamental requirement, and each analysis adds uncertainty to the criteria. Derived standards are only used to facilitate regulation and therefore can always be replaced by more precise, higher-level criteria without jeopardizing safety. In this case, the more expedient but ultra-conservative derived release limits can be replaced by the higher-level, more exact dose limits. The release limits are intended only to provide a simplified method of evaluation and are not a true measure of risk. Complying with the release requirements is sufficient, but not necessary, to demonstrate compliance with the fundamental criterion. Dose limits provide a more precise measule of actual risk but require more extensive site characterizations and performance assessments. An unsafe repository could not comply with either dose or release limits, so there is no advantage in using both standards.

A preliminary performance evaluation may be needed to selcat the most appropriate standard for a particular repository. Repository evaluations using release limits are less expensive and can be completed in less time because they require less site characterization and less complex PA. However, the conservative, approximate release limits may not adequately represent the attenuating processes of some repositories, and the more accurate dose standards may be required. 
The dose option could be used with either type of generic release limits. Multimode release limits produce more accurate and uniform predictions of risk than single generic release limits for all repositories and scenarios. Since multimode release limits would be appropriate more often, fewer reposjtories would have to use the more expensive and timeconsuming dose option.

Table 9 summarizes the characteristics of the four alternatives discussed in this chapter and in Chapter 4. 


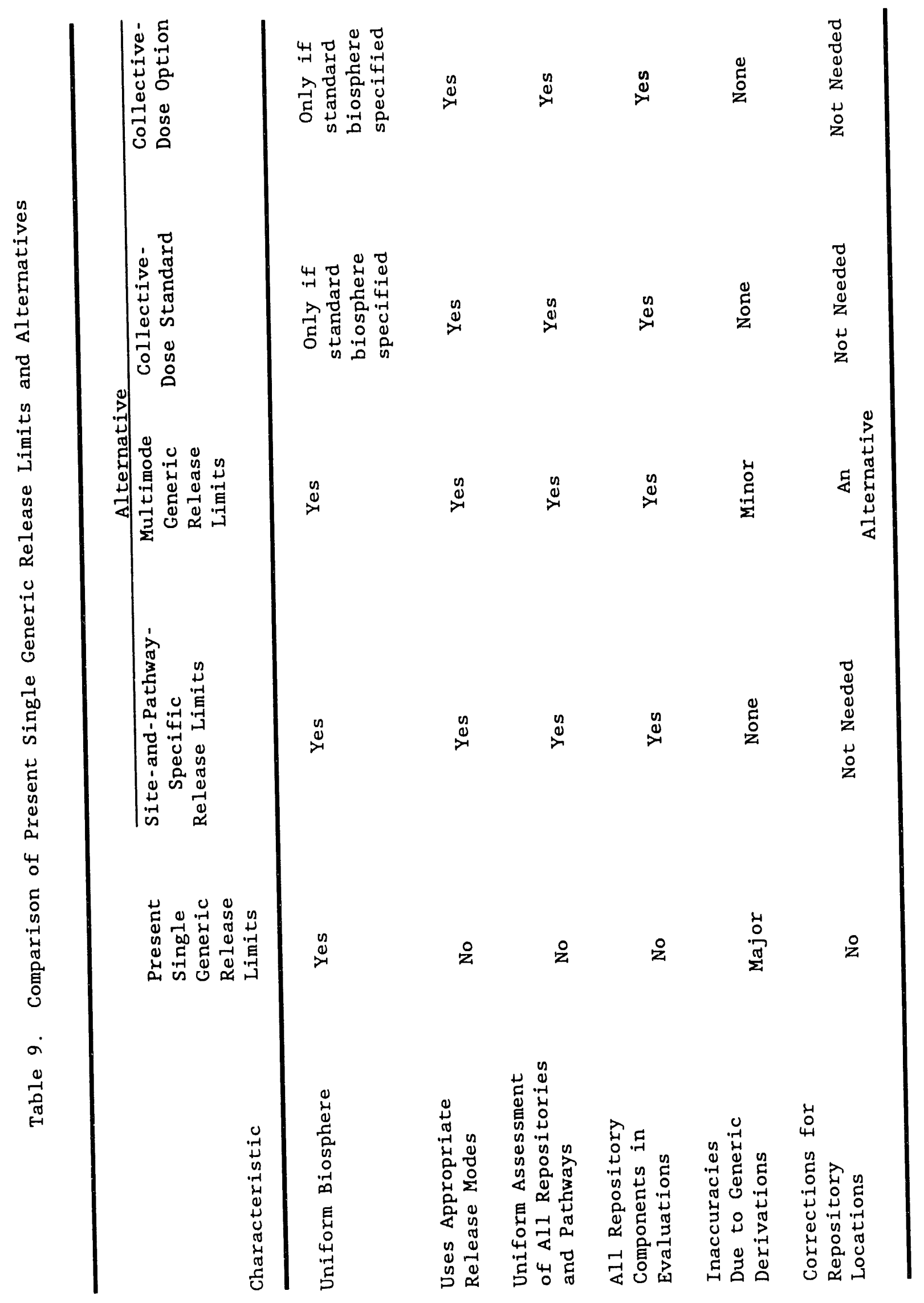




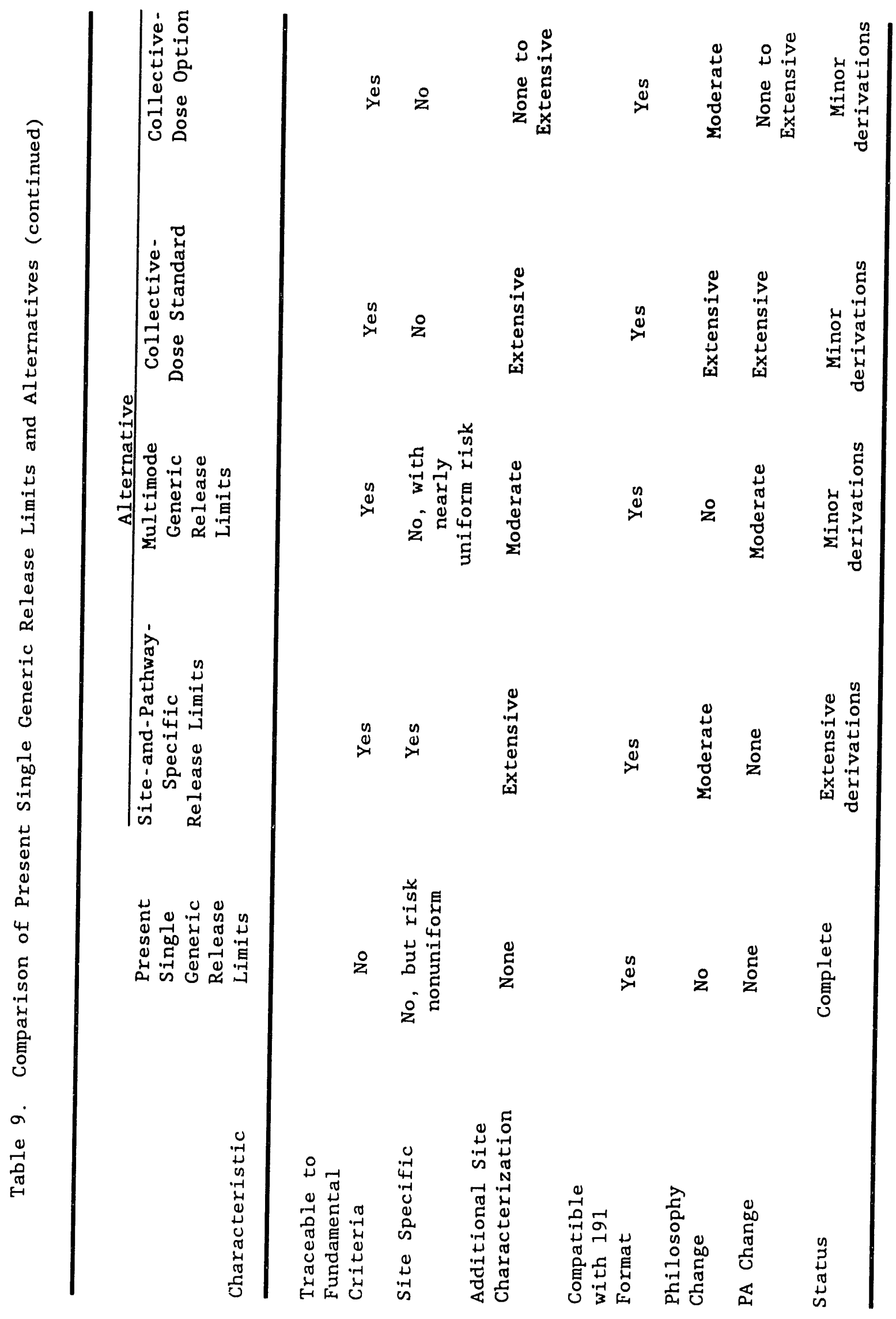




\section{PROBABILISTIC CONTAINMENT REQUIREMENTS FOR RADIOACTIVE-WASTE DISPOSAL}

The containment requirements in 40 CFR 191 define a procedure for evaluating compliance of probabilistic events and processes using deterministic release limits. This chapter covers three basic approaches to containment requirements for probabilistic doses and radionuclide releases to the accessible environment. These are: a modification of the risk approach proposed by the ICRP and che NEA [4]; a stepped limit that controls the shape and magnitude of the repository-release CCDF as defined in the 1985 version of 40 CFR 191 [1]; and separate requirements for three probability categories or "three buckets" as suggested in an attachment to a letter from R.F. Browning, U.S. Nuclear Regulatory Commission (NRC), to R. Guimond, EPA, "Comments on Working Draft No. 2 of EPA's High-Level Waste Standards," dated August 27, 1990. The technical bases of each approach is reviewed, implementation is discussed, and their relative attributes and deficiencies are evaluated.

The following comments by the ICRP [5] and the NEA [37] apply to all three basic approaches. Predictive assessments will inevitably be subject to considerable uncertainty because of the uncertainties in human behavior and in natural processes and events. There is also uncertainty about when some events and processes will occur, or even whether they will occur at all. There may be a very wide range of predicted radiation doses to the populace, with the highest doses associated with very unlikely events or processes. In evaluating the acceptability of a waste-disposal system, it is therefore necessary to consider not only the magnitude of exposures, but also the probability that various levels of dose will be received and the uncertainties in these probabilities.

The ICRP has defined a criteria curve that corresponds to an annual individual risk of $10^{-5}$ (Figure 14). The only nonlinearity in this curve is caused by the relationship between dose and health effects in the high-dose region. The ICRP recommends using this curve to eliminate disposal concepts, designs, and site locations that are unacceptable. If the dose from any single event falls into the unacceptable region of the ICRP probability/dose plot, the disposal system is unacceptable. This curve cannot be used to show that a repository is acceptable. The NEA summarizes the uses of the ICRP dose-limit curve, the dose CCDF, and their relation to risk as follows [37]:

The area enclosed by the curve of probabilities of exceeding levels of dose (CCDF) corresponds to the overall risk. It must be shown that the sum of risks from all exposure scenarios that could affect the same individual is less than the maximum allowed risk value. The boundary line of the ICRP dose limit curve represents only the limit of risk if 


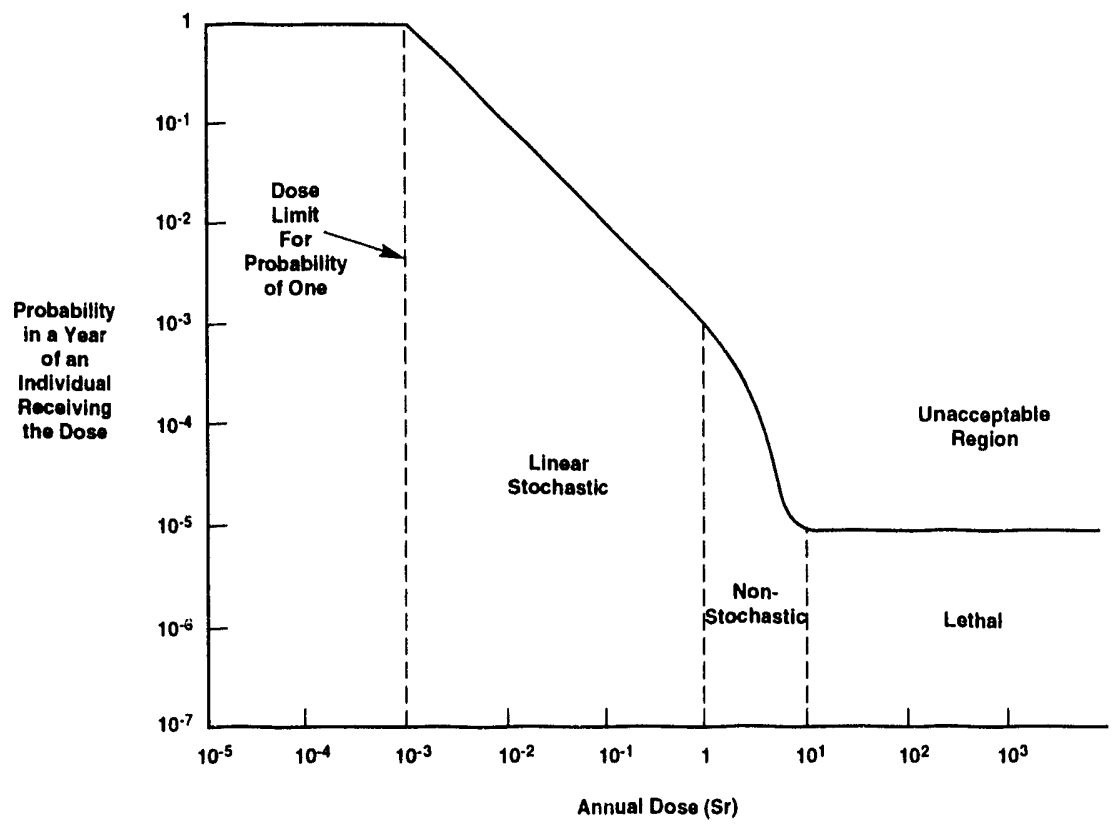

Figure 14. Criterion curve corresponding to an annual individual risk constraint of 10-5 [Reference 5].

the risk arises from a single well-defined scenario and is not therefore directly comparable with the CCDF curve. It is not sufficient to demonstrate that the whole curve of probabilities exceeding levels of dose (CCDF) lies to the left and below the boundary of the dose limit curve.

These comments by the ICRP and NEA concerning the definitions of risk and single-event risk limits apply to annual-population and collective-population criteria as well as to those for maximally exposed individuals. They also apply to normalized release and dose limits as well as to risk limits.

\subsection{Modified Risk Limit}

One of the more widely accepted approaches for handling probabilistic events is that recommended by the ICRP [5] and the NEA [37,47]. They suggest using a limit on individual risks as the primary criterion. The same approach can be used for population risks or time-integrated radionuclide releases [4]. When a probabilis ic distribution of doses exists that reflects variability and uncertainty in modeling parameters and the variety of probabilistic events and processes, the risk is defined as the integral of 
this distribution. Stated another way, risk is the consequence of an event or parameter variation, times the probability that the event or variation will occur, summed over all events or variations. This is the area under the consequence CCDF, as illustrated in Figure 15 where the risk of a single event or variation is represented by the shaded region. The advantage of using a risk limit is that the contribution of unlikely events which may or may not occur in the future can be taken into account in a straightforward and consistent manner. This is the measure of risk used by the EPA in the Background Information Document for 40 CFR 191 [17] for sensitivity studies and risk assessments of generic mined geologic repositories in support of the value selected for the HLW fundamental criterion. However, this is not the method used by the EPA for containment requirements in 40 CFR 191.

The modified risk-based limits suggested in this report apply to probabilistic releases to the environment and build on the procedures in the current version of $40 \mathrm{CFR}$ 191. The generic single-mode [1] or multimode [29] release tables for each radionuclide would be used with summation rules to produce the summed normalized release ( $R$ ) for each event and each parameter sample. The first step in the PA would be to develop the scenarios and a logic diagram with estimated probabilities, using the procedures defined in Reference 48. Entire events or sequences of events with estimated probabilities of occurrence below the credible level (usually 10-7 to 10-9

per year) would be excluded from the assessment. After conducting the required nuclide-transport analyses, the next step in a PA would be to generate separate CCDFs, that include all analyzed events, for each parameter sample. This procedure would be repeated for all parameter samples. An example of such a family of CCDFs generated by Latin hypercube sampling is shown in Figure 16. This is similar to the methodology presented in Reference 49. These distributions contain all the probabilistic-release information but are rather difficult to read and even more difficult to interpret. These problems could be eliminated by integrating all of the CCDFs to produce the risks for each parameter sample. These risks would be divided by the number of data sets to produce the probabilistic normalized risks for the repository. A cumulative distribution function (CDF) of the normalized releases could then be plotted to show the effect of variability in the system (Figure 17). In this illustration the $\mathrm{CDF}$ extends beyond the normalized release goal of one, showing a finite probability of exceeding the goal. Regulations could allow some fraction of the predicted risks to exceed the goal. The Science Advisory Board ( $S A B$ ) recommended allowing no more than a 508 chance of exceeding the summed normalized release limit [13]. Risk sensitivity to property and process variations, and uncertainties in process definitions and data depend on the robustness of the disposal system [2]. The same procedures could be used with normalized dose or mixed normalized release and dose CCDFs. 


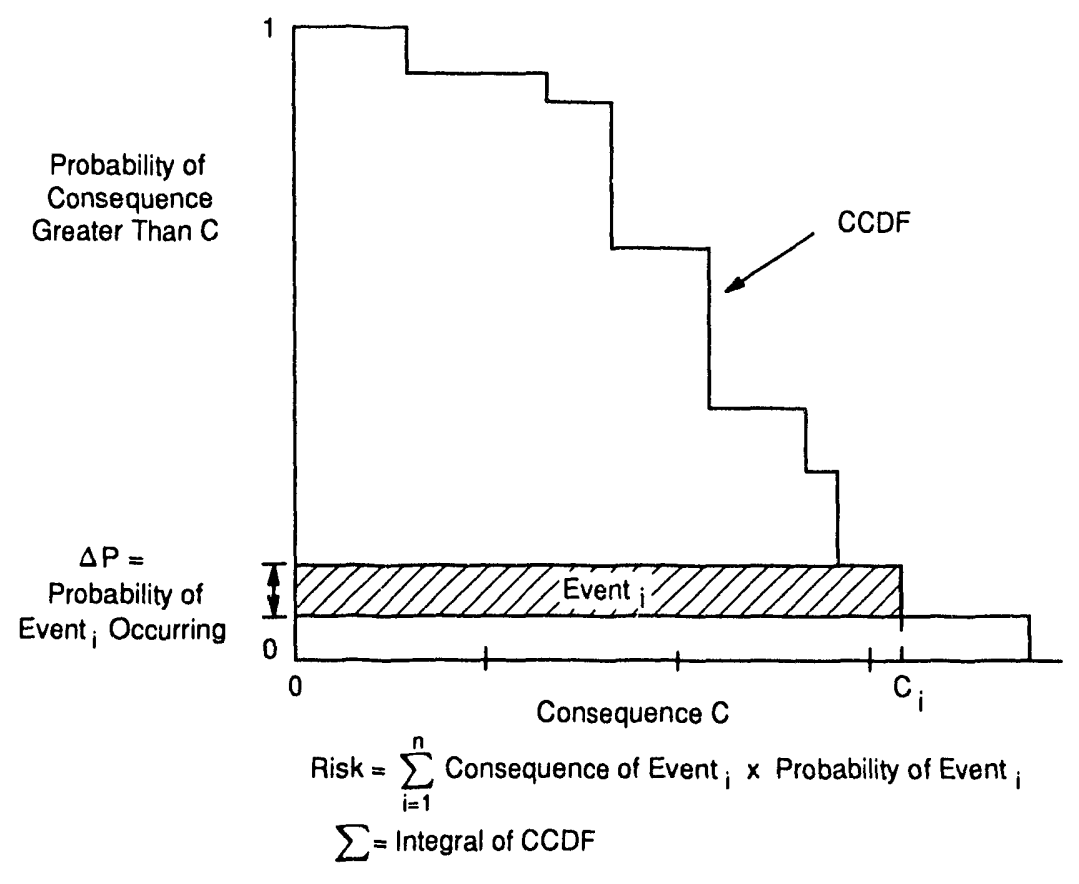

Figure 15. Graphical representation of risk.

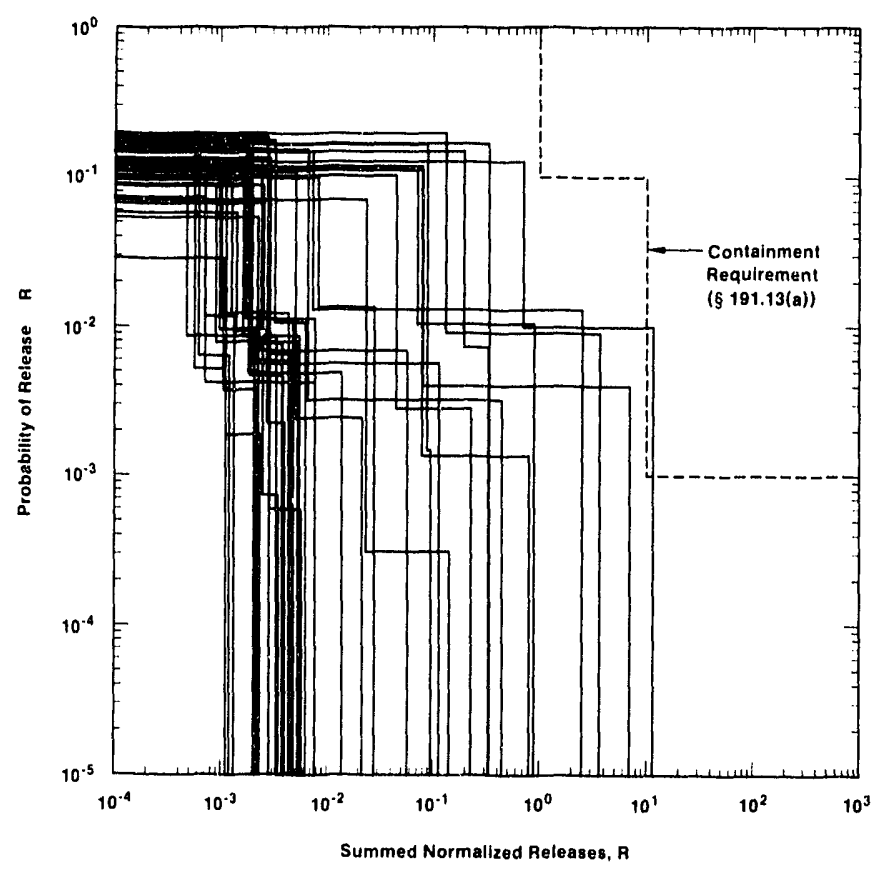

Figure 16. Family of CCDFs generated by Latin hypercube sampling of input parameters. 


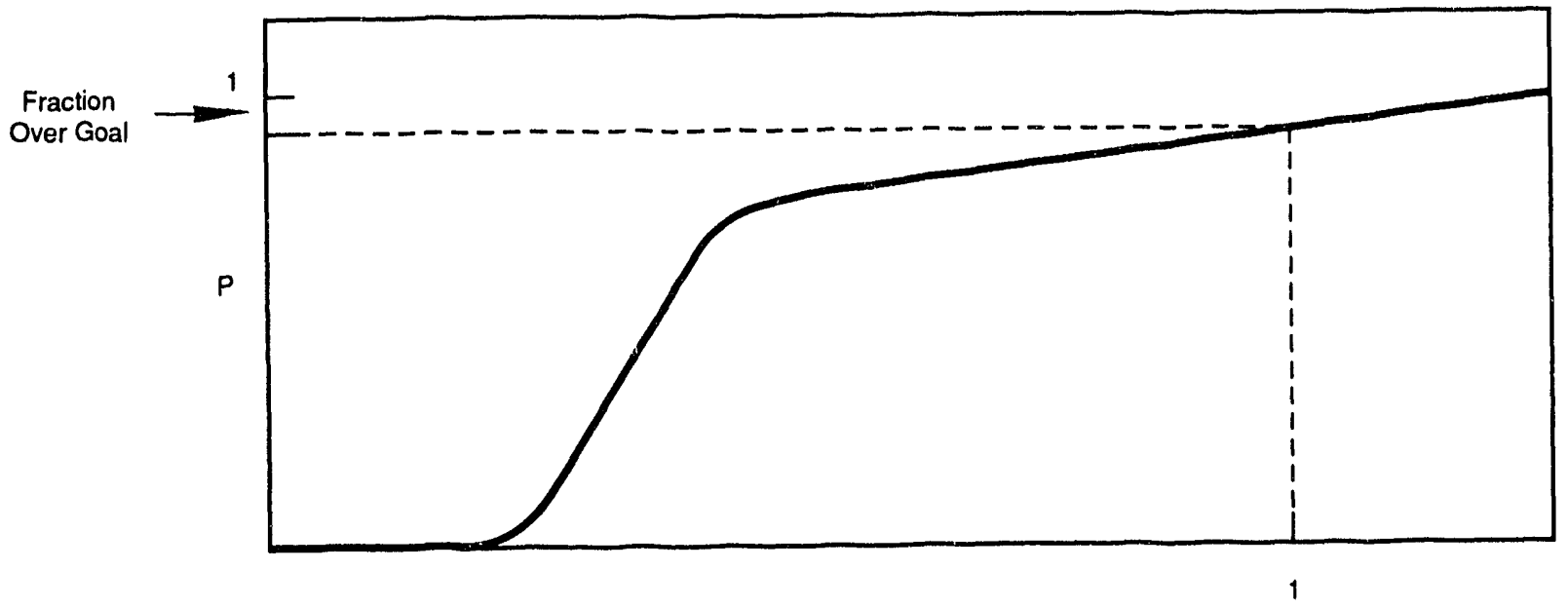

Normalized Risks, Doses, or Releases

TRI-6342-1875-0

Figure 17. CDF of predicted normalized risk, dose, or release showing variability in events, processes, and parameter vaiues.

PA procedures leading up to the normalized release CCDFs would be the same as those required for the present version of 40 CFR 191 . Since the intermediate steps of $\mathrm{PA}$ are usually retained, it would not be a major task to update previous assessments by integrating the CCDFs to produce risk. distributions.

In summary, the modified risk limits require the use of normalized fractional releases to compute a risk CDF. The procedures are similar to those currently being used to compute normalized releases. The risk distribution is defined by integrating release CCDFs for each parameter sample. Some fraction of this distribution could be allowed to exceed the normalized risk goal of one. Characteristics of this approach are:

1. It can be used with risk, dose, or release-limit criteria provided dose and release criteria can be traced to the fundamental-risk criteria.

2. It treats all credible events equally and computes the total risk of the disposal system. However, when unlikely scenarios could contribute significantly to the potential detriment (catastrophic events), information should be presented separately on probabilities, individual doses, and collective doses for consideration in multi-attribute analyses [37].

3. The accuracy requirements for probability estimates depend on the relative risk of the event rather than the probability of the event. 
4. The risk distribution shows the effects of process and parameter variability on predicted risks. Uncertainties can be included in the risk distribution or can be shown as confidence bands [4].

5. This approach requires the same $P A$ as the present containment requirements, plus the integration of the CCDFs. Therefore, there would be no major change in PA and all previous assessments could be utilized.

6. It is the only proposed approach that computes risk from the repositories.

\subsection{Probability/Consequence Limit on System CCDF}

The current containment requirement in 40 CFR 191, section 191.13, is that the cumulative summed normalized releases (R), as defined by Note 6 and Table 1 of Appendix A, cannot exceed 1 for probabilities greater than 10-1 over 10,000 years, and cannot exceed 10 for probabilities greater than $10^{-3}$. Cumulative releases with probabilities less than $10^{-3}$ are not regulated (implied). This unique requirement controls the shape of the release CCDF instead of the area under the curve, which is the measure of system risk. The similar ICRP limit (Figure 14) is used to evaluate disposal system unacceptability based on single, well-defined events and is not intended to evaluate the acceptability of multi-event disposal processes with variations and uncertainties in processes and parameters. Furthermore, the ICRP limit is linear whereas the present standards have arbitrary discontinuities. The relationship of risk to the populace is not a stepped function of consequences and probabilities.

Figure 18 shows the present CCDF limit and a line of constant risk. Only points $A, B$, and $C$ on the CCDF limit represent uniform risk. $D$ is 10 times as restrictive as $A$, and $E$ is 100 times as restrictive as $B$. Cumulative releases with a probability of $10^{-3}$ can be only 10 times higher than those with a probability of 1 , but cumulative releases with a probability slighily less than $10^{-3}$ have no limit. These discontinuities make it necessary to have accurate probability predictions of events and parameters because small changes in estimated probabilities can have a significant effect on the evaluation of compliance. Reference 1 states that the three probability groups are based on groups of expected individual events, not on the cumulative event probabilities used in the requirements and not on safety requirements. Probabilities from $10^{-1}$ to 1 over 10,000 years are expected to represent normal operation and human intrusions, 10-3 to $10^{-1}$ are expected to represent the more likely natural events such as faulting and breccia pipes, and probabilities less than $10^{-3}$ represent 


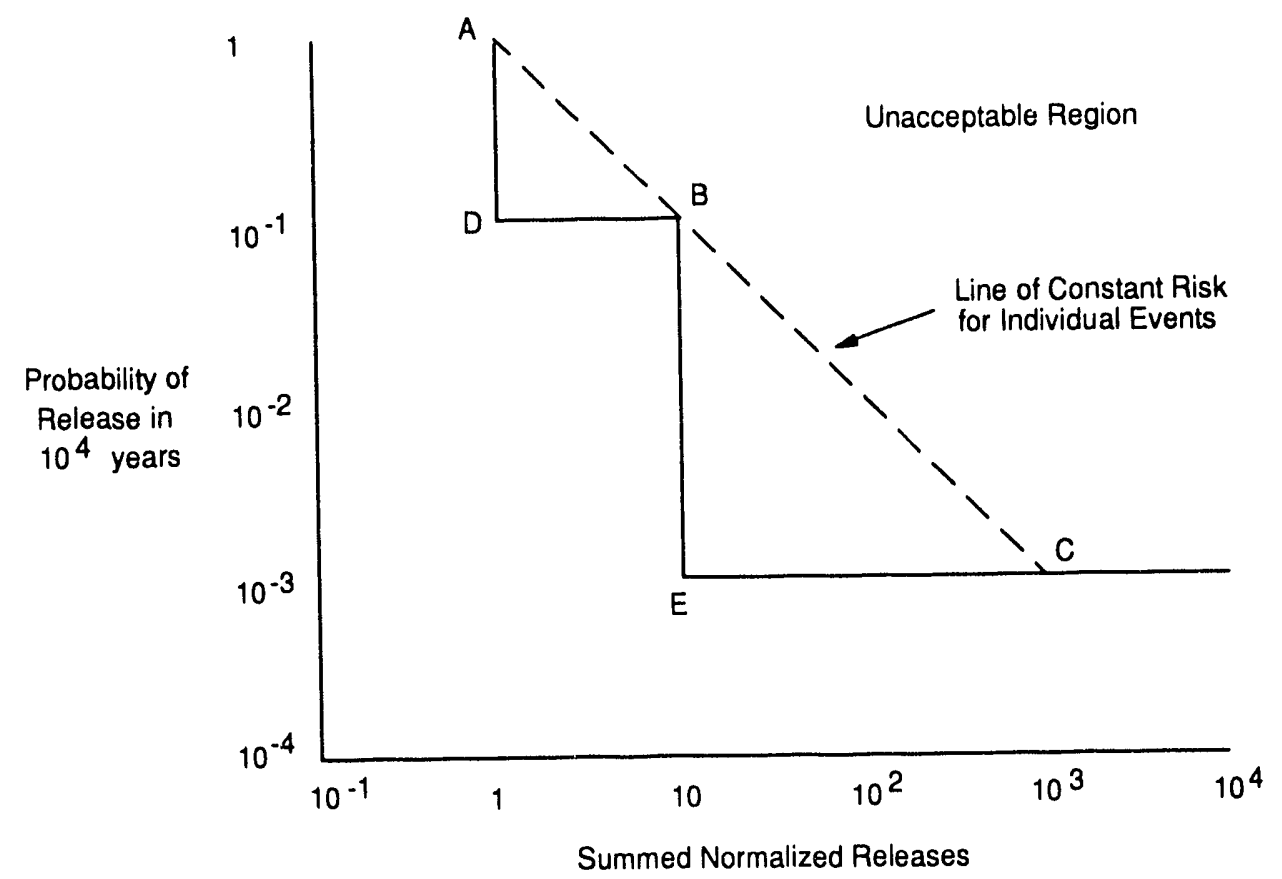

TRIf-6342-7-0

Figure 18. Normalized containment requirements in 40 CFR 191 [Reference 1].

unlikely natural events such as new volcanic activity. The traditional method of grouping requirements simplified assessments when analyses were conducted by hand, but the loss of accuracy is no longer warranted.

The assessments necessary to show compliance with this requirement consist of computing a single CCDF of normalized releases for all events and variations. The repository is in compliance if there is reasonable expectation that the CCDF is below and to the left of the limit. An alternate method consists of computing separate CCDFs for each data set and comparing the mean, median, or some upper standard deviation of the resulting CCDFs to the limit.

No rationale has been given for using this approach: specifically, how this requirement relates to the safety of repositories or to the fundamental criterion, why risk is not evaluated, and what the significance is of the CCDF limit's contour. Since none of these are apparent, a detailed justification for its use is needed. 


\subsection{Hybrid Containment Requirements}

The three-category or "three-bucket" approach was suggested in an attachment to a letter from R.F. Browning (NRC) to R. Guimond (EPA), "Comments on Working Draft No. 2 of EPA's High-Level Waste Standards," dated August 27, 1990, as an alternative to the present containment requirements. The main purpose of this proposed change is to eliminate the need to develop precise numerical probability estimates for very unlikely processes and events. Another reason given for using this approach is that it provides a way of separating human intrusion from anticipated or natural events and evaluating them with deterministic requirements. The NRC and the EPA [16] use different wording to describe this approach.

The proposed requirements for the three categories are defined as follows and are illustrated in Figure 19:

1. Cumulative normalized releases (CCDF) to the accessible environment, of only anticipated processes and events, shall not have a probability of greater than $10^{-1}$ of exceeding the release limit defined by Note 6 and Table 1 of Appendix A of Reference 1. Anticipated is defined by the NRC as natural events that are likely to occur during the period of regulation.

2. The normalized release from any unanticipated credible single process, event, or sequence of processes and events (any process, event, or sequence of processes and events that have probabilities of occurrence less than $10^{-1}$ and greater than $10^{-4}$ as defined by the EPA), shall not exceed ten times the release limit defined by Note 6 and Table 1 of Appendix A of Reference 1. Unanticipated is defined by the NRC as natural events and human intrusion that are unlikely to occur during the period of regulation.

3. Noncredible processes and events with probabilities of occurrence in 10,000 years less than $10^{-4}$ are not regulated and would not be included in PAs.

The requirements have been stated several ways, and there are at least three interpretations of category membership and how this option would be implemented. In addition, there are ambiguities in all versions that need clarification. The following is a brief description of the interpretations and methods of implementation:

1. Category membership in this interpretation is based on the event or process description and a qualitative probability estimate of the event. Category 1 would consist of natural events that are anticipated to occur during the period of intended performance. Category 2 would consist of unanticipated natural events and human actions. All noncredible events would be in category 3 . Human intrusions 


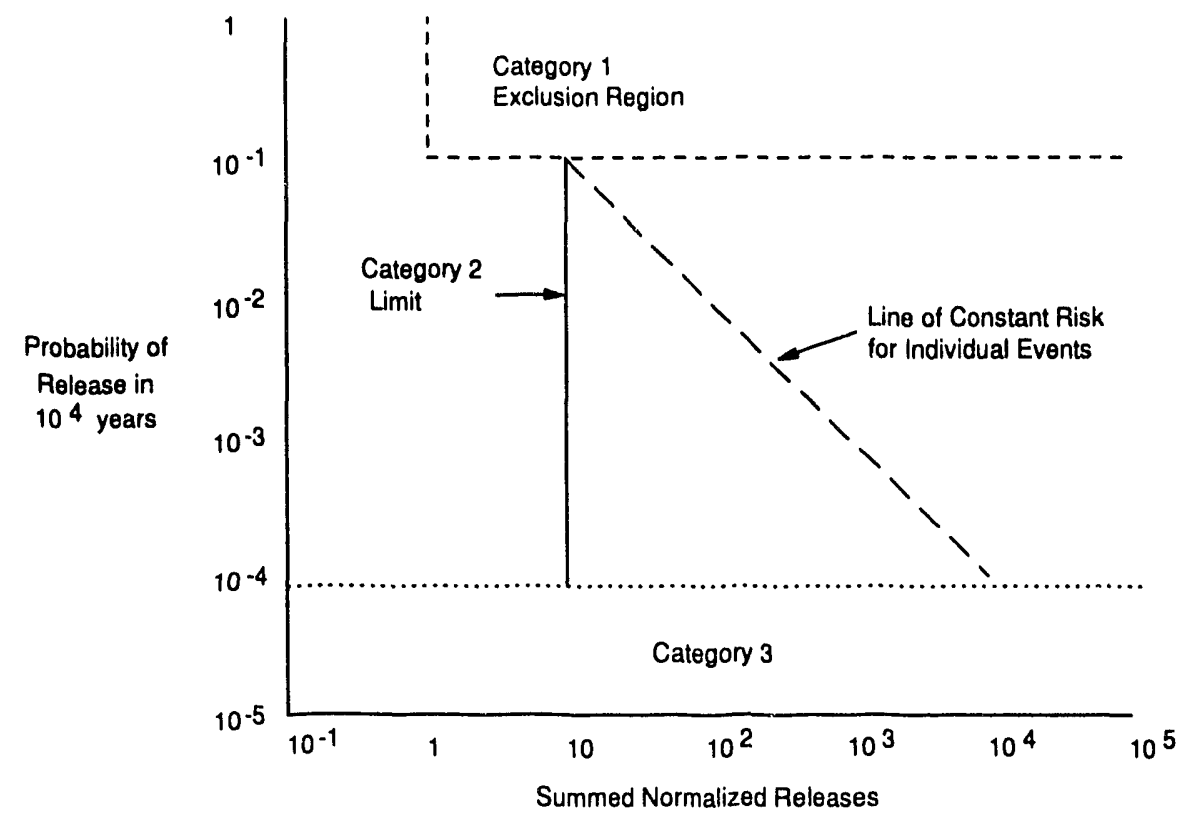

TRII-6342.8.0

Figure 19. Three-category containment requirements.

that have a high probability of occurrence do not seem to be covered by this definition. The implementation procedures for either interpretation 2 or 3 could be used with this definition.

2. Category membership would be based solely on probabilities, and category 2 would control the membership. Any single event or sequence of events with a probability of occurrence between $10^{-4}$ and $10^{-1}$ would be in category 2 , and individual releases could not exceed ten times the release limits. Events with probabilities less than $10^{-4}$ would be in category 3 and would not be regulated. The requirement for category 1 is essentially the same as requirement (a)(1) in Section 191.13 of Reference 47 except for the events that make up the CCDF. In the present standards all credible events are included in the CCDF that is regulated by the containment requirement shown in Figure 18. In this interpretation of the three-category limit, no part of a CCDF consisting of events with probabilities between $10^{-1}$ and 1 (those not in categories 2 and 3 ) could be in the exclusion region shown in Figure 19. This would be an incomplete CCDF with the upper value less than one and conceivably less than the lower level of the exclusion region. 
3. Category membership in this interpretation would be based on probabilities and consequences of the events, and categories 1 and 3 would control the membership. Category 1 would require a CCDF of all events with normalized releases less than one to have a maximum probability of at least 0.9 . This also would be an incomplete CCDF but the upper value would have to be at least as high as the lower value of the exclusion region. This interpretation is inconsistent with the wording in Reference 16. In category 2 the projected releases from individual events with probabilities of occurrence between $10^{-4}$ and $10^{-1}$ cannot exceed ten times the release limits. Some events could be regulated by both categories 1 and 2 . Events with probabilities less than $10^{-4}$ would be in category 3 and would not be regulated.

Some ambiguities and inconsistencies apply to all three interpretations. The probabilities used to define category membership and to generate the category 1 CCDF could be the mean, median, or upper bound of the estimates. The interpretation of "events and sequence of events" could determine their category membership and have a significant effect on compliance. Whenever probabilities of individual events or sequences of events are used, there is the opportunity to subdivide them to decrease probabilities and make compliance easier. Events also could be grouped together to increase probabilities and possibly exclude a safe repository.

The present containment requirements were set to regulate an entire disposal system containing all radionuclides, including all pathways, release modes, events, and scenarios. These same cumulative release or dose requirements cannot be used when the potentially dominant release mechanism is removed from the CCDF and handled deterministically or qualitatively. No new cumulative containment requirements for the CCDF have been proposed.

This approach has some problems that must be resolved before it could replace the present containment requirements. The system CCDF in category 1 would be incomplete, and the upper level would always be less than one. Comparison of an incomplete CCDF to a risk limit that was defined for complete CCDFs, made up of all events, would be inappropriate. The upper level of this incomplete system CCDF also would be different for each repository, making the requirement inconsistent. One partial solution would be to normalize the incomplete system CCDF so that it would be complete for anticipated events. The requirement would still be inconsistent, and it would not be traceable to the fundamental standard that applies to the entire disposal system, not just to some events. If all events were included in the category 1 CCDF to make it complete, the need for precise probability estimates would be the same as the present approach. 
The goal of eliminating the need for precise probability estimates for unanticipated processes and events is only pariially fulfilled. Probability estimates of unanticipated events in the middle of the category 2 probability range could be off by as much as 1.5 orders of magnitude without affecting the assessment. The accuracy requirements of the probability estimates increase as the actual probabilities of the events approach either of the category 2 boundaries. If the estimates are not very precise in the $10^{-1}$ and 10-4 probability ranges, the event could be placed in the wrong category, resulting in an erroneous evaluation. As an example, an event just above the lower probability limit would have to comply with the same requirements as an event with a probability of $10^{-1}$, but an event just below the lower limit would not even be regulated.

Another problem is the nonuniformity of category 2. This requirement is analogous to the ICRP risk limit (Figure 14) in the function of eliminating options that have a single event that exceeds the limit. As can be seen in Figure 19, the proposed requirement is 1000 times as restrictive for events with probabilities of $10^{-4}$ as for events with probabilities of $10^{-1}$. This nonuniformity could be eliminated by using the line of constant risk in Figure 19 as the category 2 limit. This would be the same as the ICRP approach. The accuracy requirements for probability estimates would be uniform for the entire category.

The three-category approach may not achieve its potential advantage of separating human intrusion from other phenomena. There is no assurance that human intrusion will be in category 2 if the category definition is based on probabilities. For some repositories, the only credible releases in 10,000 years would be from human intrusion, or human intrusion would be the dominant release mechanism with a probability greater than $10^{-1}$. Human intrusion would definitely be in category 1 for these repositories.

Implementation of this approach is straightforward and would require few procedure changes. All data acquisition, process modeling, nuclide-transport analyses, scenario development, and release analyses would remain the same. Only compliance evaluation, which is the final step of the analysis, would be changed. The credible events would be divided into two categories, a CCDF of the anticipated events would be generated and compared to the category 1 limits, and the unanticipated events would be compared event-by-event to the category 2 limit. The definition of noncredible individual events for category 3 is in the range recommended by the ICRP and is the value currently being used in PAs.

It has been claimed that the three-category approach may simplify licensing or permitting of repositories, but this may not be the case. The concept and some definitions need clarification, and some modifications are 
needed to reduce inconsistencies and nonuniformities before it can be used. The most difficult task will be to show how categories 1 and 2 fulfill the total system risk requirements of the fundamental criterion.

\subsection{Evaluatic.. of Options}

There are significant differences in the degree of definition and in the rationale for using each of the three options, and these differences limit comparisons. Table 10 contains some of their characteristics that can be compared. In the present form of the options, the modified risk limit is the most uniform, consistent, and justifiable. It is the only option that is a direct measure of risk and is traceable to the fundamental criterion. If either of the other two options is selected, the requirements should be stated more precisely, and a detailed explanation is needed of how it relates to the safety of repositories and to the fundamental risk criterion.

Neither of the two alternatives to the present containment requirements would require significant development or changes in PA procedures. Both could utilize the results of previous assessments. 
Table 10. Characteristics of Containment Requirement Options

\begin{tabular}{|c|c|c|c|}
\hline \multirow[b]{2}{*}{ Characteristic } & \multicolumn{3}{|c|}{ Option } \\
\hline & $\begin{array}{l}\text { Modified } \\
\text { Risk Limit }\end{array}$ & $\begin{array}{c}\text { Present } \\
\text { Limit on } \\
\text { System CCDF }\end{array}$ & $\begin{array}{l}\text { Three- } \\
\text { Category } \\
\text { Limit }\end{array}$ \\
\hline $\begin{array}{l}\text { Changes in } \\
\text { implementation and } \\
\text { PA }\end{array}$ & Minor & None & Minor \\
\hline $\begin{array}{l}\text { Probability } \\
\text { accuracy } \\
\text { requirements }\end{array}$ & $\begin{array}{l}\text { Relative to } \\
\text { risk of } \\
\text { event }\end{array}$ & Uniform & Nonuniform \\
\hline $\begin{array}{l}\text { Separates natural } \\
\text { events from human } \\
\text { intrusion }\end{array}$ & No & No & $\begin{array}{l}\text { Depends on } \\
\text { category } 2 \\
\text { definition }\end{array}$ \\
\hline $\begin{array}{l}\text { Traceable to } \\
\text { fundamental } \\
\text { criterion }\end{array}$ & Yes & No & No \\
\hline Measure of risk & Yes & No & No \\
\hline $\begin{array}{l}\text { Applicable to dose- } \\
\text { and release-limit } \\
\text { criteria }\end{array}$ & Yes & Yes & Yes \\
\hline $\begin{array}{l}\text { Uniform evaluation } \\
\text { of all events and } \\
\text { repositories }\end{array}$ & Yes & No & No \\
\hline
\end{tabular}




\section{CRITERIA FOR TRANSURANIC-WASTE DISPOSAL}

Since 40 CFR 191 was not developed as an integrated system, it contains many provisions and constraints that prevent effective modifications and additions, such as criteria for TRU-waste disposal. Although far from ideal, the following are the only feasible options that have been suggested for regulating TRU-waste disposal. The options are: two types of fundamental criterion developed specifically for TRU waste [4,50], and a family of procedures that use a TRU-waste reference unit with commercial HLW criteria $[1,4,50]$. This chapter compares these options. Background information pertinent to both options is covered in the following sections on the functions of fundamental criteria, and a description of the HLW fundamental criterion and release limits presently in 40 CFR 191. The section on criteria specifically for TRU waste suggests a niethodology for developing or adapting fundamental and derived criteria that are consistent with all other aspects of the standards. The section on TRU-waste reference units covers all the parameter variations that have been suggested for this option. The technical bases of each approach are reviewed, implementation is discussed, and their relative attributes and deficiencies are evaluated.

TRU-waste repositories will contain some radioactive wastes that are not officially classified as transuranic waste. Actinides and daughters of short-lived transuranics can be a significant part of the risk potential. Since all radionuclides constitute a potential risk, the standards for TRUwaste repositories should be based on and apply to all radionuclides in the inventories.

\subsection{Fundamental Criteria}

Fundamental criteria (Level 1) are the only standards that explicitly define the radiological safety requirements of the repositories. Level 1 criteria control risks to the populace, have a significant effect on the cost of repositories, and are the basis for other levels of radiological criteria. To have any radiological-risk significance, all other levels of criteria must be traceable to an appropriate fundamental criterion [4]. The position of the NEA is

The general risk limit should be considered as the lower boundary of a region of unacceptable risks rather than as the upper demarcation of a region of unchallenged acceptability. Therefore, the level at which these objectives are set should be based as far as possible on a scientific assessment of risk in relation to well established radiation protection standards. Where exposures could arise from various sources, there will be a need to take this into account by an apportionment of the general limit [37]. 
Appropriate fundamental criteria are needed for all repositories and for each waste category. These criteria should be based on established principles and set at the lower boundary of unacceptable risk. The regulatory philosophy for any fundamental criteria that is added to 40 CFR 191 should be consistent with that of the HLW fundamental criterion, and it should be compatible with existing release limits.

\subsubsection{HLW Fundamental and Derived Criteria in 40 CFR 191}

The present fundamental criterion for HLW and spent fuel (SF) allows no more than 1000 premature cancer deaths over the first 10,000 years from disposal of the wastes from 100,000 metric tons of reactor fuel (average of 10-6 HE/MTHM-yr). This is a risk/benefit criterion that allows the risk from waste disposal to be proportional to the amount of power generated. Power is equated to the amount of fuel used to generate the power (MTHM) for convenience of analyses. It is also based on collective world-population risk over the 10,000-year period of regulation with no constraints on population-risk rates. Derived standards for HLW must follow this format. The HLW release limits were derived by computing risk factors (fatal cancers per curie released) for each radionuclide for several release modes [19]. The fundamental criterion was divided by each of these risk factors to produce a table containing release limits for each radionuclide [17], which is compatible with the risk/benefit fundamental criterion for collective population risk.

The allowable risk level for HLW disposal was based on predicted capabilities of the HLW reference repository in several geologic media instead of the lower bound of unacceptable risk. This accounts for the high level of stringency compared with standards for other carcinogens. The 100,000-MTHM size of the reference repository was selected because it was the estimated cumulative inventory by the year 2000 [51]. Reference 1 states this is the quantity of existing U.S. HLW plus the future wastes from all currently operating U.S. reactors. There has never been a clear and consistent statement of the basis or rationale for the HLW fundamental criterion, nor has it been shown that it assures an acceptable level of risk to the populace. TRU waste was not considered in the development of this fundamental standard, and therefore it does not apply to TRU-waste disposal.

\subsubsection{Fundamental and Derived Standards for TRU-Waste Disposal}

The present version of 40 CFR 191 contains no fundamental criteria for TRU-waste disposal, and no safety requirements have been established that apply to TRU waste. This may be the only major waste-disposal process without a fundamental safety requirement. Military TRU waste is not associated with commercial reactor fuel, does not have a unit comparable to a 
MTHM of fuel, and does not have a comparable risk/benefit relationship. These TRU-waste characteristics preclude direct application of the HLW fundamental criterion, but a fundamental criterion can be developed specifically for TRU-waste disposal.

One approach would be to develop a fundamental criterion for TRU waste based on acceptable risk to the populace and the expected quantity of TRU waste. This is the general approach recommended by the ICRP and the NEA $[5,37]$. Assuming collective population risks will continue to be used as the basis for the fundamental criteria and derived release limits will be used to show compliance in 40 CFR 191, neither the recommended ICRP standards nor the EPA standards for chemical carcinogens could be used for TRU waste. The ICRP fundamental standards are based on a peak individual risk rate, which is not compatible with collective risks or release limits. The standards for chemical carcinogens are based on individual risks as a function of the number of people at risk. This method is aiso incompatible. Since there is no quantifiable benefit associated with military TRU waste, the EPA would have to develop a new absolute collective risk limit. This TRU-waste fundamental criterion would be completely independent of the HLW fundamental criterion and based solely on expected quantities of TRU waste and acceptable levels of risk. One difficulty with an absolute TRU-waste criterion is the uncertainty in predicting the total quantity of TRU waste that will be generated, which is needed to allocate a risk for each repository. New release limits would also have to be developed based on the absolute TRUwaste fundamental criterion. Developing the new absolute collective-risk limit, agreeing on the total future TRU-waste inventory, and developing new release limits could be a very time-consuming process. There also would be some inconsistencies in regulatory philosophy between the risk/benefit HLW criteria and an absolute TRU-waste criterion, and these differences would have to be justified. It is probably not practical to develop this form of fundamental criteria for TRU-waste disposal at this time.

Another approach would be to develop a TRU-waste fundamental criterion that is related to the allowable risk for HLW repositories. There is a straightforward and simple method of developing a TRU-waste fundamental criterion using rationale and analyses that are parallel to those used by the EPA to develup the HLW standards $[17,19]$. No new release limits would be needed, and it would be compatible with the HLW criteria and all other requirements in $40 \mathrm{CFR}$ 191. Although this TRU-waste fundamental would not be a true risk/benefit criterion, the allowable risk would be scaled relative to repository size, making the TRU-waste allowable risk units comparable to those of HLW. This would allow either single-mode or multimode HLW release limits to be used for TRU waste with no changes or additions. 
One justification used by the EPA for the level of the HLW fundamental risk criterion was that it assures adequate protection for the EPA's HLW reference repository $(100,000 \mathrm{MTHM})$. The reference repository was used in derivations [17] and in comparison studies of waste-disposal systems and undisturbed ore bodies $[1,52]$. It should then be acceptable to establish a TRU-waste reference repository and equate the risk to that of the HLW reference repository. With this risk level as the basis, the only task remaining would be to define the size of the TRU-waste reference repository.

The EPA based the size of the HLW reference repository on the expected inventory in the year 2000, including all existing HLW and projected waste from then-operating reactors. A consistent size for a TRU-waste reference repository could be defined using the same guidelines. The Integrated Data Base for 1991 [53] lists the total known remotely handled (RH) and contacthandled (CH) TRU waste in the year 2000 as $9.8 \mathrm{MCi}$. This value is $14.3 \mathrm{MCi}$ in 2013, which is the last year 1isted. Following the rationale used to select the size of the HLW reference repository, a conservative size for the TRU-waste reference repository would be $20 \mathrm{MCi}$ including $\mathrm{RH}$ and $\mathrm{CH}$ waste. Given the conservatism built into the HLW criteria, this size would give the TRU-waste reference repository a very conservative allowable risk. The allowable risk for either the HLW or TRU-waste reference repository would then be 1000 premature cancer deaths over the first 10,000 years for an average of 1 premature death every 10 years. The allowable risk for smalier TRU-waste repositories, such as the WIPP, would be scaled down proportional to their size relative to the reference repository.

The size of the proposed TRU-waste reference repository is based on current inventory predictions. If larger quantities of TRU waste are generated because of changes in waste-management strategy such as decommissioning and decontamination of DOE facilities, the size of the TRUwaste reference repository could be increased. However, there is 0 parallel provision in the HLW criterion that would increase the size of the HLW reference repository if new reactors are built or new sources of Hhb arise.

If this approach is adopted, no new release limits would have to be derived. The risk factors used to derive the release limits were computed for individual radionuclides and apply to any inven ory or was category. Presently the HLW fundamental criterion and dose limiry in Wring Draft 4 of 40 CFR 191 [41] are based on 100,000 MTHM, but the re1ens litits are based on 1000 MTHM. The standards would be more consistent and itsis scaling would be required if the 100,000 MTHM for HLW (20 MCi for TRU waste) base is used throughout the standards. Scaling the release limits to different size TRUwaste repositories could be the same as the method defined in the present version of 40 CFR 191. Release limits for both HLW and TRU-waste repositories would be the values in a 100,000 MTHM (20 MCi) based release- 
limit table, multiplied by the ratio of repository size to the reference repository size. For example, for a TRU-waste repository with an inventory of $5 \mathrm{MCi}$ and a TRU-waste reference repository of $20 \mathrm{MCi}$, the release limits applicable to the repository would be $5 / 20$, or one-fourth the values in the release-limit table. The purpose of this scaling is to prevent compliance by using the strategy of making repositories small instead of well designed.

The characteristics of this approach to TRU-waste disposal regulations are :

1. It is based on repository safety and applies equally to all release modes, all repositories, all inventories, and at all times.

2. It uses the same format and regulatory philosophy as the HLW standards, so additional justification is not needed.

3. It is completely compatible with other aspects of the standards.

4. No new derivations are required.

5. There is no need for a quasi-equivalent TRU-waste unit.

6. It is as conservative and defensible as the HLW standard.

7. Repository risks can be computed because the release limits are traceable to a fundamental criterion.

The parallelism of TRU-waste and HLW criteria with this approach is shown in Table 11.

This is definitely not an endorsement of the present HLW fundamental criterion. If the HLW fundamental criterion is improved, a combined HLW/TRUwaste criterion should be considered, or the same new procedure should be used to develop both the HLW and TRU-waste fundamental criteria.

\subsection{TRU-Waste Reference Úrits}

The present version of 40 CFR 191 contains no fundamental criterion or safety requirements that apply to TRU waste. Instead, TRU-waste repositories are evaluated using $\mathrm{HLW} / \mathrm{SF}$ criteria and a TRU-waste unit ( $1 \mathrm{MCi}$ ) that is "equivalent" to $1000 \mathrm{MTHM}$ of commercial HLW.

A whole family of quasi-equivalent TRU-waste units has been suggested for use with the regulations developed for HLW disposal. These include the 
Table 11. Features of HLW and TRU-Waste Criteria When Parallel Development of the Fundamental Criterion Is Used

\section{Waste Type}

\begin{tabular}{|c|c|c|}
\hline \multirow[b]{2}{*}{ Feature } & \multirow[b]{2}{*}{$\mathrm{HLW} / \mathrm{SF}$} & \multirow[b]{2}{*}{ TRU Waste } \\
\hline & & \\
\hline $\begin{array}{l}\text { Maximum deaths from the } \\
\text { reference repository in } \\
10,000 \text { years }\end{array}$ & 1000 & 1000 \\
\hline $\begin{array}{l}\text { Basis for reference } \\
\text { repository size }\end{array}$ & $\begin{array}{l}\text { Cumulative inventory } \\
\text { by year } 2000 \text { [51], } \\
\text { waste from currently } \\
\text { operating reactors [1] } \\
100,000 \text { MTHM }\end{array}$ & $\begin{array}{l}\text { Cumulative inventory } \\
\text { by year } 2013 \text { from [ } 53 \text { ] } \\
\text { existing facilities, } \\
\text { rounded up to } 20 \mathrm{MCi}\end{array}$ \\
\hline $\begin{array}{l}\text { Fundamental } \\
\text { Criterion }\end{array}$ & $\begin{array}{l}\text { Deaths per } 10,000 \\
\text { years/Reference } \\
\text { repository size }\end{array}$ & $\begin{array}{l}\text { Deaths per } 10,000 \\
\text { years/Reference } \\
\text { repository size }\end{array}$ \\
\hline Release limit values & 40 CFR 191, Table 1 & 40 CFR 191, Table 1 \\
\hline $\begin{array}{l}\text { Scaling factor for } \\
\text { release limits }\end{array}$ & $\begin{array}{l}\text { Actual repository } \\
\text { size/Reference } \\
\text { repository size }\end{array}$ & $\begin{array}{l}\text { Actual repository } \\
\text { size/Reference } \\
\text { repository size }\end{array}$ \\
\hline
\end{tabular}

one that is presently in 40 CFR 191. Combinations of four or five groups of parameters could be used to compute the quasi-equivalent TRU-waste unit, with varying degrees of realism. These parameter groups are:

1. Reference HLW inventory-Reprocessed high-level waste, spent fuel, or some average.

2. Included nuclides-All radionuclides in the inventories or only actinides with half-lives greater than 20 years.

3. Time-Initial, averaged over the time of regulation, or end of the regulatory period.

4. Metric-Risk potential, untreated dilution index, or activity.

If the risk-potential metric is selected, the release-mode parameters-rivers, oceans, withdrawal wells, land, and atmosphere-also would be included. There is also variability in the HLW/SF reference inventories and the TRU-waste inventories that are equated. Sample analyses of 20 of the possible 126 combinations have shown that these TRU-waste 
reference units could vary by at least a factor of 1200 depending on the parameters selected. This large spread makes the selection of parameters difficult to justify. None of these parameter combinations produce a true equivalent unit, and subjective judgment must be used in the selection of the best combination. Any of the TRU-waste reference units can be equivalent to only one HLW or SF inventory, at a single time, for one repository, and for only one metric that is not proportional to actual risk. A clear statement of the basis for equating waste units, including substantiated reasons for the selection, would be required.

The parameters selected from each parameter group affect the value of the waste reference unit. In the following discussion of two of the 126 combinations, the effects of each parameter will be discussed separately, but the effects of all parameters must all be viewed together to see the net result.

One of the above combinations was used to compute the TRU-waste reference unit presently in the standards. Initial activities of the actinides with half-lives greater than 20 years in a TRU-waste reference inventory were equated to those in a 1000-MTHM HLW reference inventory. This quasi-equivalent TRU-waste unit was computed to be $3 \mathrm{MCi}$, which was rounded to $1 \mathrm{MCi}$ in the standards.

Appendix A of 40 CFR 191 limits the summed normalized release fractions of both transuranics and fission products. Risk and performance assessments [54,55] have shown that releases and doses from undisturbed HLW repositories during the first 10,000 years would be completely dominated by the more mobile fission products (Tc-99, I-129, Se-79, C-14, etc.), with almost no contribution from transuranics. Since the radionuclides in the summed normalized release from HLW repositories are almost entirely fission products and those from TRU-waste repositories are almost entirely transuranics, this aspect of the present regulations requires a higher degree of control and higher retention fraction of transuranics in a HLW repository than in a TRUwaste repository.

Another inconsistency arises from the selection of initial activities as the parameter that was equated for the two types of waste. Most of the releases and risks come near the end of the regulation period, not the beginning. Using the initial value of any parameter for equating risk potentials would not typify actual releases to the environment. Also, the risk from each radionuclide depends on the dose-equivalent weighting factor, pathways to humans, and risk attenuation of the entire disposal system [2], not just the actirity of the nuclide. 
Reference 4 suggests a combination of parameters that partially rectifies some of the problems with the present TRU-waste reference unit. An approximation to the risk potential was chosen as the metric for equating the entire inventory of a TRU-waste reference inventory to an average HLW/SF reference inventory. The time-varying risk potential was approximated by multiplying the activity of each radionuclide by the risk factors (cancers per curie) for surface-water release given in Table 7.8-1 of Reference 1?. This accounts for nuclide-transport pathways from a generic river to human.s and resulting biological effects but does not include the risk attenuation between the repository and the river, which is assumed to be the release location. This risk potential is both unsuitable and incomplete for computing an equivalent waste unit. Actual release modes of planned repositories include atmospheric, land, and wells-not surface water [29]. It is incomplete because risk attenuation between the repositories and release locations is not included and is different for each repository, each release scenario, and each radionuclide, so actual risk potentials would not be comparable to the risk potential used in this analysis, and risk potential ratios between repositories would be far from uniform. The inappropriateness could be eliminated by using the five risk potentials from the multimode release-limit derivation. However, this would result in five different equivalent TRU-waste units, one that is appropriate for each release mode, and they would still be derived with incomplete risk factors.

These approximate risk potentials for both the HLW and TRU-waste inventories were then integrated over the time of regulation. Actual risks could occur any time, but a time-averaged value is a better representation than the initial value. The resulting average risk potentials were equated to define a TRU-waste reference unit. This quasi-equivalent TRU-waste unit was computed to be $8.1 \mathrm{MCi}$. The same analysis was later repeated by other investigators using different pairs of $\mathrm{HLW}$ and TRU-waste inventories [56,57], which made their results slightly different, as expected.

Although this time-averaged parameter combination appears to be more logical and appropriate than the method used to derive the present TRU-waste standards, it does not produce a TRU-waste unit with the same risk as the HLW unit. The ability to equate risks could be worse than the present "equivalent" TRU-waste unit for some repositories and scenarios. The problem is not in the combination of parameters selected or the method of analysis. The entire concept of trying to equate risks by matching repository-component parameters, using specific inventories, at specific times is unsound. No generic equivalencies between any waste categories apply uniformly to all repository designs and locations, to all inventories, and at all times. The variability and inconsistency of this approach can be illustrated with the following parametric example. All the cases used the previously described risk potentials as the metric. Only two release modes (river and land) were 
analyzed. The inventory pairs were SF and reprocessed HLW, equated to a single TRU-waste inventory. All radionuclides in the inventories were included in the analyses. The TRU-waste and HLW risk potentials were equated at times 0 and 10,000 years and averaged over the 10,000-year duration. The results are shown in Table 12. The variability is demonstrated by the factor of 485 separating the highest and lowest "equivalent" TRU-waste units. The variability with time of evaluation can be a factor of 261, with waste form a factor of 43, and with release mode a factor of 17 . There are also interactions between parameters. Variations with time range from 1.96 to 261 depending on the waste form and release mode selected. Similarly, variations with waste form range from 1.05 to 43 and variations with release mode range from 1.07 to 17.4 .

Table 12. Examples of TRU-Waste Units (MCi) That Are "Equivalent" to 1000 MTHM HLW Based on Risk-Potential Metrics

\begin{tabular}{ccccc}
\hline $\begin{array}{c}\text { Reference } \\
\text { HLW }\end{array}$ & $\begin{array}{c}\text { Release } \\
\text { Mode }\end{array}$ & $\begin{array}{c}\text { Initial } \\
\text { Time }\end{array}$ & $\begin{array}{c}10,000-\mathrm{Yr} \\
\text { Average }\end{array}$ & $\begin{array}{c}10,000 \\
\text { Yrs }\end{array}$ \\
\hline Spent Fuel & River & 63 & 12. & 6.0 \\
Spent Fuel & Land & 11. & 6.9 & 5.6 \\
Reprocessed HLW & River & 60. & 4.0 & 0.23 \\
Reprocessed HLW & Land & 5.3 & 0.23 & 0.13 \\
\hline
\end{tabular}

All quasi-equivalent TRU-waste units would make the acceptable risk proportional to the amount of waste placed in a repository, similar to the HLW criteria. However, none of these TRU-waste reference units equate repository risks, and there would be no rationale for using the HLW/SF criterion. There would still be no fundamental safety criterion for TRU waste.

\subsection{Evaluation of the Options}

The three basic options for regulation of TRU-waste disposal are so different that there can only be a limited characteristic-by-characteristic comparison. These are compared in Table 13. The remaining characteristics are summarized separately. 
TRU-waste fundamental criteria could be related to the allowable risk from a HLW repository or could be completely independent of the HLW fundamental criterion. Either method of developing separate fundamental standards for TRU waste would base them on repository safety and acceptable risk. Both methods would apply to all release modes and all repositories, would scale with repository size, and would apply any time during the regulatory period. This allows easy computations of repository risk from release analyses. The method that equates the allowable risk from the TRU-waste reference repository to the risk from the HLW reference repository would require no new derivations of risk criteria or release limits and is more compatible wi $h$ HLW criteria and other requirements in the standards. It would be as conservative and defensible as the HLW standards. The method that develops an independent absolute-risk limit for TRU-waste disposal would require the derivation of a new fundamental criterion and new derived release limits. It would be at least as defensible as the HLW standards.

A TRU-waste repository-risk limit is not used by the family of TRU-waste reference units. Instead, several combinations of parameters are used to equate MCi units of TRU waste to MTHM units of HLW. HLW criteria are then used to evaluate TRU-waste repositories. All the quasi-equivalent TRU-waste units scale with repository size and are compatible with HLW criteria and other requirements in the standards. However, collective risk is not evaluated or equated to HLW risk. Other parameters that do not scale linearly to risk are equated at a single time during the regulation period or the average is equated over a specified time interval. The reference units can differ by factors of at least 525 depending on the combination of parameters selected. It would be difficult to justify the selection of any parameter combination and to rationalize the use of any waste reference unit. Protection provided by TRU-waste reference units is far from uniform. It is different for each repository, scenario, pathway, release mode, and inventory. The present standards give no rationale for using this method of regulating TRU-waste disposal or for equating the initial activity of only some radionuclides. If this method of regulation is retained, a detailed explanation of how it assures repository safety is needed. Development time would be insignificant even if a different combination of parameters is selected.

In addition to the technical arguments concerning uniformity, appropriateness, and defensibility, it is also useful to put the risks allowed by each regulatory option in perspective. References 10 and 11 reviewed and analyzed U.S. regulations governing exposure to environmental carcinogens, which were promulgated by several regulating agencies. Both found a high degree of consistency in the agencies' implicit definition of de minimis levels of lifetime individual risk as a function of the population size at risk. Using the results of their studies, the total de minimis risks 
Table 13. Characteristics of TRU-Waste Criteria Options

Option

\begin{tabular}{|c|c|c|c|}
\hline Characteristic & $\begin{array}{l}\text { TRU-Waste } \\
\text { Absolute } \\
\text { Fundamental } \\
\text { Criterion }\end{array}$ & $\begin{array}{c}\text { TRU-Waste Fundamental } \\
\text { Criterion Parallel to } \\
\text { HLW Criterion }\end{array}$ & $\begin{array}{l}\text { TRU-Waste } \\
\text { Reference Unit }\end{array}$ \\
\hline $\begin{array}{l}\text { Based on } \\
\text { acceptable risk }\end{array}$ & Yes & Similar to HLW & No \\
\hline $\begin{array}{l}\text { Derivation } \\
\text { uniform for all } \\
\text { repositories and } \\
\text { scenarios }\end{array}$ & Yes & Yes & No \\
\hline Defensible & Yes & Partially & No \\
\hline $\begin{array}{l}\text { Scales to } \\
\text { repository size }\end{array}$ & Yes & Yes & Yes \\
\hline $\begin{array}{l}\text { New derivations } \\
\text { required }\end{array}$ & Major & None & None or minor \\
\hline $\begin{array}{l}\text { Follows } 40 \text { CFR } 191 \\
\text { format }\end{array}$ & No & Yes & Yes \\
\hline $\begin{array}{l}\text { Uses HLW release } \\
\text { limits }\end{array}$ & No & Yes & Yes \\
\hline
\end{tabular}

from a carcinogen over a 10,000-year period were computed for three population sizes significant to the WIPP. If the carcinogen placed the entire U.S. population at risk, the de minimis number of premature cancer deaths would be 26,000 for 10,000 years. If only the population of New Mexico were at risk, the de minimis level would be 2570 premature deaths. If only the residents of Eddy County, where the WIPP is located and where any human intrusion and well-water withdrawal would take place, were at risk, the de minimis level would be 514 premature deaths.

The projected total inventory for the WIPP used in the 1991 WIPP PA, including all radionuclides of both $\mathrm{CH}$ and $\mathrm{RH}$ waste, was $11.1 \mathrm{MCi}$ [36]. More 
recent inventories given in the draft report, "The Radionuclide Inventory for the Waste Isolation Pilot Plant," DOE/WIPP 91-058, by H. M. Batchelder, define the total WIPP inventory to be $7.7 \mathrm{MCi}$. It is unlikely that any future TRU-waste repository would be more than twice the size of the WIPP because of geologic limitations. Table 14 lists the allowable premature cancer deaths for HLW repositories and TRU-waste repositories using the most recent inventories, with requirements based on a fundamental criterion and on waste reference units. It compares the WIPP requirements to the de minimis risk level if all the risk were confined to Eddy County. The 8.1-MCi equivalent TRU-waste unit would allow the WIPP to have only one percent of the risk allowed for the YMP, and the risk level would be a factor of 50 lower than de minimis. The TRU-waste fundamental criterion also would be conservative, but the level of protection would be more realistic.

Table 14 shows the allowable risks that are computed using methods prescribed in the standards. Actual risks would be orders of magnitude lower because of the present conservatism in the release limits used for human intrusion, the absence of aquifer risk attenuation for the well, river, and ocean release modes, and the conservatism in the stepped containment requirements. Also, actual releases from repositories would be far below the limits for most scenarios.

In establishing the TRU-waste reference repository, the size could be increased to $60-\mathrm{MCi}$ to accommodate projected waste inventories produced by decommissioning of DOE facilities. This would be equivalent to eight WIPP repositories. The factor of three increase in the base for the TRU-waste fundamental criterion would decrease the allowable risk for any given TRUwaste repository by a factor of three. The HLW criteria do not have this flexibility to account for changes in expected inventories, so the option to change to a $60-\mathrm{MCi}$ TRU-waste reference repository could create an inconsistency in the standards.

Figure 20 shows another way to put the alternate TRU-waste criteria in perspective. The bar graph compares the amount of TRU waste that would be required to produce the same $\mathrm{risk}$ as the 100,000-MTHM HLW reference repository with each of the proposed TRU-waste criteria. These values are compared to the amount of TRU waste that is predicted for the year 2000. This is the same year that was used to define the inventory for the HLW reference repository. All proposed TRU-waste criteria are higher (more conservative) than the year 2000 inventory. However, the 1-MCi equivalent waste unit is a factor of 10.2 higher than the year-2000 TRU-waste inventory, and the 8.1-MCi equivalent waste unit is a factor of 82.7 higher, making these criteria inconsistent with projected TRU-waste inventories and risk levels set for HLW. Also shown in Figure 20 is the inventory for eight 
Table 14. Relative Stringency of Several Radioactive-Waste Disposal Criteria Alternatives

\begin{tabular}{|c|c|c|c|c|}
\hline $\begin{array}{l}\text { Source of } \\
\text { Risk }\end{array}$ & Standard & $\begin{array}{l}\text { Reference } \\
\text { for } \\
\text { Standard }\end{array}$ & $\begin{array}{l}\text { Allowable } \\
\text { Premature } \\
\text { Deaths per } \\
10,000 \text { Yrs }\end{array}$ & $\begin{array}{l}\text { Fraction of } \\
\text { Allowable } \\
\text { Risk to } \\
\text { Eddy County } \\
\text { de minimus }\end{array}$ \\
\hline $\begin{array}{l}\text { HLW } \\
\text { reference } \\
\text { repository } \\
(100,000 \text { MTHM })\end{array}$ & $\begin{array}{c}\text { HLW } \\
\text { fundamental } \\
\text { criterion }\end{array}$ & 3 & 1000 & NA \\
\hline $\begin{array}{l}\text { YMP } \\
(70,000 \text { MTHM })\end{array}$ & $\begin{array}{l}\text { HLW } \\
\text { fundamental } \\
\text { criterion }\end{array}$ & 3 & 700 & NA \\
\hline $\begin{array}{l}\text { TRU-waste } \\
\text { reference } \\
\text { repository } \\
\text { (20 MCi) }\end{array}$ & $\begin{array}{l}\text { TRU-waste } \\
\text { fundamental } \\
\text { criterion }\end{array}$ & $\begin{array}{l}\text { This } \\
\text { report }\end{array}$ & 1000 & NA \\
\hline $\begin{array}{l}\text { WIPP } \\
(7.7 \text { MCi })\end{array}$ & $\begin{array}{l}\text { TRU-waste } \\
\text { fundamental } \\
\text { criterion }\end{array}$ & $\begin{array}{l}\text { This } \\
\text { report }\end{array}$ & 385 & 0.75 \\
\hline $\begin{array}{l}\text { WIPP } \\
(7.7 \mathrm{MCi})\end{array}$ & $\begin{array}{c}1-\mathrm{MCi} \\
\text { equivalent } \\
\text { waste unit }\end{array}$ & 3 & 77 & 0.15 \\
\hline $\begin{array}{l}\text { WIPP } \\
(7.7 \mathrm{MCi})\end{array}$ & $\begin{array}{l}8.1-\mathrm{MCi} \\
\text { equivalent } \\
\text { waste unit }\end{array}$ & 1 & 9.5 & 0.02 \\
\hline
\end{tabular}

repositories the size of the WIPP, which is one of the higher estimates of TRU waste from decommissioning and decontamination of DOE facilities. Both values for equivalent waste-unit criteria are even greater than this inventory, while the 60-MCi-based TRU-waste fundamental criterion has the same value.

The above discussions and the Table 13 summary show that all the TRUwaste reference units are nonuniform, inappropriate, and indefensible, and Table 14 and Figure 20 show that their risk limits are unrealistic. The TRUwaste fundamental standard is more defensible, is consistent with the development of the HLW fundamental criterion, and has levels of protection 


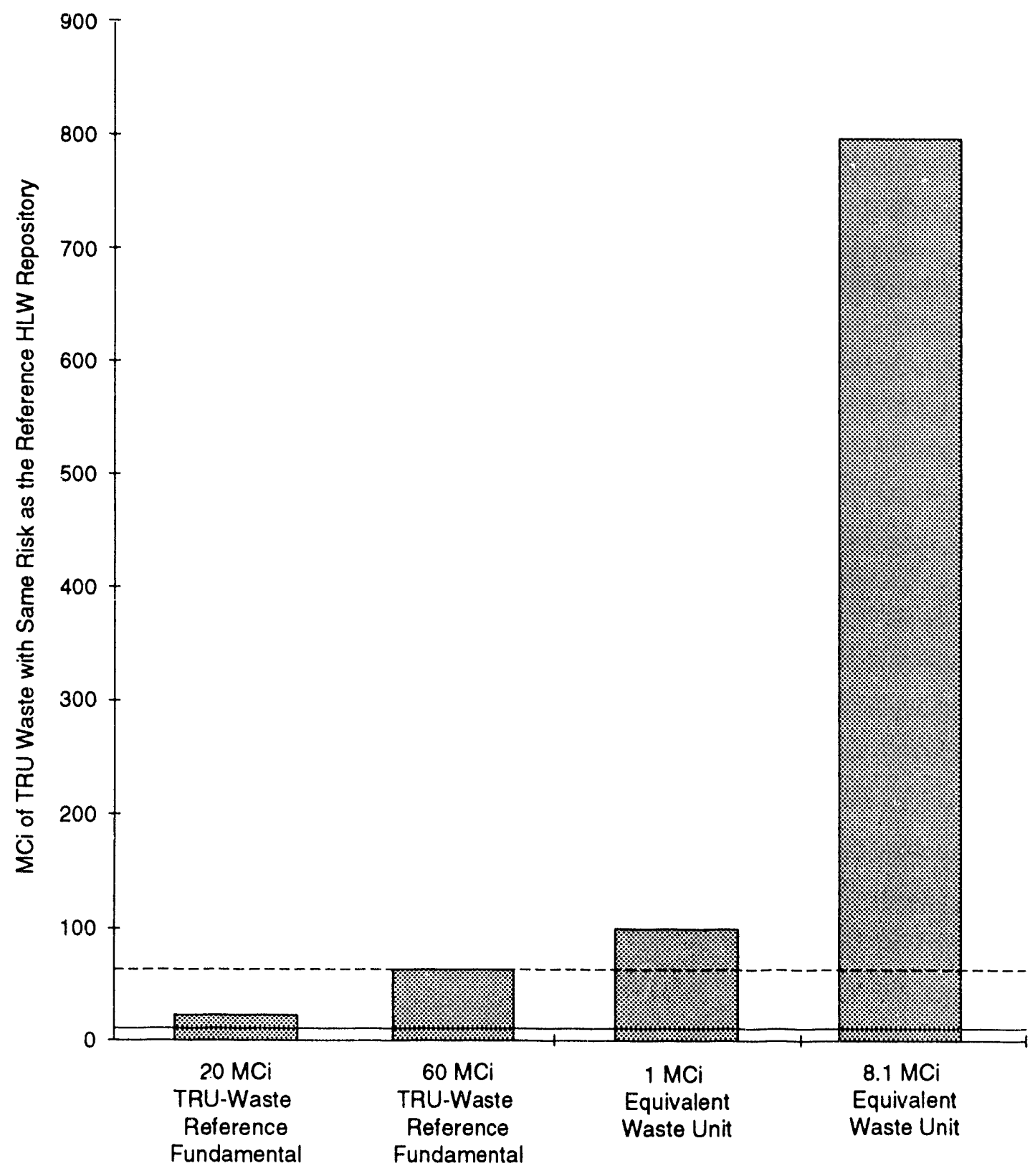

8 WIPP

Repositories

TRU Waste,

Year 2000

TRI.6342.1843-0

Figure 20. Comparison of TRU-waste criteria with the reference HLW risk and two quantities of TRU waste. 
that are more realistic. However, as stated earlier, it is not possible to develop a TRU-waste standard that is completely defensible and still be compatible with the unique structure of 40 CFR 191. It may be necessary to make the final decision on TRU-waste criteria using expert judgment based on acceptable risk used in other standards. If more significant changes in regulatory philosophy are made that involve changes in the HLW fundamental criterion, the new criterion could include TRU waste, or a TRU-waste fundamental crite ion could be developed in parallel. 


\section{SUMMARY AND CONCLUDING DISCUSSION}

The EPA standards for radioactive-waste disposal in the 1985 version of 40 CFR 191 are unique in several ways. In describing the overall approach of the rule, the EPA acknowledged in the supplementary information for 40 CFR 191 that

Developing the standards for disposal of spent fuel and high-level and transuranic wastes involved much more unusual circumstances than those for waste management and storage. Because these materials are dangerous for so long, very long time frames are of interest. Standards must be implemented in the design phase for these disposal systems because active surveillance cannot be relied upon over such periods. At the same time, the standards must accommodate large uncertainties, including uncertainties in our current knowledge about disposal system behavior and the inherent uncertainties regarding the distant future. Subpart B addresses these issues by combining several different types of standards. The primary objective of these standards is to isolate most of the wastes from man's environment by limiting long-term releases and the associated risks to populations. In addition, subpart B limits risks to individuals in ways compatible with this primary objective. [1]

Over the past several years, the EPA has been working on revisions to 40 CFR 191, its standards for radiological-waste disposal, in response to a 1987 remand by the U.S. Court of Appeals. Only the individual protection and groundwater protection requirements of Subpart B were cited specifically, but review panels, advisory boards, and individual investigators have recommended numerous modifications to the EPA radioactive-waste standards as a whole. To date, the EPA has proposed four drafts of a new rule, and each has generated a considerable amount of comment and a number of suggestions for modifications and extensions. Most of the reviewers recommended substantial changes in regulation philosophy, format, and stringency. In the four versions of the draft proposed rule, the EPA has made minor changes to the 1985 regulation that have not involved the philosophy, methodology, or format of the standards. The only major change is the proposed option of dose limits in addition to release limits. The EPA has given no indication that it plans to deviate from its overall approach to radioactive-waste disposal as stated in the supplementary information for the 1985 version of 40 CFR 191.

Although extensive changes in 40 CFR 191 could produce better standards, that approach may not be feasible given the regulatory philosophy selected by the EPA and the late stage in the development of the standards. Therefore, all options discussed in this report are within the existing framework. The 
total-systems approach was used to evaluate options to assure that changes would be compatible with the rest of the standards. Other self-imposed constraints placed on the suggested modifications are that they would require little time to devel'sp, use existing technology and data, and have only minor effects on the way sites are characterized and performance assessments are conducted.

A critical area of concern in proposing extensions or modifications to 40 CFR 191 is technical justification. In the approximately seven years since promulgation of $40 \mathrm{CFR} 191$, the scientific community and publicinterest groups have had ample opportunity to compare the development procedures for the 1985 version of $40 \mathrm{CFR} 191$ and the resulting regulations to the requirements for standards, traditional methods of regulating chemical and radiological carcinogens, and recommendations made by the ICRP, NEA, $B R W M, S A B, N W T R B$, and numerous individual investigators. Development methodology, logic, assumptions, decisions, and models have been examined for appropriateness, consistency, and completeness relative to the requirements for long-term disposal of radioactive waste. Through such examinations, weaknesses in features of 40 CFR 191 other than the individual protection and groundwater protection requirements cited in the remand have been identified. For these reasons, it is crucial at this stage of standards development that the new rule be founded on acceptable methodology, models, and assumptions, and that the logic and decisions used in developing the repromulgated standards be easily traceable and rigorously defensible.

\subsection{Summary}

A previous report [4] identified four significant problems with the 1985 version of 40 CFR 191-the fundamental criteria for HLW and for TRU waste, derived release limits, and risk limits for probabilistic releases. Suggestions were also made for extensions of the existing standards that would remove inconsistencies, make them more appropriate for specific disposal sites and waste forms, and relate them more closely to risk, without changing their form or the way they are developed.

In September 1991 and February 1992, the Electric Power Research Institute (EPRI) held workshops in which participants evaluated the technical bases for the EPA radioactive-waste disposal criteria. This report contains material that was presented at those workshops and studies for the DOE's technical support to the EPA for the repromulgation of $40 \mathrm{CFR} 191$. This report has expanded the discussions in the previous report [4] and provides an in-depth, technical justification for those options that would correct or ameiiorate three problem areas-derived release limits, risk limits for 
probabilistic releases, and fundamental criteria for TRU waste. Background information on repository systems and standards to regulate the repositories is also included.

\subsubsection{Technical Bases for Regulations}

Regulators need a thorough knowledge of the way a class of repositories functions and is evaluated for reliability before they set standards for long-term waste disposal. Information is needed on potential waste composition, containers, repository layouts and design, geology, geochemistry, hydrology, gas permeability, tectonics, natural resources, demography, and geography.

The highest priority for any repository is meeting acceptable risk limits for individuals, single generations, or collective populations. Many characteristics of a repository that make it reliable also enhance confidence in risk predictions. Repository resilience and stability of system components make a system less sensitive to changes and performance assessments less sensitive to the quality of input data. Stability of the surrounding environment also increases confidence in risk prediction.

Risk potential for mined geologic repositories is attenuated by retardation, dilution, and time and space dispersion of radionuclides along the entire length of all pathways from the source to humans. The magnitude of the attenuation factor of each component in a waste-disposal system depends on what is being attenuated (individual versus collective dose), waste inventory, pathways, time span of interest, and performance of all the components of the disposal system that precede a radionuclide on the pathway to humans. Each pathway will attenuate the risk potential by a different amount. The risk potential of each radionuclide will be attenuated by a different amount because of factors such as half-life, solubility, diffusivity, retardation, and concentration.

Although system reliability is an important consideration in long-term disposal of radioactive wastes, predicted capabilities should not be the major influence in determining the level of regulation for radioactive-waste repositories. In a hierarchy of criteria, the fundamental criterion is the most basic and is the only level of criteria that explicitly specifies the level of risk that is acceptable for a specific material or process.

Ranking below the fundamental criterion in the hierarchy, dose limits correspond to the risk limits of the fundamental criterion. Derived criteria are computed from dose criteria using nuclide-transport models and are requirements placed on the performance of components or processes in the 
disposal system or on the flux or concentration of radionuclides at locations along pathways from the waste site to humans. Prescriptive criteria are requirements placed on a repository that are intended to reduce risk but are not derived mathematically from the fundamental criterion. Examples of prescriptive criteria are specifications for waste containment or retrieval. Functional requirements define how a repository must function to meet the higher-level criteria. Primary and secondary design requirements are specifications for the design of a repository.

If criteria levels lower than dose limits are issued before repositories, pathways, and processes are adequately defined, the criteria may put unrealistic requirements on a system and have adverse effects on the design and safety of a repository. Optimizing a disposal system and evaluating actual system resilience and component stability is more difficult when regulations contain lower-level criteria.

\subsubsection{Release and Dose Limits}

The release limits in 40 CFR 191 are derived standards. Derived standards require modeling of specific pathways and processes, using specific data. The single-mode release limits in $40 \mathrm{CFR} 191$ are generic derived standards that are intended to be applied to all repositories and all pathways. By their nature, generic derived standards are inherently inaccurate and the more generic they are, the more inaccurate they are. As indicated in Chapter 3, certain features of the release limits and their derivation in $40 \mathrm{CFR} 191$ do not meet the requirements for derived standards or are internally inconsistent:

- the release limits are applied at the repository boundary instead of at the actual release locations,

- only one set of release limits, based on releases to surface waters, is used for all release modes,

- the risk-limit derivation was based on world-average parameters,

- some assumptions, predictions, and simplifications used in the derivation of the release limits were conservative and some nonconservative. 
Several options to the current release limits were discussed in Chapter 4. One alternative would eliminate the generic derived release limits and replace them with dose limits. Dose standards are more versatile than derived standards because they apply to all repositories and all pathways. An individual-dose standard has been recommended by several international organizations and is being used or is under consideration in other countries. An individual-dose standard is not feasible for $40 \mathrm{CFR} 191$ in its current format, however, because the fundamental criterion defines the maximum allowable cancer deaths per unit of waste during the time of regulation; collective dose per MTHM is the only type of dose limit that would be compatible. A change to dose standards would not require additional derivations by the EPA but would require the greatest change in the regulatory philosophy stated in the supplementary information for 40 CFR 191 . In addition, using dose standards would increase the amount of site characterization and would require additional PA analyses.

Providing dose limits as an option to using release limits would allow the allicant or regulating agency to select the method most appropriate for the repository being regulated. Consequences would be normalized for any event or process using dose limits, similar to the way they are normalized using release limits. Performance assessments would produce the same type of normalized CCDF that is presently being produced using release limits. The CCDF would be constructed using all normalized releases, all normalized doses, or a combination of the two. Using a combination of normalized releases and doses in the CCDF would be particularly advantageous for repositories that are expensive to characterize and analyze and have only a few events or processes that cannot be represented adequately by the conservative generic release limits.

One alternate approach that uses releases limits but is site and pathway specific is an extension of the present derivations. More complete and appropriate release limits applied at the surfaces of the CV could be obtained by determining possible pathways, attenuation factors, and release modes and then computing release tables for each site. The disadvantages of using this approach are that the requirements would be site specific, would not pertain to future repositories, and would require additional site characterization and considerable time and effort to develop.

Another approach that uses generic release limits would set the limits at the locations of release to the biosphere for each release mode. A multimode, five-column release table would cover all possible release modes-land, river, well, ocean, and atmospheric-for generic repositories. Performance assessments for specific repositories would select the appropriate release mode for each pathway and include all dis, osal-system components in the assessment. EPA generic analyses from the release points 
to humans, most of which have already been conducted in support of the current release-limits table, would ensure uniform modeling of the biosphere for all applications. Multimode release limits would still be generic derived standards and consequently would contain some generalizations that may not apply to specific repositories, but the generalizations would be limited to the processes between the release locations and humans. Multimode standards would apply uniformly to all repositories and all pathways. All major components in the disposal system would be included in risk assessments. Besides eliminating inconsistencies and omissions, this approach would not be site specific and would allow the fundamental standard to remain nearly constant for all repositories and all pathways.

\subsubsection{Probabilistic Containment Requirements}

Evaluating the acceptability of a waste-disposal system requires considering not only the magnitude of exposures but also the probability that various levels of dose will be received and the uncertainties in their values. The containment requirements in $40 \mathrm{CFR} 191$ define a procedure for evaluating compliance of probabilistic events and processes using deterministic release limits. The unique wording of the containment requirements provides for a stepped function of consequences and probabilities and controls the shape of the release CCDF instead of the area under the curve, which is the measure of system risk. The arbitrary discontinuities of the function necessitate having accurate probability predictions of events and parameters because small changes in estimated probabilities can have a significant effect on the evaluation of compliance. Predictive assessments, however, are inevitably subject to considerable uncertainty because of the uncertainties in human behavior and in natural processes and events.

Some proposed alternatives to the current containment requirements attempt to eliminate the need to develop precise numerical probability estimates for very unlikely events and processes and to separate human intrusion from anticipated or natural events so that they can be evaluated with deterministic requirements. The various versions of a proposed "threebucket" approach provide for three categories based on probability of event or process occurrence, on event or process description, or on both. All of the proposed versions of the "three-bucket" approach have some ambiguities and inconsistencies. The interpretation of "events and sequence of events" could determine their category membership and have a significant effect on compliance. Probabilities of individual events or sequences of events could be subdivided to decrease probabilities and make compliance easier. Events also could be grouped together to increase probabilities and possibly exclude a safe repository. The wording of the "three-bucket" approach does not 
provide for a complete system CCDF, and the upper level of this incomplete system CCDF could be different for each repository. The goal of eliminating the need for precise probability estimates for unanticipated processes and events is only partially fulfilled; probability estimates of unanticipated events that fall in the mid-range of one category could be off by as much as 1.5 orders of magnitude without affecting the assessment, but the acciracy requirements of the probability estimates increase as the actual probabilities of the events approach that category's boundaries. The "threebucket" approach also may not achieve its potential advantage of separating human intrusion from other phenomena; for a repository for which human intrusion has a high probability of occurrence, a category definition based on probabilities may not separate human intrusion from anticipated natural events. The "three-bicket" approach may have the potential to simplify licensing or permitti of repositories, but in its current versions the concept does not achieve these goals.

One of the more widely accepted approaches for handling probabilistic events uses a limit on individual risks as the primary criterion. The same approach can be used for population risks or time-integrated radionuclide releases. Risk is the consequence of an evert or parameter variation multiplied by the probability that the event or variation will occur, summed over all events or variations. As thus defined, risk is the area under a consequence CCDF. Modified risk-based limits appiy to probabilistic releases to the environment and build on the procedures in the current version of 40 CFR 191. This approach would generate a family of CCDFs for all credible events or sequences of events for each parameter sample. All of the CCDFs would be integrated to produce the risks for each parameter sample. The risks would be divided by the number of data sets to produce probabilistic normalized risks for the repository. Normalized fractional releases would be used to compute a risk cumulative distribution function. The advantage of using a risk limit is that the contribution of unlikely events that may or may not occur in the future can be accounted for in a straightforward and consistent manner. Unlikely events or sequences of events that could contribute significantly to the potential detriment could be considered by presenting separately information on probabilities, individual doses, and collective doses for consideration in multi-attribute analyses. Accuracy requirements for probability estimates could depend on the relative risk of the event rather than on the probability of the event. The modified risklimits approach is the only proposed approach that is a direct measure of risk and is traceable to the fundamental criterion. 


\subsubsection{Criteria for TRU-Waste Disposal}

The current fundamental criterion for HLW and SF in $40 \mathrm{CFR} 191$ is a risk/benefit criterion that allows no more than 1000 premature cancer deaths over the first 10,000 years from disposal of the wastes from 100,000 metric tons of reactor fuel. This allowable risk was based on predicted capabilities of the HLW reference repository in several geologic media. The size of the HLW reference repository was based on the estimated cumulative inventory by the year 2000. The current version of 40 CFR 191 does not cortain fundamental criteria for TRU-waste disposal, and safety requirements have not been established that apply to TRU waste. TRU waste is not comparable to HLW/SF, so direct application of the HLW fundamental criterion is not possible. Instead, in the 1985 version of 40 CFR 191, TRU-waste repositories are evaluated using a TRU-waste unit that is intended to be "equivalent" to 1000 MTHM of commercial HLW. The current "equivalent" TRUwaste unit is a member of an entire family of quasi-equivalent TRU-waste units that has been suggested for use with the regulations developed for HLW disposal. Combinations of four or five groups of parameters could be used to compute the quasi-equivalent TRU-waste unit, with varying degrees of realism. However, none of these parameter combinations produce a true equivalent unit. Any of the TRU-waste reference units can be equivalent to only one HLW or SF inventory, at a single time, for one repository, and for only one parameter that is not proportional to actual risk.

An alternative to using a quasi-equivalent TRU-waste unit is to develop a fundamental criterion specifically for TRU-waste disposal. One approach would be to develop a TRU-waste fundamental criterion based on acceptable risk to the populace and the expected quantity of TRU waste. Assuming collective-population risk will continue to be used as the basis for the fundamental criteria and derived release limits will be used to show compliance in 40 CFR 191, a new absolute collective-risk limit could be developed. This TRU-waste fundamental criterion would be completely independent of the HLW fundamental criterion and based solely on expected quantities of TRU waste and acceptable levels of risk. This approach would require determining the total future TRU-waste inventory so that a risk allocation could be made for each repository and developing new release limits based on the absolute TRU-waste fundamental criterion. Developing this approach would be a time-consuming process, and inconsistencies in regulatory philosophy between the risk/benefit HLW criteria and an absolute TRU-waste criterion would have to be justified.

Another approach would be to develop a TRU-waste fundamental criterion that is related to the allowable risk for HLW repositories. This approach uses rationale and analyses that are parallel to those used by the EPA in developing the HLW standards. The method would equate the allowable risk 
from a TRU-waste reference repository to the allowable risk from the HLW reference repository. The size of the TRU-waste reference repository would be defined by determining the projected inventory of $\mathrm{RH}$ - and $\mathrm{CH}-\mathrm{TRU}$ waste and establishing the TRU-waste reference repository based on this amount. This method parallels the manner in which the HLW reference repository was determined. The allowable risk for TRU-waste repositories smaller than the reference repository would be scaled down proportional to $m$ ir size relative to the reference repository. No new release limits would have to be derived for this approach because the risk factors used to derive the current release limits in 40 CFR 191 apply to any inventory or waste category. Because this approach to developing a TRU-waste fundamental criterion uses the format already established in $40 \mathrm{CFR} 191$ and parallels the : gulatory philosophy used to derive the HLW standards, no additional justification by the EPA for using the approach would be needed. However, it is not possible to develop a TRU-waste disposal standard that is completely defensible and compatible with the present form of the HLW standards.

\subsection{Concluding Discussion}

While working with the EPA, the DOE, participants in the two EPRI workshops, members of the Board on Radioactive Waste Management of the National Academy of Sciences (BRWM), and other concerned individuals, several observations were made concerning standards for radioactive-waste disposal and the development of these standards. These observations are discussed in the remainder of this chapter.

\subsubsection{Standards for Radioactive-Waste Disposal}

Although there has been considerable guidance on radiologic standards froru whe ICRP, NEA, and IAEA, 40 CFR 191 was the first attempt to formulate standards for high-level and transuranic radioactive-waste disposal in the

United States. Prior to 40 CFR 191, there was little experience and no proven methodologies or procedures to draw on. As a result, these first standards contain some new and innovative methods, and they were not developed as a cohesive unit. Much has been learned during the development of the standards and more has been learned applying the new standards to the two prospective repositories. This information can now be used to modify and improve the present version of the standards and eventually to develop a new and better set of standards.

The present standards have many unique features not found in the recommendations of the ICRP, NEA, and IAEA, standards for HLW disposal being considered by other countries, and standards for enviroiumental carcinogens 
issued by U.S. regulatory agencies. These unique features include: the segment of the populace that is protected, the level of protection, the metric of evaluation, the use of generic derived criteria, the location where the standard is applied, the time frame for evaluation, and the treatment of probabilistic events and uncertainty. Some of the problems with the present regulations can be traced to the unconventional approach used to develop them. In the future, unconventional methods should be investigated more thoroughly before they are used.

Modifications of the present standards or their eventual replacement need better definitions and rationale for the selection of criteria and evaluation procedures, stressing consistency and appropriateness. Repository safety is the primary function of the standards. Achievability should only be used to show the standards are economically feasible and that the resulting costs would be commensurate with the reduction of risk. Acceptable risk should be the basis of the fundamental criterion, and the method for evaluating acceptability must be thoroughly documented.

Fundamental criteria are the only level of standards that explicitly define the radiological safety requirements of repositories. However, derived standards must reflect the characteristics of individual wastedisposal systems. Appropriate derived standards cannot be set until they have operational meaning and there is sufficient information on repository waste forms, designs, and site characteristics. Generic derived standards are inherently inaccurate, and it is recommended that their use be more limited in the future. If they are used, care should be taken to assure they apply to all repositories being regulated, are traceable to the fundamental criterion, and do not inhibit optimization of the disposal system. A better procedure would be to have regulators set derived and lower-level criteria for specific applications as needs arise.

For some parts of the standards, quantitative requirements may be difficult to meet with a high degree of confidence. One alternative for these cases would be to selectively substitute qualitative requirements. There are several things to consider before this type of substitution is made. A statement is needed to define what will be accomplished by the qualitative requirement and how it will show that the repository is safe. The qualitative requirement must be carefully defined, and the requirements for acceptance and how it will be evaluated must be clearly stated. Even then qualitative requirements are more open to interpretation than quantitative requirements, which may slow the licensing process. General qualitative requirements that do not consider all potential disposal systems could exclude sites and designs that would prove to be safe using quantitative requirements. It is also necessary to show how evaluating some parts of the system qualitatively will affect the rest of the evaluation, 
such as the effects on event trees. There is no reason to change the requirements for insignificant nuclides, pathways, release modes, events, or scenarios. If they constitute a significant contribution to total risk, they cannot be removed from a quantitative evaluation without modifying the allowable limit for that evaluation. The uncertainty of quantitative requirements will have to be weighed against the problems of qualitative requirements for each individual case.

Having optional evaluation procedures adds versatility to the standards and can simplify site characterization and PA, saving time and money. On the negative side, if the standards are not properly worded, the hierarchy and relative conservatism of the options could be clouded. This could result in evaluating all options or in more challenges to the assessments.

\subsection{Standards Development}

An overall plan for all levels of criteria that takes into account all waste categories to be covered by the standards, all potential sites, and all repository designs is needed before criteria development begins. The plan would assure that all components of the standards are compatible and work together to provide adequate safety at a reasonable cost. Independent studies can produce a wide range of of ions, but they tend to produce repetitious cursory analyses with inadequately substantiated suggestions for regulations or modifications of existing regulations. Future studies would be more productive if they are organized efforts that conduct in-depth analyses and look at the entire set of standards as a single system.

Repository-program developers have more knowledge about how repositories function than any other group. Their expertise concerning repository operation and nuclide transport would be valuable to developers of wastedisposal standards and should not be a conflict of interest if used as input and not to develop policy. If the concept of total quality management is applied to standards development, the staff that conducts the analyses and develops the methodology would be involved in decisions concerning the final form of the standards. Their contribution could be an important addition to those of recognized experts and management.

The use of best-estimate data and assumptions is recommended in the development of standards instead of conservative values and assumptions that have unknown margins of safety that are different for each repository and each scenario. Conservative omissions of disposal-system components and attenuation processes also should be minimized. A single safety factor, applied to the standards as a whole, based on sensitivity, stochastic, and bracketing studies and on natural analogs, is more meaningful than a serics 
of safety factors that is buried in the development. The systematic use of sensitivity and stochastic analyses in conjunction with best estimates also would provide a better measure of the uncertainty in the standards. The credibility of the standards relates directly to how well the margin of safety and the confidence limits are defined.

One of the most significant improvements that could be made in the regulation development process would be to establish a more compiehensive quality assurance (QA) program. It could eliminate many of the problem sources and would provide a clear, documented account of the development from the planning stage, through analyses and interpretations, to the applications. The standards could be made more defensible by using QA for the standards development that is functionally comparable to that used in performance assessments and repository design. An adequate QA program would include the following elements:

- A documented development plan with a clear statement of objectives.

- A docume,ted, clear, traceable logic trail with reasons given for all decisions.

- Precise definitions of all assumptions used in the studies and limitations of the results of all studies, and assurance that this information is carried through the entire standards development.

- Justification of all assumptions, simplifications, and omissions.

- The use of verified models that represent pathways and consequences as accurately as possible.

- Assurance that the analyses are appropriate to the applications.

- Controlled documentation of all important information to assure all participants are using consistent and correct information on configurations, assumptions, parameter values, and results.

- Systematic trade-off studies with reasons given for selections.

- Documentation that is in a concise, orderly format to facilitate reviews.

- Peer reviews of each major stage of development.

- Consistent use of units to reduce the possibility of error. This includes the size of the waste unit for all analyses and regulations. 
- Training of participants in QA principles and in the transport and risk-attenuation processes of geologic repositories for radioactive wastes.

The methods described in this section to develop better standards are similar to those being used to improve disposal systems and performance assessments. These procedures are warranted because the accuracy and appropriateness of the fundamental criteria define the safety level of the repository, and because derived standards become a significant part of the risk assessment. 


\section{REFERENCES}

1. US Environmental Protection Agency, "40 CFR Part 191: Environmental Standards for the Management and Disposal of Spent Nuclear Fuel, HighLevel and Transuranic Radioactive Wastes; Final Rule," Federal Register, Vo1. 50, No. 182, September 19, 1985, pp. 38066-38089.

2. R.D. Klett, Waste Disposal Performance Assessment Using Attenuation Factors, SAND84-2624, Sandia National Laboratories, Albuquerque, NM, March 1988.

3. Natural Resources Defense Council v. U.S.E.P.A., 824 Federal Reporter, $2 d$ Series, US Court of Appeals for the First Circuit, July 17, 1987, as amended August 12, 1987, pp. 1258-1294.

4. R.D. Klett, Proposed Extensions of United States Fundamental and Derived Standards for High-Level and Transuranic Radioactive Waste Disposal, SAND91-0211, Sandia National Laboratories, Albuquerque, NM, July 1991.

5. International Commission on Radiological Protection, "Publication 46--Radiation Protection Principles for the Disposal of Solid Radioactive Waste," Annals of the International Commission on Radiological Protection, Vol. 15, No. 4, 1985.

6. International Commission on Radiological protection, "Publication 60-1990 Recommendations of the International Commission on Radiological Protection," Annals of the International Commission on Radiological Protection, Vol. 21, No. 1-3, 1990.

7. International Commission on Radiological Protection, "Publication 42-A Compilation of the Major Concepts and Quantities in use by ICRP," Annals of the International Commission on Radiological Protection, Vol. 14, No. 4, 1984 .

8. International Commission on Radiological Protection, "Publication 29-Radionuclide Release into the Environment: Assessment of Doses to Man," Annals of the International Commission on Radiological Protection, Vol. 2, No. 2, 1979.

9. Nuclear Energy Agency, Joint RWMC/CRPPH Workshop on Radiation Protection and Safety Criteria for the Disposal of High-Level Wastes, November 5-7, 1990, Nuclear Energy Agency, Paris.

10. C.C. Travis, S.A. Richter, E.A.C. Crouch, R. Wilson, and E.D. Klema, "Cancer Risk Management," Environmental Science and Technology, Vol. 21, No. 5, May 1987, pp. 415-420.

11. P. Milvy, "A General Guideline for Management of Risk from Carcinogens," Risk Analysis, Vol. 6, No. 1, 1986, pp. 69-79.

12. Waste Isolation Systems Panel, Board on Radioactive Waste Management, $A$ Study of the Isolation System for Geologic Disposal of Radioactive Wastes, National Academy Press, Washingtor, DC, 1983. 
13. High-Level Radioactive Waste Disposal Subcommittee, Science Advisory Board, Report on the Review of Proposed Environmental Standards for the Management and Disposal of Spent Fuel, High-Level, and Transuranic Radioactive Wastes (40 CFR 191), US Environmental Protection Agency, Washington, DC, January 1984.

14. Nuclear Waste Technical Review Board, First Report to The U.S. Congress and The U.S. Secretary of Energy, March 1990.

15. US Environmental Protection Agency, "40 CFR Part 191: Environmental Standards for the Management and Disposal of Spent Nuclear Fuel, HighLevel and Transuranic Radioactive Wastes," Federal Register, Vol. 47, No. 250, December 29, 1982, pp. 58196-58206.

16. US Environmental Protection Agency, "Proposed Rule--40 CFR 191: Environmental Standards for the Management and Disposal of Spent Nuclear Fuel, High-Level and Transuranic Radioactive Wastes," US Environmental Protection Agency, Washington, DC, April 25, 1991. (Copy on file at the Waste Management and Transportation Library, Sandia National Laboratories, Albuquerque, NM.)

17. US Environmental Protection Agency, Background Information Document-Final Rule for High-Level and Transuranic Radioactive Wastes, EPA 520/1-85-023, US Environmental Protection Agency, Washington, DC, August 1985 .

18. P.J. O'Brien, R.B. Lantz, and J. Gormley (Arthur D. Little, Inc.), Technical Support of Standards for High-Level Radioactive Waste Management: Volume $C$, Assessment of Migration Pathways, EPA 520/4-79-007C, Office of Radiation Programs, US Environmental Protection Agency, Washington, DC, March 1977.

19. J.M. Smith, T.W. Fowler, and A.S. Goldin, Environmental Pathway Models for Estimating Population Health Effects from Disposal of High-Level Radioactive Waste in Geologic Repositories; Final Report, EPA 520/5-85-026, Eastern Environmental Radiation Facility, Office of Radiation Programs, US Environmental Protection Agency, Montgonery, AL, August 1985 .

20. C.R. Murray and E.B. Reeves, Estimated Use of Water in the United States in 1975, USGS Circular 765, US Geological Survey, Washington, DC, 1977.

21. R.D. Klett, "Risk Assessment for Subseabed Disposal of High Leve1 Radioactive Waste," presented at the 7 th International Ocean Disposal Symposium, Wolfville, Nova Scotia, September 21-25, 1987. (Copy on file at the Waste Management and Transportation Library, Sandia National Laboratories, Albuquerque, NM.)

22. G. de Marsilly et al., Feasibility of Disposal of High-Level Radioactive Waste into the Seabed: Volume 2, Radiological Assessment, Nuclear Energy Agency, Paris, 1988.

23. M.F. Kaplan, 1985 Subseabed Disposal Project Annual Report: Systems, October 1984 through September 1985, Ed. R.D. Klett, SAND86-0244, Sandia National Laboratories, Albuquerque, NM, Maj 1986. 
24. T.W. Fowler and C.B. Nelson, Health Impact Assessment of Carbon-14 Emissions from Normal Operations of Uranium Fuel Cycle Facilities, EPA 520/5-80-004, U.S. Environmental Protection Agency, Washington, DC, June 1979 .

25. W.R. Rish, S.A. Schaffer, and J.J. Mauro, Uncertainty and Sensitivity Analysis of the Exposure Pathways Model Used as the Basis for Draft 40 $C F R$ 191, Supplementary Report to National Waste Terminal Storage Technical Support Team-USDOE, Envirosphere Company, November 1983.

26. Envirosphere Company, Revised Uncertainty Analysis of the EPA River Mode Pathways Model Used as the Basis for 40 CFR 191 Release Limits, EPA 520/1-85-026, August 1985.

27. The President, "Reorganization Plan No. 3 of 1970," Federal Register, vol. 35, No. 194, 1970, pp. 15623-15626.

28. W.F. Holcomb, R.L. Clark, R.S. Dyer, and F.L. Galpin, "USEPA Radioactive Waste Disposal Standards: Issued and Under Development," Nuclear and Chemical Waste Management, Vol. 8, no. 1, 1988, pp. 3-12.

29. R.D. Klett, "Basis for Release Limits in 40 CFR 191," presented at the EPRI Workshop-Technical Basis for EPA HLW Disposal Criteria, Arlington, VA, September 24-26, 1991. (Copy on file at the Waste Management and Transportation Library, Sandia National Laboratories, Albuquerque, NM.)

30. W.B. Solley, C.F. Merk, and R.R. Pierce, Estimated Use of water in the United States in 1985, USGS Circular 1004, US Geological Survey, Washington, DC, 1988 .

31. M.I. Lvovitch, "World Water Balance (General Report)," Proceedings of the world Water Balance Symposium, July 1970, Vol. 2, UNESCO, Paris, 1972, pp. 401-415.

32. D.A. Ensminger, C.M. Koplik, and J.Y. Nalbandian, User's Guide to MARINRAD IV: Model for Assessing the Consequences of Release of Radioactive Material into the oceans, SAND87-7067, Sandia National Laboratories, Albuquerque, NM, September 1987.

33. G.M. Smith and I.F. White, A Revised Global-Circulation Model for Iodine-129, National Radiological Protection Board-Chilton, Didcot, Oxon, June 1983.

34. US Environmental Protection Agency, Clean Air Act, 42 U.S.C.A., Section 7401 et seq., 1983, modified in 1991.

35. US Environmental Protection Agency, "40 CFR 61, Subpart I: National Emission Standards for Hazardous Air Pollutants," as anended and published in the most recent Code of Federal Regulations, Office of the Federal Register, National Archives and Records Administration, Washington, DC. 
36. WIPP Performance Assessment Division, Preliminary Comparison with 40 CFR Part 191, Subpart $B$ for the Waste Isolation Pilot plant, Volume 3: Reference Data, SAND91-0893/3, Sandia National Laborato ies, Albuquerque, NM, December 1991.

37. Nuclear Energy Agency, Long-Term Radiation Protection objectives for Radioactive Waste Disposal, Office of Economic Co-Operation and Development, Nuclear Energy Agency, Paris, 1984.

38. International Atomic Energy Agency, Safety Principles and Technical Criteria for the Underground Disposal of High-Level Radioactive Wastes, Safety Series No. 99, International Atomic Energy Agency, Vienna, 1989.

39. US Environmental Protection Agency, "40 CFR Part 264: Standards for Owners and Operators of Hazardous Waste Treatment, Storage, and Disposal Facilities," as amended and published in the most recent code of Federal Regulations, Office of the Federal Register, National Archives and Records Administration, Washington, DC.

40. US Environmental Protection Agency, "40 CFR Part 268: Land Disposal Restrictions," as amended and published in the most recent code of Federal Regulations, Office of the Federal Register, National Archives and Records Administration, Washington, DC.

41. US Environmenta1 Protection Agency, "Proposed Rule--40 CFR 191: Environmental Standards for the Management and Disposal of Spent Nuclear Fuel, High-Level and Transuranic Radioactive Wastes," U.S. Environmental Protection Agency, Washington, DC, February 3, 1992. (Copy on file at the Waste Management and Transportation Library, Sandia National Laboratories, Albuquerque, NM.)

42. International Commission on Radiological Protection, "Publication 30-Limits for Intakes of Radionuclides by Workers, Parts 1-3, "Annals of the International Commission on Radiological Protection, Vols. 2-8, 1979.

43. National Radiation Protection Board, Metabolic and Dosimetric Models for Application to Members of the Public: Recommended Models for the Metabolism of Iodine and Values for the Gut Transfer Fraction of Plutonium, Americium, Curium and Neptunium, NRPB-GS3, National Radiation Protection Board, Chilton, January 1984.

44. US Department of Energy, Internal Dose Conversion Factors for Calculation of Dose to the Public, DOE/EH-0071, US Department of Energy, Washington, DC, July 1988.

45. US Department of Energy, External Dose-Rate Conversion Factors for Calculation of Dose to the Public, DOE/EH-0070, US Department of Energy, Washington, DC, July 1988.

46. International Commission on Radiological Protection, "Publication 26--Recommendations of the International Commission on Radiological Protection," Annals of the International Commission on Radiological Protection, Vol. 1, No. 3, 1977. 
47. Nuclear Energy Agency, System Performance Assessments for Radioactive Waste Disposal, Office of Economic Co-Operation and Development, Nuclear Energy Agency, Paris, October 1985.

48. R.W. Cranwel1, R.V. Guzowski, J.E. Campbell, and N.R. Ortiz, Risk Methodology for Geologic Disposal of Radioactive Waste: Scenario Selection Procedure, NUREG/CR-1667, SAND80-1429, Sandia National Laboratories, Albuquerque, NM, April 1990.

49. J.C. Helton, J.W. Garner, R.D. McCurley, and D.K. Rudeen, Sensitivity Analysis Techniques and Results for Performance Assessment at the Waste Isolation Pilot Plant, SAND90-7103, Sandia National Laboratories, Albuquerque, NM, March 1991.

50. R.D. Klett, "Evaluation of a TRU Fundamental Criterion and Reference TRU Waste Unit," presented at the EPRI Workshop II - Technical Basis for EPA HLW Disposal Criteria, Arlington, Virginia, February 4-6, 1992. (Copy on file at the Waste Management and Transportation Library Sandia National Laboratories, Albuquerque, NM.)

51. US Environmental Protection Agency, Environmental Impact Statement for 40 CFR 191: Environmental Standards for Management and Disposal of Spent Nuclear Fuel, High-Level and Transuranic Radioactive Wastes, EPA 520/1-82-025, US Environmental Protection Agency, Washington, DC, December 1982 .

52. W.A. Williams, Population Risks from Uranium Ore Bodies, EPA 520/3-80-009, US Environmental Protection Agency, Washington, DC, October 1980 .

53. US Department of Energy, Integrated Data Base for 1991: U.S. Spent Fuel and Radioactive Waste Inventories, Projections, and Characteristics, DOE/RW-0006, Rev.7, US Department of Energy, Washington, DC, October 1991.

54. US Department of Energy, Environmental Assessment: Yucca Mountain Site, Nevada Research and Development Area, Nevada - Volume II, DOE/RW-0073, US Department of Energy, Washington, DC, May 1986.

55. National Cooperative for the Storage of Radioactive Waste, Project Gewahr 1985 - Nuclear Waste Management in Switzerland: Feasibility Studies and Safety Analyses, NGB 85-09, June 1985.

56. J.K. Channell, "What is an Appropriate TRU Waste Unit for 40 CFR 191?" presented at the EPRI Workshop II - Technical Basis for EPA HLW Disposal Criteria, Arlington, Virginia, February 4-6, 1992. (Copy on file at the Waste Management and Transportation Library, Sandia National Laboratories, Albuquerque, NM.)

57. N.J. Numark and S.R. Phelps, "Equivalence to 1,000 MTHM of Spent Fuel: Application of 40 CFR Part 191 to Other Wastes," Proceedings of the International High-Level Radioactive Waste Management Conference, Las Vegas, Nevada, April 14, 1992. 


\section{DISTRIBUTION}

\section{Send Distribution changes to}

M.M. Gruebel, Dept. 6342, Sandia National Laboratories, PO Box 5800, Albuquerque, NM 87185-5800

\section{Federal Agencies}

US Department of Energy (2)

office of Environmental Restoration and Waste Management

Attn: L.P. Duffy, EM-1

C. Frank, EM-50

Washington, DC 20585

US Department of Energy (3)

Office of Environmental Restoration and Waste Management

Attn: M. Frei, EM-34 (Trevion II)

Director, Waste Management Projects Washington, DC 20585-0002

US Department of Energy

Office of Environmental Restoration and Waste Management

Attn: J. Lytle, EM-30 (Trevion II)

Washington, DC 20585-0002

US Department of Energy

Office of Environmental Restoration and Waste Management

Attn: S. Schneider, EM-342

(Trevion II)

Washington, DC 20585-0002

US Department of Energy (3)

WIPP Task Force

Attn: G.H. Daly

S. Fucigna

B. Bower

12800 Middlebrook Rd.

Suite 400

Germantown, MD 20874

US Department of Energy (5)

office of Environment, Safety and Health

Attn: R.P. Berube, EH-20

C. Borgstrum, EH-25

R. Pelletier, EH-231

K. Taimi, EH-232

E. Regnier, EH-232

Washington, DC 20585
US Department of Energy (6)

WIPP Project Integration Office

Attn: W.J. Arthur III

R. Becker

P. Dickman

L.W. Gage

P.J. Higgins

D.A. Olona

PO Box 5400

Albuquerque, NM 87115-5400

US Department of Energy (10)

WIPP Project Site Office (Carlsbad)

Attn: A. Hunt (4)

V. Daub (4)

$\mathrm{J}$. Lippis

$K$. Hunter

PO Box 3090

Carlsbad, NM 88221-3090

US Department of Energy, (7)

Office of Civilian Radioactive Waste Management

Attn: Deputy Director, RW-2

Associate Director, RW-10

Office of Program

Administration and

Resources Management

Associate Director, RW-20

Office of Facilities

Siting and Development

Associate Director, RW-30

Office of Systems

Integration and

Regulations

J. P. Roberts, RW-33

J. Parker, RW-332

Associate Director, RW-40

Office of External

Relations and Policy

Office of Geologic Repositories

Forrestal Building

Washington, DC 20585

US Department of Energy

Office of Energy Research

Attn: W.L. Warnick, ER-9

19901 Germantown Rd.

Germantown, MD 20874 
US Department of Energy

Deputy General Counsel for

Environment, Conservation, and

Legislation

Attn: M.S. Crosland, GC-11

Forrestal Building

1000 Independence Ave. SW

Washington, DC 20585

US Department of Energy

Attn: National Atomic Museum Library

Albuquerque Operations office

PO Box 5400

Albuquerque, NM 87185

US Department of Energy

Research \& Waste Management Division

Attn: Director

PO Box E

Oak Ridge, TN 37831

US Department of Energy

(2)

Idaho Operations office

Fuel Processing and Waste

Management Division

785 DOE Place

Idaho Falls, ID 83402

US Department of Energy

Savannah River Operations Office

Defense Waste Processing

Facility Project office

Attn: W.D. Pearson

PO Box A

Aiken, SC 29802

US Department of Energy (2)

Richland Operations Office

Nuclear Fuel Cycle \& Production

Division

Attn: R.E. Gerton

825 Jadwin Ave.

PO Box 500

Richland, WA 99352

US Department of Energy

Office of Geologic Disposal--YMPO

Attn: J.M. Boak

PO Box 98608

Las Vegas, NV 89193
US Department of Energy (7)

Nevada Operations Office

Attn: J.R. Bol and

D. Livingston

P.K. Fitzsimmons

Technical Information office (4)

2753 S. Highland Drive

Las Vegas, NV 89183-8518

US Department of Energy (2)

Technical Information Center

PO Box 62

Oak Ridge, TN 37831

US Department of Energy (2)

Oak Ridge National Laboratory

Attn: C. Travis

PO Box 2008

A.G. Croff

Oak Ridge, TN 37831-6235

US Department of Energy (2)

Chicago Operations Office

Attn: J.C. Haugen

9800 South Cass Avenue

Argonne, IL 60439

US Department of Energy

Los Alamos Area Office

528 35th Street

Los Alamos, NM 87544

US Department of Energy

Rocky Flats Area Office

Attn: W.C. Rask

G. Huffman

T. Lukow

PO Box 928

Golden, CO 80402-0928

US Department of Energy

Dayton Area Office

Attn: R. Grandfield

PO Box 66

Miamisburg, OH 45343-0066

US Department of Energy

Attn: E. Young

Room E-178

GAO/RCED/GTN

Washington, DC 20545 
US Bureau of Land Management 101 E. Mermod

Carlsbad, NM 88220

US Bureau of Land Management

New Mexico State Office

PO Box 1449

Santa Fe, NM 87507

US Environmental Protection Agensy (12)

Office of Radiation Protection Programs, ANR -460

Attn: J.W. Gunter

M. Oge

R.L. Clark

F.L. Galfin (2)

J. Gruhlke

C. Petti

C. Rogers

W.E. Russo

L. Weinstock

A. Richardson

F. Caparuscio

Washington, DC 20460

US Environmental Protection Agency ALONM RCRA Permits Section

Attn: W.J. Gallagher

1445 Ross Avenue

Dallas, TX 75202-2733

US Environmental Protection Agency

Attn: M. Hale, OS-341

Washington, DC 20460

US Environmental Protection Agency (2)

Science Advisory Board, A101F

Attn: D. Barnes K.W. Conway

401 M Street, SW

Washington, DC 20460

US Geological Survey (2)

Water Rasources Division

Attn: C. Peters

Suite 200

4501 Indian School, NE

Albuquerque, NM 87110

US Geological Survey

Attn: D.K. Nordstrom, US4

325 Rroadway

Boulder, CO 80303
US Nuclear Regulatory Commission (8) Division of Waste Management

Attn: N. Eisenberg, 4H3

B.J. Youngblood, $4 \mathrm{H} 3$

S. Copland, $4 \mathrm{H} 3$

J. Bunting, $4 \mathrm{H} 3$

R. Ballard, $4 \mathrm{H} 3$

H. Marson, $4 \mathrm{H} 3$

J. Philip

NRC Library

11555 White Flint North

Washington, DC $20 \$ 55$

US Nuclear Regulatory Commission (4)

Advisory Committee on Nuclear Waste

Attn: D. Moeller

M.J. Steindler

P.W. Pomeroy

W. J. Hinze

7920 Norfolk Avenue

Bethesda, MD 20814

Committee on Energy \& Natural

Resources

Attn: B. Cooper

US Senate--Room 364

Dirksen Bldg.

Washington, DC 20510-6150

Defense Nuclear Facilities Safety Eoard

Attn: D. Winters

625 Indiana Avenue, NW

Suite 700

Washington, DC 20004

General Accounting office

Attn: V. Sgobba, GB230

1000 Independence Ave., SW

Washington, DC 20585

House Government Operations Committee Attn: D.M. Berick

B-371B Rayburn House Office Bldg.

Washington, DC 20515

Nuclear Waste Technical Re iew Board

Attn: Library

Suite 910

1100 Wilson Blvd.

Arlington, VA 22209-2297 
Office of Management and Budget

Attn: A.G. Fraas

600 Pennsylvania Ave., SE

Washington, DC 20510-8025

Office of Management and Budget

Energy and Science Division

Attn: $K$. Yuracko

725 17th Street NW

Washington, DC 20503

Office of the Nuclear Waste Negotiator Attn: D. Leroy

1823 Jefferson Place, NW

Washington, DC 20035

Office of Technology Assessment

Attn: A. Govan

600 Pennsylvania Ave., SE

Washington, DC 20510-8025

\section{State Agencies}

Environmental Evaluation Group (5)

Attn: R. Neill

Suite F-2

7007 Wyoming Blvd., NE

Albuquerque, NM 87109

New Mexico Bureau of Mines and Mineral Resources

Socorro, NM 87801

New Mexico Energy, Minerals and

Natural Resources Department

Attn: Librarian

2040 South Pacheco

Santa Fe, NM 87505

New Mexico Energy, Minerals and

Natural Resources Department

New Mexico Radioactive Task Force (2)

(Governor's WIPP Task Force)

Attn: A. Lockwood, Chairman

C. Wentz, Coordinator/Policy Analyst

2040 South Pacheco

Santa Fe, NM 87505

Bob Forrest

Mayor, City of Carlsbad

PO Box 1569

Carlsbad; NM 88221
Executive Director

Carlsbad Department of Development

Attn: C. Bernard

PO Box 1090

Carlsbad, NM 88221

New Mexico Environment Department

Secretary of the Environment

Attn: J. Espinosa (3)

PO Box 968

1190 St. Francis Drive

Santa Fe, NM 87503-0968

New Mexico Environment Department

Attn: P. McCasland

WIPP Project Site Office

PO Box 3090

Carlsbad, NM 882.21-3090

New Mexico State Engineer's Office

Attn: M. Chudnoff

PO Box 25102

Santa Fe, NM 87504-5102

Desert Research Institute

Water Resources Center

Attn: J. Fordham

PO Box 60220

Reno, NV 89506

Desert Research Institute

Water Resources Center

Attn: M. Mifflin

2505 Chandler Avenue

Suite 1

Las Vegas, NV 89120

New York Department of Health

Division of Laboratories and Research

Attn: J. Matuszek

Empire State Plaza

Albany, NY 12201

Nevada Nuclear Waste Task Force

Executive Director

Attn: J. Treiche1

4550 W. Oakey Blvd., Suite 111

Las Vegas, NV 89102 
Office of High Level Nuclear Waste Management (2)

Department of Ecology

Attn: N. Pierce, Director $T$. Husseman

5826 Pacific Ave., M.S. PV-11

Olympia, WA 98504-8711

State of Nevada (4)

Nuclear Waste Project Office

Executive Director

Attn: R.R. Loux, Jr. (3)

Technical Program Manager

Attn: C.H. Johnson

Evergreen Center, Suite 252

1802 North Carson Street

Carson City, NV 89710

\section{Advisory Committee on Nuclear Facility Safety}

John F. Ahearne

Executive Director, Sigma Xi

99 Alexander Drive

Research Triangle Park, NC 27709

James E. Martin

109 Observatory Road

Ann Arbor, MI 48109

\section{WIPP Panel of National Research Council's Board on Radioactive Waste Management}

\author{
Charles Fairhurst, Chairman \\ Department of Civil and \\ Mineral Engineering \\ University of Minnesota \\ 500 Pillsbury Dr., SE \\ Minneapolis, MN 55455-0220 \\ John 0. Blomeke \\ 3833 Sandy Shore Drive \\ Lenoir City, TN 37771-9803 \\ John D. Bredehoeft \\ Western Region Hydrologist \\ Water Resources Division \\ US Geological Survey (M/S 439) \\ 345 Middlefield Road \\ Menlo Park, CA 94025
}

Fred M. Ernsberger

$1325 \mathrm{NW}$ 10th Avenue

Gainesville, FL 32601

Rodney C. Ewing

Department of Geology

University of New Mexico

200 Yale, NE

Albuquerque, NM 87131

B. John Garrick

PLG, Inc.

Suite 400

4590 MacArthur Blvd.

Newport Beach, CA 92660-2027

Leonard F. Konikow

US Geological Survey

431 National Center

Reston, VA 22092

Jeremiah O'Driscoll

505 Valley Hill Drive

Atlanta, GA 30350

Christopher Whipple

Clement International Corp.

160 Spear St.

Suite 1380

San Francisco, CA 94105-1535

National Research Council (11)

Board on Radioactive Waste Management RM HA456

Attn: P.B. Myers, Staff Director (8)

G.J. Grube

L.G. Eriksson

C. Anderson

2101 Constitution Avenue

Washington, DC 20418

\section{Performance Assessment Peer Review Panel}

G. Ross Heath

College of Ocean and

Fishery Sciences $\mathrm{HN}-15$

583 Henderson Hall

University of Washington

Seattle, WA 98195 
Thomas H. Pigford

Department of Nuclear Engineering

4159 Etcheverry Hall

University of California

Berkeley, CA 94720

Thomas A. Cotton

JK Research Associates, Inc.

4429 Butterworth Place, NW

Washington, DC 20016

Robert J, Budnitz

President, Future Resources

Associates, Inc.

2000 Center Street

Suite 418

Berkeley, CA 94704

C. John Mann

Department of Geology

245 Natural History Bldg.

1301 West Green Street

University of Illinois

Urbana, IL 61801

Frank W. Schwartz

Department of Geology and Mineralogy

The Ohio State University

Scott Hall

1090 Carmack Rd.

Columbus, $\mathrm{OH} 43210$

\section{National Laboratories}

Argonne National Laboratory (2)

Attn: A. Smith

D. Tomasko

9700 South Cass, B1dg. 201

Argonne, IL 60439

Battelle Pacific Northwest

Laboratory (5)

Attn: R.E. Westerman

S. Bates

H.C. Burkholder

P.W. Eslinger

P.G. Doctor

Battelle Boulevard

Richland, WA 99352
Idaho National Engineering Laboratory

(2)

$\begin{array}{ll}\text { Attn: } & \text { H. Loo } \\ & \text { J. Pruitt }\end{array}$

Mail Stop 5219

Idaho Falls, ID 83403-4000

Lawrence Livermore National

Laboratory (3)

Attn: L. Ramspott, L-209

R. Van Konynenburg, L-370

V.M. Oversby, L-353

PO Box 808

Livermore, CA 94551

Los Alamos National Laboratory

Attn: B. Erdal, CNC-11

PO Box 1663

Los Alamos, NM 87545

Los Alamos National Laboratory

Attn: A. Meijer

Mail Stop J514

PO Box 1663

Los Alamos, NM 87545

Los Alamos National Laboratory (3)

HSE - 8

Attn: M. Enoris

L. Soholt

$\mathrm{J}$. Wenze1

PO Box 1663

Los Alamos, NM 87545

Los Alamos National Laboratory

EM- 7

Attn: S. Kosiewicz

Mail Stop J595

PO Box 1663

Los Alamos, NM 87545

Oak Ridge National Laboratory Martin Marietta Systems, Inc. Attn: J. Setaro

PO Box 2008, Bldg. 3047

Oak Ridge, TN 37831-6019

Savannah River Laboratory (3)

Attn: N. Bibler

M.J. Plodinec

G.G. Wicks

Aiken, SC 29801 
Savannah River Plant (2)

Attn: R.G. Baxter

Building 704-S

K.W. Wierzbicki

Building $703-\mathrm{H}$

Aiken, SC 29808-0001

\section{Corporations/Members of the Public}

Arthur D. Little, Inc.

Attn: C.R. Hadlock

Acorn Park

Cambridge, MA 02140-2390

Assoc. Universities

Attn: G. Tape

1717 Massachusetts, Ave., NW

Suite 603

Washington, DC 20036

BDM Corporation

Attn: A. Kubo

7915 Jones Branch Drive

McLean, VA 22102

Benchmark Environmental Corp. (2)

Attn: C. Frederickson

K. Lickliter

4501 Indian School, NE

Suite 105

Albuquerque, NM 87110

Center for Nuclear Waste Regulatory Analyses

Attn: R.E. Adler

1235 Jefferson Davis Hwy, Suite 102

Arlington, VA 22202

Center for Risk Management (2)

Resources for the Future

Attn: A. Finke1

M. Gough

1616 P Street, NW

Washington, DC 20036

Chemical Industry Institute of Technology

Attn: R.0. McClellan

PO Box 12137

6 Davis Drive

Research Triangle Park, NC 27709
City of Albuquerque

Public Works Department

Utility Planning Division

Attn: W.K. Summers

PO Box 1293

Albuquerque, NM 87103

Clement International Corp.

Attn: E.L. Anderson

9300 Lee Highway

Fairfax, VA 22031-1207

Davis Wright Tremaine

Attn: L.L. Brothers

2600 Century Square

1501 Fourth Avenue

Seattle, WA 98101-1688

Decision Focus

Attn: D.W. North

4984 E1 Camino Road

Los Altos, CA 94022

Decision Research (2)

Attn: P. Slovic

N. Kraus

1201 Oak Street

Eugene, OR 97401

Deuel and Associates, Inc.

Attn: R.W. Prindle

7208 Jefferson, NE

Albuquerque, NM 87109

Disposal Safety, Inc.

Attn: B. Ross

Suite 314

1660 L Street, NW

Washington, DC 20036

Eastern Research Group, Inc.

Attn: M.F. Kaplan

6 Whittemore St.

Arlington, MA 02174

Eckert, Seamons, Cherin, \& Mellot

Attn: J. Tourtellotte

$818 \mathrm{~N} \mathrm{St}, \mathrm{NW}$

Suite 700

Washington, DC 20036 
Ecodynamics (2)

Attn: P. Roache

R. Blaine

PO Box 9229

Albuquerque, NM 87119-9229

\section{EEI/UWASTE}

Attn: C. Henke1

701 Pennsylvania Avenue, NW

Washington, DC 20004-2696

Electric Power Research Institute (5)

Attn: R.F. Williams

PO Box 10412

Palo Alto, CA 94303

EG \& G Idaho (3)

1955 Fremont Street

Attn: C. Atwood

C. Hertzler

T.I. Clements

Idaho Falls, ID 83415

Environmental Defense Fund

Attn: E.K. Silbergeld

1616 P Street, NW

Washington, DC 20036

Geomatrix

Attn: K. Coppersmith

100 Pine Street \#1000

San Francisco, CA 94111

Golder Associates, Inc. (4)

Attn: M. Cunnane

R. Kossik

I. Miller

W. Roberds

4104 148th Avenue, NE

Redmond, WA 98052

Golder Associates, Inc.

Attn: J. Voss

3730 Chamblee Tucker Road

Atlanta, GA 30341

INTEPA, Inc.

Attn: A.M. LaVenue

8100 Mountain Road, NE

Suite 213

Albuquerque, NM 87110
INTERA, Inc. (2)

Attn: J.F. Pickens S. Pahwa

Suite $\# 300$

6850 Austin Center Blvd.

Austin, TX 78731

INTERA, Inc.

Attn: W. Stensrud

PO Box 2123

Carlsbad, NM 88221

INTERA, Inc.

Attn: W. Nelson

101 Convention Center Drive

Suite 540

Las Vegas, NV 89109

IT Corporation (2)

Attn: R.F. McKinney

$\mathrm{J}$. Myers

Regional Office - Suite 700

5301 Central Avenue, NE

Albuquerque, NM 87108

Jacobs Engineering Co.

Attn: S. Meyers

529 14th St., NW, Suite 1234

Washington, DC 20045

J.K. Associates

Attn: S.D. Wiltshire

77 Fox Run Road

PO Box 2219

Hamilton, MA 01982

MACTEC (2)

Attn: J.A. Thies

D.K. Duncan

8418 Zuni Road, SE

Suite 200

Albuquerque, NM 87108

Malcolm Pirnie, Inc.

Attn: P. Busch

2 Corporate Park Drive

White Plains, NY 10602

National Academy of Sciences

Office of International Affairs

Attn: E.W. Colglazier

2101 Constitution Ave

Washington, DC 20418 
Natural Resources Defense Council

Attn: T. Cochran

D.W. Reicher

1350 New York Avenue, NW

Suite 300

Washington, DC 20005

Newman \& Holtzinger, PC

Attn: M.A. Bauser

1615 L Street, NW, Suite 1000

Washington, DC 20036

Nuclear Management Resources Council

Attn: R. Bishop

1776 I Street NW

Suite 300

Washington, DC 20006-2496

Pacific Northwest Laboratory

Attn: B. Kennedy

Battelle Blvd.

PO Box 999

Richland, WA 99352

Radioactive Exchange (2)

Attn: E. Helminski

M.E. Conley

PO Box 9528

Washington, DC 20016

RE/SPEC, Inc. (2)

Attn: W. Coons

P. Gnirk

Suite 300

4775 Indian School, NE

Albuquerque, NM 87110

$\mathrm{RE} / \mathrm{SPEC}$, Inc .

Attn: J.L. Ratigan

PO Box 725

Rapid City, SD 57709

Reynolds Elect/Engr. Co., Inc.

Building 790, Warehouse Row

Attn: E.W. Kenda11

PO Box 98521

Las Vegas, NV 89193-8521

Risk Engineering, Inc.

Attn: R. McGuire

5255 Pine Ridge Road

Golden, CO 80403
Rogers \& Associates Engineering Corp. Attn: V.C. Rogers

PO Box 330

Salt Lake City, UT 84110-0330

Rogers \& Associates Engineering Corp. c/o Roy F. Weston

Attn: L.D. Rickertsen

955 L'Enfant Plaza, SW, 8th Floor

Washington, DC 20024

Roy F. Weston, Inc. (3)

CRWM Tech. Supp. Team

Attn: C.J. Noronha

R. Palabrica

N. Norman

955 L'Enfant Plaza, SW

North Building, Eighth Floor

Washington, DC 20024

Roy F. Weston, Inc.

Attn: D. Lechel

One Park Square, Suite 800

6501 Americas Parkway NE

Albuquerque, NM 87110

S. Cohen and Assoc., Inc.

Attn: S. Phelps

2010 Miracle Lane

Falls Church, VA 22043

S. Cohen and Assoc., Inc.

Attn: N. Numark

2939 28th Street, NW

Washington, DC 20008

Science Applications International Corporation (SAIC)

Attn: H.R. Pratt

10260 Campus Point Drive

San Diego, CA 92121

Science Applications International Corporation (2)

Attn: G. Dymmel

C.G. Pflum

101 Convention Center $\mathrm{Dr}$.

Las Vegas, NV 89109 
Science Applications International

Corporation (3)

Attn: M. Davis

J. Tollison

M. Glora

2109 Air Park Road, SE

Albuquerque, NM 87106

Science Applications International Corporation (2)

Attn: J. Young

D. Lester

18706 North Creek Parkway

Suite 110

Bothe11, WA 98011

Science Applications International Corporation

Attn: R. Stein

20201 Century B1vd, 3rd Floor

Germantown, MD 20874

Slosky \& Associates

Attn: L. Slosky

Bank Western Tower

Suite 1400

1675 Broadway

Denver, CO 80202

Southwest Research Institute

Center for Nuclear Waste Regulatory Analys is (2)

Attn: P.K. Nair

6220 Culebra Road

San Antonio, TX 78228-0510

Systems, Science, and Software (2)

Attn: E. Peterson

Box 1620

P. Lagus

La Jolla, CA 92038

TASC (3)

Attn: S.G. Oston

C.M. Koplik

D.A. Ensminger

55 Walkers Brook Drive

Reading, MA 01867
Tech Reps, Inc. (11)

Attn: J. Chapman

V. Gilliland

D. Marchand

J. Stikar

P. Oliver

D. Scott

M. Gruebe1 (5)

5000 Marble, NE

Suite 222

Albuquerque, NM 87110

The Conservation Foundation

Attn: A. Arnold

1250 24th Street, NW

Washington, DC 20037

Tolan, Beeson, \& Associates

Attn: T.L. Tolan

2320 W. 15th Avenue

Kennewick, WA 99337

TRW Environmental Safety Systems (TESS) (4)

Attn: I. Sacks

L. Berkowitz

J. Dameron

M. Birch

2650 Park Tower Drive

Suite 800

Vienna, VA 22180

TRW/M \& 0

Attn: M. Lugo

101 Convention Center Dr.

Suite 540

Las Vegas, NV 89109

Westinghouse Electric Corporation (5)

Attn: Library

L. Trego

C. Cox

L. Fitch

R.F. Kehrman

PO Box 2078

Carlsbad, NM 88221

Westinghouse Hanford Company

Attn: D. Wood

PO Box 1970

Richland, WA 99352 
Westinghouse Savannah River Company Attn: M. Wells

PO Box 616, B1dg. 704-Z

Aiken, SC 29802

Western Water Consultants

Attn: D. Fritz

1949 Sugarland Drive \#134

Sheridan, WY 82801-5720

Western Water Consultants

Attn: P.A. Rechard

PO Box 4128

Laramie, WY 82071

S. Burstein

7475 North Crossway Road

Milwaukee, WI 53217

M. Carter

4621 Ellisbury Drive

Atlanta, GA 30338

C. Cohen

928 N. California Avenue

Palo A1to, CA 94303

P. Drez

8816 Cherry Hills Road, NE

Albuquerque, NM 87111

T. Lash

1112 W. Fayette Avenue

Springfield, IL 62704

A. Pasternak
Consultant
PO Box 1638
Lafayette, CA $94549-1638$
D.W. Powers
Star Route Box 87
Anthony, TX 79821
Shirley Thieda
PO Box 2109, RR1
Bernalillo, NM 87004
Jack Urich
C/o CARD
14.4 Harvard, SE
Albuquerque, NM 87106
R.E. Wilems
1400 Ocean Drive, No. $1103 \mathrm{C}$
Corpus Christi, TX 78404

\section{Universities}

Cornel1 University

Department of Chemistry

Attn: F.W. McLafferty

I thaca, NY 14853-1301

Illinois Institute for Technology

Attn: G. Paulson

421 W. Melrose St., Apt. 10C

Chicago, IL 60657-3807

Massachusetts Institute of Technology

Department of Civil Engineering

Attn: D.H. Marks

7 Massachusetts Avenue

Cambridge, MA 02139

Rutgers University

Environmental Communication Research Program

Attn: C. Chess

PO Box 231

New Brunswick, NJ 08903-0231

Stanford University

Department of Civil Engineering

Attn: P.L. McCarty

Stanf $\cdots d$, CA 94305-4020

University of California

Rock Mechanics Engineering

Mine Engineering Dept.

Attn: N. Cook

Berkeley, CA 94720

University of California

Mechanical, Aerospace, and Nuclear Engineering Department (2)

Attn: W. Kastenberg

D. Browne

5532 Boelter Hall

Los Angeles, CA 90024

University of California, Los Angeles

Mechanical, Aerospace, \& Nuclear

Engineering Department

Attn: D. Okrent

48-121 Engineering 4

Los Angeles, CA 90024-1597

University of Hawaii at Hilo

Attn: S. Hora

Busines: Administration

Hilo, HI 96720-4091 
University of New Mexico

Geology Department

Attn: Library

Albuquerque, NM 87131

University of New Mexico

Research Administration

Attn: H. Schreyer

102 Scholes Hall

Albuquerque, NM 87131

University of Pennsylvania

The Wharton School

Risk and Decision Process Center

Attn: J. Kunreuther

130 Steinberg Hall-Dietrich Hall

Philadelphia, PA 19104

University of Pittsburgh

Department of Physics

Attn: B.L. Cohen

Pittsburgh, PA 15260

University of Tennessee

Department of Geological Sciences

Attn: R.D. Hatcher

301 G \& G Building

Knoxville, TN 37996-1410

University of Washington

Institute of Environmental Studies

2015 Federal Ave., East

Seattle, WA 98102

University of Washington

Attn: A.E. Nevissi, WH-10

Seattle, WA 98195

University of Wisconsin-Madison

Department of Geology and Geophysics

Attn: J.M. Bahr

Weeks Hall

1215 West Dayton Street

Madison, WI 53706

University of Wyoming

Department of Civil Engineering

Attn: V.R. Hasfurther

Laramie, WY 82071
University of Wyoming

Department of Geology

Attn: J.I. Drever

Laramie, WY 82071

University of Wyoming

Department of Mathematics

Attn: R.E. Ewing

Laramie, WY 82071

Vanderbilt University

Environmental Systems Eng.

Attn: F. Parker

Clemson, SC 29634-0919

Williams College

Center for Environmental Studies

Attn: K. Lee, Director

Kellogg House

PO Box 632

Willianstown, MA 01267

\section{Libraries}

Thomas Brannigan Library

Attn: D. Dresp

106 W. Hadley St.

Las Cruces, NM 88001

Hobbs Public Library

Attn: M. Lewis

509 N. Ship Street

Hobbs, NM 88248

New Mexico State Library

Attn: N. McCallan

325 Don Gaspar

Santa Fe, NM 87503

New Mexico Tech

Martin Speere Memorial Library

Campus Street

Socorro, NM 87810

New Mexico Junior College

Pannell Library

Attn: R. Hill

Lovington Highway

Hobbs, NM 88240 
Carlsbad Municipal Library

WIPP Public Reading Room

Attn: L. Hubbard

$101 \mathrm{~S}$. Halagueno St.

Carlsbad, NM 88220

University of New Mexico

General Library

Government Publications Department

Albuquerque, NM 87131

\section{Foreign Addresses}

Studiecentrum Voor Kernenergie

Centre D'Energie Nucleaire

Attn: A. Bonne

SCK/CEN

Boeretang 200

B- 2400 Mo1, BELGIUM

Atomic Energy of Canada, Ltd.

Whiteshell Research Estab.

Attn: M.E. Stevens

B.W. Goodwin

D. Wushke

C. Allan

Pinewa, Manitoba

ROE 1L0, CANADA

Esko Peltonen

Industrial Power Company Ltd.

TVO

Fredrikinkatu 51-53

SF-00100 Helsinki 10, FINLAND

Ghislain de Marsily

University Pierre et Marie Curie Laboratorie de Geologie Applique

4, Place Jussieu - T.26 - 5e etage

75252 Paris Cedex 05, FRANCE

Jean-Pierre Olivier

OECD Nuclear Energy Agency (2)

38, Boulevard Suchet

F-75016 Paris, FRANCE

D. Alexandre, Deputy Director

ANDRA

31 Rue de 1a Federation

75015 Paris, FRANCE
Claude Sombret

Centre D'Etudes Nucleaires

De La Vallee Rhone

CEN/VALRHO

S.D.H.A. BP 171

30205 Bagnols-Sur-Ceze, FRANCE

Bundesministerium fur Forschung und Technologie

Postfach 200706

5300 Bonn 2, GERMANY

Bundesanstalt fur Geowissenschaften und Rohstoffe

Attn: M. Langer

Postfach 510153

3000 Hanover 51, GERMANY

Gesellschaft fur Reaktorsicherheit

(GRS) (2)

Attn: B. Baltes

W. Muller

Schwertnergasse 1

D-5000 Cologne, GERMANY

Hahn-Mietner-Institut fur

Kernforschung

Attn: W. Lutze

Glienicker Strasse 100

100 Berlin 39, GERMANY

Institut fur Tieflagerung (2)

Attn: K. Kuhn

Theodor-Heuss-Strasse 4

D-3300 Braunschweig, GERMANY

Physikalisch-Technische Bundesanstalt

Attn: P. Brenneke

Postfach 3345

D-3300 Braunschweig, GERMANY

Shingo Tashiro

Japan Atomic Energy Research

Institute

Tokai-Mura, Ibaraki-Ken

319-11, JAPAN

Netherlands Energy Research

Foundation (ECN)

Attn: L.H. Vons

3 Westerduinweg

PO Box 1

1755 ZG Petten, THE NETHERLANDS 
Johan Andersson

Swedish Nuclear Power Inspectorate

Statens Kärnkraftinspektion (SKI)

Box 27106

S-102 52 Stockholm, SWEDEN

Fred Karlsson

Svensk Karnbransleforsorjning $A B$

SKB

Box 5864

S-102 48 Stockholm, SWEDEN

Nationale Genossenschaft fur die Lagerung Radioaktiver Abfalle (NAGRA) (2)

Attn: S. Vomvoris

P. Zuidema

Hardstrasse 73

$\mathrm{CH}-5430$ Wettingen, SWITZERLAND

D.R. Knowles

British Nuclear Fuels, plc

Risley, Warrington, Cheshire WA3 6AS

1002607, UNITED KINGDOM

AEA Technology

Attn: J.H. Rees

D5W/29 Culham Laboratory

Abington

Oxfordshire OX14 3DB, UNITED KINGDOM

AEA Technology

Attn: W.R. Rodwell

044/A31 Winfrith Technical Centre

Dorchester

Dorset DT2 8DH, UNITED KINGDOM

AEA Technology

Attn: J.E. Tinson

B4244 Harwell Laboratory

Didcot, Oxfordshire OX11 ORA

UNITED KINGDOM

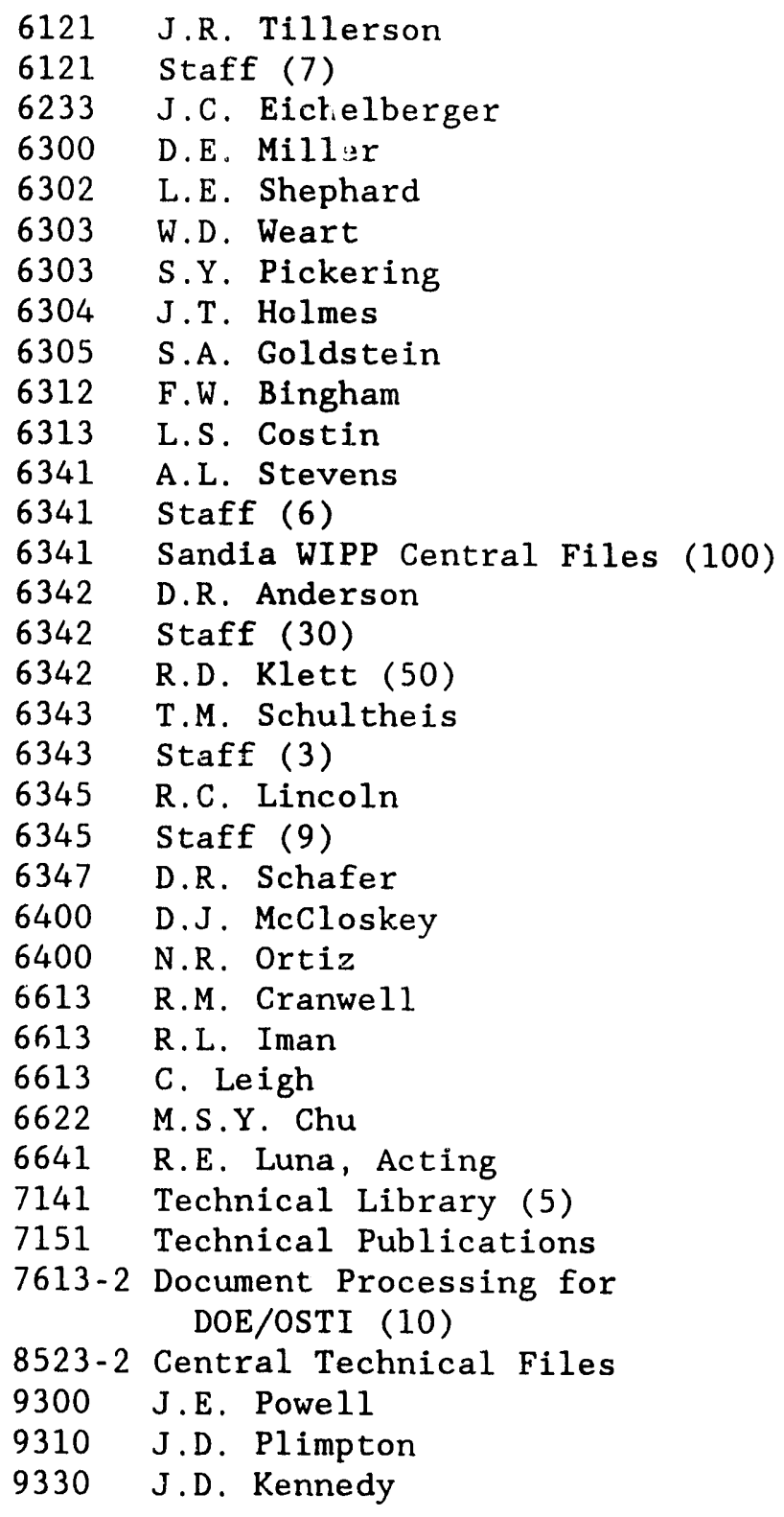

\section{Internal}

1 A. Narath

20 O.E. Jones

1502 J.C. Cummings

1511 D.K. Gartling

6000 D.L. Hartley

6115 P.B. Davies

6119 E.D. Gorham

6119 Staff (14) 

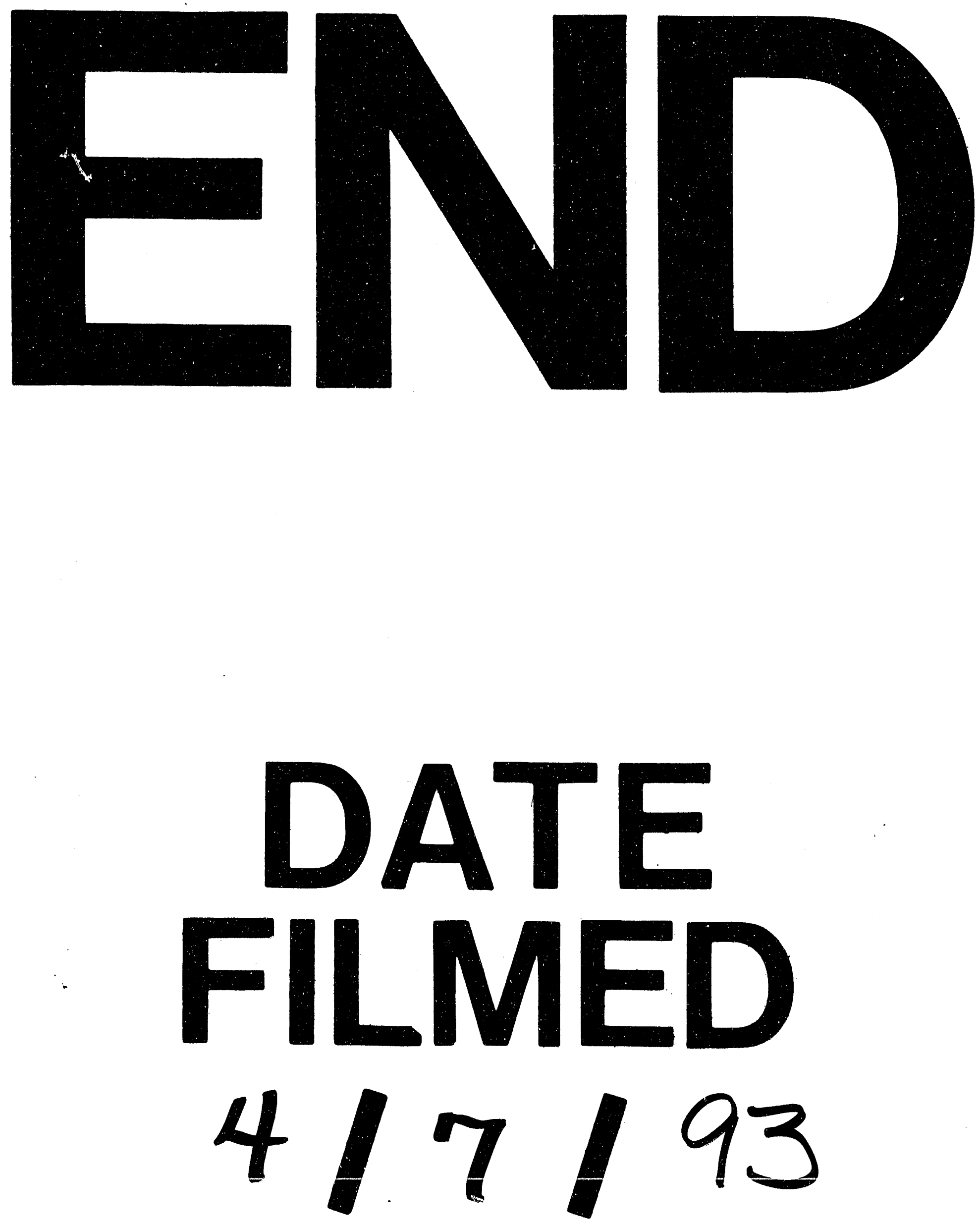
